\title{
Assessing the Impact of Rock-Bed Storage for Tempering Air-to-Air Heat Pumps
}

by

\author{
Nina Dmytrenko, B.A.Sc., Heat and Power Engineering \\ Kyiv Polytechnic Institute \\ M.A.Sc., Heat and Power Engineering \\ Kyiv Polytechnic Institute
}

\author{
A thesis submitted to the \\ Faculty of Graduate and Postdoctoral Affairs \\ in partial fulfillment of the requirements for the degree of
}

Master of Applied Science in Mechanical Engineering

\author{
Department of Mechanical and Aerospace Engineering \\ Carleton University \\ Ottawa, Ontario
}

August, 2018

(C) Copyright

Nina Dmytrenko, 2018 
The undersigned hereby recommends to the Faculty of Graduate and Postdoctoral Affairs acceptance of the thesis

\title{
Assessing the Impact of Rock-Bed Storage for Tempering Air-to-Air Heat Pumps
}

\author{
submitted by Nina Dmytrenko \\ in partial fulfilment of the requirements for the degree of \\ Master of Applied Science in Mechanical Engineering
}

Professor Cynthia Cruickshank, Thesis supervisor, Department of Mechanical and Aerospace Engineering

Professor Ian Beausoleil-Morrison, Thesis Co-supervisor, Department of Mechanical and Aerospace Engineering

Professor Ronald E. Miller, Chair, Department of Mechanical and Aerospace Engineering

Department of Mechanical and Aerospace Engineering

Carleton University

August, 2018 


\section{Abstract}

Over the past decade, improvements have been made in air-source heat pump units; however, performance during periods of extreme high and low temperatures remains poor. In order to increase the COP and thermal capacity of the heat pump during these extreme periods, the unit was coupled to a short-term underground rock-bed thermal store which enables tempering ambient air that is drawn to the outdoor heat exchanger. The system was designed, built, and commissioned at the Urbandale Centre for Home Energy Research at Carleton University. Experimentally during the cooling season, it was found that the rock bed is suitable to moderate the outdoor temperature. However, the overall system performance did not improve as a result of increased flow resistance through the ductwork, significant thermal losses

and air leaks within the outdoor system. Although the proposed configuration of the heat pump and rock bed demonstrated some potential in improving the heat pump performance, the design issues of the outdoor setup must be addressed in order to harness this potential. 
To babusya Mariya 


\section{Acknowledgments}

I am grateful to my supervisors - Dr. Cynthia Cruickshank and Dr. Ian Beausoleil-Morrison - and our industry partner Mark Riley for this exciting journey taking place in my life. Mark's fresh and brave vision motivated me to be an explorer. Ian's and Cynthia's immense knowledge, patient guidance, incredible observance, and unwavering encouragement were essential for me to navigate throughout this endeavour.

It was an incredible few years started on a beautiful day in May when I entered the campus of Carleton University blooming with the rose bushes in front of the Canal Building welcoming a newcomer. Since then, I was fortunate to work and study alongside kind wonderful intelligent people whom I am proud to know.

I would like to express my sincere appreciation for Geoff Johnson, who voluntarily spent with me a couple of weeks in a pithole without gloves installing thermocouples in the middle of the dead-cold winter. I do not think I would have survived without his cheerfulness, efficiency, and experience.

Many thanks to the very supportive machine shop and laboratory technologists - Alex Proctor, Pierre Trudel, Ian Lloy, Kevin Sangster, David Raude, Steve Truttmann, and Stephan Biljan - for lending me tools and instruments for sometimes 
indefinite time periods and for demonstrating me how nicely the right tools can be utilized in the hands of experts.

I would like to thank Bruce Johnston for rescuing my computers without judging me for the number of open tabs and programs.

Thanks to the CHEeR house team - Briana, Curtis, Sarah, Lumi, Mihai, Ashley, Derrick, Isabelle, Fred, and Keelia - it was a pleasure working with you, coordinating the ongoing tests, and sharing sometimes painful experiences of experimental work. Special thanks to those involved in shopping and delivering of the materials for my project.

Thanks to the Waterdone staff and Rick Ordyniec from Ecologix for their cooperation and assistance.

Thanks to Chris Weissflog from EcoGen for being a great example of a truly engineer-experimentalist who is persistent in implementing his progressive vision on sustainability and energy efficient houses.

I would like to thank my colleagues - Adam, Chris, Brocikus, Dylanio, Jordan, Tyler, Calene, Kevin, Patrichek, Jayson, Tiwachka, Sébastien, Dave Ouellette, Daniel, Paula, Patrice, Tom Mackintosh, and Jenny - for your friendship, advice, guidance, support, and willingness to assist in any issues.

I would like to acknowledge my family who sacrificed years of our face-to-face and hugs time while I was pursuing my goal. Thank you for valuing my education so high. Thank you for your unconditional love and support I always felt across the Atlantic Ocean.

Finally, and most importantly, I would like to express my gratitude to my gentleman Eddy and his mom who accepted me with open hands and who became so 
invested in me and my work. Eddy, thank you for selflessly being by my side and living with me throughout all the "hurricanes" in my homeland, in my family, and at school. I truly admire your ability to see the light at the end of the tunnel and to show it to me when I forget to look for it. Thank you also for your encouragement and inspiration to strive and be the best version of myself. 


\section{Table of Contents}

$\begin{array}{ll}\text { Abstract } & \text { iii }\end{array}$

Acknowledgments $\quad$ v

Table of Contents viii

List of Tables $\quad$ xi

List of Figures $\quad$ xiii

$\begin{array}{ll}\text { Nomenclature } & \text { xvi }\end{array}$

1 Introduction $\quad 1$

1.1 Motivation ......................... . . . 1

1.2 Research objectives . . . . . . . . . . . . . . . . . 3

1.3 Contribution to research ...................... 3

1.4 Outline of thesis . . . . . . . . . . . . . . . 4

2 Literature Review $\quad 6$

2.1 ASHP systems . . . . . . . . . . . . . . . 6 
2.2 TES systems . . . . . . . . . . . . . . . . . 11

2.3 Rock-bed TES integrated to ASHP . . . . . . . . . . . . . . 22

2.4 Gaps in literature . . . . . . . . . . . . . . . . . 24

3 Design and Commissioning of Experiment 26

3.1 Overview of experimental setup . . . . . . . . . . . . . 27

3.2 Rock-bed storage . . . . . . . . . . . . . . . . . . . . . 28

3.3 Air source heat pump . . . . . . . . . . . . . . . . 32

3.4 Instrumentation . . . . . . . . . . . . . . . . . . . . . 34

4 Uncertainty Analysis $\quad 52$

4.1 Bias and precision errors . . . . . . . . . . . . . . 52

4.2 Input quantities of the cooling capacity . . . . . . . . . . . 55

4.3 Cooling capacity uncertainty . . . . . . . . . . . . . 63

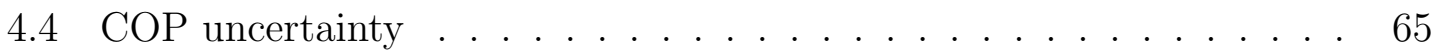

5 Experimental Results and Discussion $\quad 70$

5.1 Methodology ...................... . . 70

5.2 Conventional heat pump scenario . . . . . . . . . . . . . 73

5.3 Discharging the rock bed . . . . . . . . . . . . . . 77

5.4 Discharging the rock bed and adding ambient air . . . . . . . . . . 79

5.5 Maximizing the flow rate . . . . . . . . . . . . . . 84

5.6 Matching the flow rate . . . . . . . . . . . . . . 88

5.7 Charging the rock bed . . . . . . . . . . . . . . . . 94

5.8 Closing remarks . . . . . . . . . . . . . . . . . . . . . . . 98 
6 Conclusions and Future Work 103

6.1 Conclusions .......................... . . 104

6.2 Future work . . . . . . . . . . . . . . . . . . 105

$\begin{array}{ll}\text { References } & 106\end{array}$

Appendix A Performance of the heat pump under five scenarios 113

Appendix B Uncertainty of the heat transfer rate of the rock bed 116

B.1 Velocity at the outdoor heat exchanger . . . . . . . . . . . 116

B.2 Thermocouples . . . . . . . . . . . . . . . . . 117

B.3 Air properties . . . . . . . . . . . . . . . . 118

B.4 Cross-sectional area . . . . . . . . . . . . . . . . . . 119

B.5 Uncertainty of $\dot{Q}_{a i r} \ldots \ldots \ldots \ldots$. . . . . . . . . . 120

$\begin{array}{lll}\text { Appendix C Fan curve } & 122\end{array}$ 


\section{List of Tables}

3.1 List of charging and discharging scenarios . . . . . . . . . . . 32

3.2 Thermocouple calibration . . . . . . . . . . . . . . 38

3.3 Thermocouple bias error . . . . . . . . . . . . . . . . 43

3.4 RTD regression equations . . . . . . . . . . . . . . . . . . 44

3.5 Thermocouple bias error . . . . . . . . . . . . . . . . 45

3.6 Thermopile regression equations . . . . . . . . . . . . . . . . . 47

3.7 Thermopile bias error . . . . . . . . . . . . . . . . . . . . . 48

4.1 Velocity profile bias error . . . . . . . . . . . . . . 59

4.2 Velocity bias error . . . . . . . . . . . . . . . 60

4.3 Density bias error . . . . . . . . . . . . . . . . 62

4.4 Specific heat bias error . . . . . . . . . . . . . . . . . . 62

4.5 Independent variables of the derived quantity $\dot{Q} \ldots \ldots$. . . . . . 63

4.6 Cooling capacity sensitivity parameters . . . . . . . . . . . . 64

4.7 Cooling capacity bias error . . . . . . . . . . . . . . . 64

4.8 Energy measurement bias error . . . . . . . . . . . . . . 66

4.9 Electrical power sensitivity parameters . . . . . . . . . . . 66

4.10 Rated and measured outputs . . . . . . . . . . . . . . . 68 
4.11 Energy bias error . . . . . . . . . . . . . . . . . . 68

4.12 COP sensitivity parameters . . . . . . . . . . . . . 68

4.13 COP bias error . . . . . . . . . . . . . . . . . 69

B.1 Velocity bias error . . . . . . . . . . . . . . . . . 117

B.2 Thermocouple bias error . . . . . . . . . . . . . . 118

B.3 Density bias error . . . . . . . . . . . . . . . . . . . . . . 119

B.4 Specific heat bias error . . . . . . . . . . . . . . . 119

B.5 Independent variables of the derived quantity $\dot{Q}_{a i r} \ldots \ldots . . . . . .120$

B.7 $\dot{Q}_{a i r}$ bias error . . . . . . . . . . . . . . 121

B.6 $\dot{Q}_{\text {air }}$ sensitivity parameters . . . . . . . . . . . . 121 


\section{List of Figures}

3.1 Flow diagram of the rock-bed storage coupled to the ASHP . . . . . . 29

3.2 Rock bed equipment . . . . . . . . . . . . . . . . . 30

3.3 Outdoor part of the system . . . . . . . . . . . . . . 31

3.4 Thermocouple in a heat shrink tube . . . . . . . . . . . . . . . . 35

3.5 Location of the thermocouples in the rock bed . . . . . . . . . . 36

3.6 Thermocouple installation . . . . . . . . . . . . . . 36

3.7 Shielded thermocouple . . . . . . . . . . . . . . . . . 37

3.8 Velocity meters . . . . . . . . . . . . . . . . . 50

3.9 Electrical power measurements . . . . . . . . . . . . . . . . . . . . 51

4.1 Hand-held rotating vane anemometer (OMEGA Engineering, 2018) 56

4.2 Velocity measurements . . . . . . . . . . . . . . . . 58

4.3 Velocity profile in a half of the duct . . . . . . . . . . . . 59

5.1 Conventional HP (scenario IIIb) . . . . . . . . . . . . . . . . . . 72

5.2 Performance of the heat pump with respect to $T_{a m b}-$ conventional heat pump scenario . . . . . . . . . . . . . . . . . 74

5.3 Performance of the heat pump with respect to $T_{S A}-$ conventional heat pump scenario . . . . . . . . . . . . . . . 75

xiii 
$5.4 T_{S A}$ vs COP at high, moderate and low temperature ranges of the ambient air - conventional heat pump scenario . . . . . . . . . . . 76

$5.5 T_{a m b}$ vs $T_{B F}-$ conventional heat pump scenario . . . . . . . . 78

5.6 Discharging the rock bed (scenario IIa) . . . . . . . . . . . . . 79

5.7 Discharging the rock bed and adding some ambient air (scenario IIa*) 80

5.8 Aug 17 - HP discharging the RB $\mathrm{w}$ and w/o adding some ambient air 81

5.9 Thermal response of the rock bed during different discharging scenar-

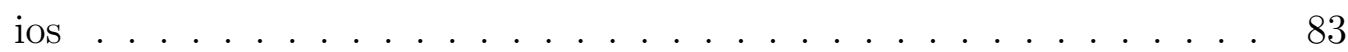

5.10 Scenario IIIb* - maximum flow rate . . . . . . . . . . . . . . . . 84

5.11 Thermal response of the system under extreme temperature conditions 86

$5.12 T_{S A}$ vs COP at high, moderate and low temperature ranges of the ambient air - max flow rate scenario . . . . . . . . . . . . 87

$5.13 Q$ vs $\mathrm{COP}-\max$ flow rate scenario . . . . . . . . . . . . 88

5.14 Discharging (scenario $\mathrm{IIIb}^{* *}$ ) - matched flow rate . . . . . . . . . 89

5.15 Sep 25 - Matched Flow Rate . . . . . . . . . . . . . . . . . . 90

5.16 COP of the heat pump under different scenarios . . . . . . . . . . . . 91

5.17 Cooling capacity of the heat pump under different scenarios . . . . . 92

5.18 Correlations between $\mathrm{T}_{a m b}, \mathrm{~T}_{B F}$, and $\mathrm{T}_{\text {disch }}$ under different scenarios 93

5.19 Conventional charging the bottom of the rock bed (scenario IVa) . . . 94

5.20 Aug 31 - charging the bottom of the rock bed . . . . . . . . . . 96

5.21 Charging/discharging scenarios where the bypass was used . . . . . . 100

5.22 Charging/discharging scenarios where the bypass was NOT used . 101

5.23 Conventional heat pump . . . . . . . . . . . . . . . . . 102

A.1 Velocity . . . . . . . . . . . . . . . . . . . 114

xiv 
A.2 Performance of the heat pump under five scenarios . . . . . . . . 115

C.1 Specification of the outdoor fan . . . . . . . . . . . . . . . 122 


\section{Nomenclature}

\section{Acronyms}

$\begin{array}{ll}\text { AF } & \text { after (outdoor) fan } \\ \text { AHU } & \text { air handling unit } \\ \text { ASHP } & \text { air source heat pump } \\ \text { BC } & \text { base case } \\ \text { BF } & \text { before (outdoor) fan } \\ \text { CHEeR } & \text { Centre for Home Energy Research } \\ \text { CJC } & \text { cold-junction compensation } \\ \text { COP } & \text { coefficient of performance } \\ \text { CT } & \text { current transformer } \\ \text { DAQ } & \text { digital multimeter } \\ \text { DMM } & \end{array}$




\begin{tabular}{|c|c|}
\hline emf & electromotive force \\
\hline $\mathrm{ET}$ & energy transducer \\
\hline GHG & greenhouse gas \\
\hline $\mathrm{HCFC}$ & hydrochlorofluorocarbon \\
\hline HP & heat pump \\
\hline $\mathrm{HTF}$ & heat transfer fluid \\
\hline HVAC & heating, ventilation and air conditioning \\
\hline HX & heat exchanger \\
\hline IRENA & International Renewable Energy Agency \\
\hline IPCC & Intergovernmental Panel on Climate Change \\
\hline NRCan & Natural Resources Canada \\
\hline $\mathrm{PCM}$ & phase change material \\
\hline $\mathrm{PVC}$ & polyvinyl chloride \\
\hline $\mathrm{RB}$ & rock bed \\
\hline RSS & root-sum-square \\
\hline
\end{tabular}

xvii 


\section{Nomenclature}

RTD

resistance temperature detector

RA return air (from the house)

SA supply air (to the house)

TES thermal energy storage

\section{Symbols}

A

$B$

$D$

E

G

$H$

$I$

$L$

$M$ cross-sectional area of a packed bed $\left[\mathrm{m}^{2}\right]$

bias error

damper

energy $[k J]$

superficial mass velocity $\left[\mathrm{kg} /\left(\mathrm{s} \mathrm{m}^{2}\right)\right]$

dimension of the packed bed (in the flow direction) [m] or

high temperature range

current $[\mathrm{A}]$

low temeprature range

number of independent variables or medium temperature range or

molecular mass $[\mathrm{kg} / \mathrm{mol}]$ 


\section{Nomenclature}

$N$

P

$\Delta P$

$\dot{Q}$

$R$

$S$

$T$

$\Delta T$

$U$

V

V

$\dot{V}$

$X$

$\bar{X}$

Y

$c_{p}$ number of samples

power $[\mathrm{kW}]$ or pressure $[\mathrm{Pa}]$

pressure drop $[\mathrm{Pa}]$

thermal capacity $[\mathrm{kW}]$

resistance $[\Omega]$ or gas constant $[\mathrm{J} /(\mathrm{mol} \mathrm{K})]$

precision error

temperature $\left[{ }^{\circ} \mathrm{C}\right.$ or $\left.\mathrm{K}\right]$

temperature difference $\left[{ }^{\circ} \mathrm{C}\right.$ or $\left.\mathrm{K}\right]$

overall uncertainty

velocity $[\mathrm{m} / \mathrm{s}]$, voltage $[\mathrm{V}]$

volume $\left[\mathrm{m}^{3}\right]$

volumetric flow rate $\left[\mathrm{m}^{3} / \mathrm{s}\right]$

independent variable

mean value of the independent variable

derived quantity

specific heat at constant pressure $[\mathrm{kJ} /(\mathrm{kg} \mathrm{K})]$

xix 


\section{Nomenclature}

$f$

$\dot{m}$

$t$

$v$

$x, y, z$

\section{Greek symbols}

$\phi$

$\rho$

$\theta$

\section{Subscripts}

$\begin{array}{ll}\text { amb } & \text { ambient } \\ \text { avg } & \text { average } \\ \text { cal } & \text { calibration } \\ \text { Comp } & \text { compressor } \\ \text { comp } & \text { compensated } \\ \text { in } & \text { indoor }\end{array}$

indoor number of pulses $[\mathrm{Hz}]$

mass flow rate $[\mathrm{kg} / \mathrm{s}]$

time

degree of freedom, velocity in a cell $[\mathrm{m} / \mathrm{s}]$

coordinates phase angle

density $\left[\mathrm{kg} / \mathrm{m}^{3}\right]$

sensitivity parameter 
Nomenclature

out

outdoor

ref

reference

xxi 


\section{Chapter 1}

\section{Introduction}

\subsection{Motivation}

Canada is one of ten large countries from the industrialized and developing worlds $^{1}$ that are responsible for $70 \%$ of the world's emissions (Intergovernmental Panel on Climate Change, 2015). In Canada, the residential and commercial sectors account for almost one-third of energy consumption and a quarter of greenhouse gas (GHG) emissions. According to Natural Resources Canada (NRCan), about 65\% of that energy usage is attributed to space heating and cooling. Switching to more efficient technologies would reduce the energy and carbon intensity of the heating and cooling systems.

An air source heat pump (ASHP) is a good example of a mature technology system that offers significant benefits in terms of energy savings, energy efficiency, and reduced environmental impact. However, the heat pump performance becomes poor when the ambient temperature is extremely low or high. In such conditions,

\footnotetext{
${ }^{1}$ The EU was treated as a single country.
} 
the system cannot meet the requirements for heating or cooling without a backup system. Moreover, if the system is continuously running under unfavourable temperature conditions, important components of the heat pump could be permanently damaged. Typically, ASHP systems are designed with the consideration that the outdoor temperature does not drop below $-5{ }^{\circ} \mathrm{C}$ or $15{ }^{\circ} \mathrm{C}$. When the weather is colder than that, the system either cannot or does not operate and the backup system is triggered. Based on Environment Canada climate data for the years 2007 to 2011, in Ottawa, Canada, the ambient temperature was below $-5{ }^{\circ} \mathrm{C}$ and $-15{ }^{\circ} \mathrm{C} 27 \%$ and $6 \%$ of the hours that required heating, respectively (Mackintosh, 2016). In the extreme Northern parts of Canada, the temperatures were below $-5{ }^{\circ} \mathrm{C}$ and $-15{ }^{\circ} \mathrm{C}$ over $60 \%$ and almost $50 \%$ of the heating hours, respectively. Hence, conventional heat pump cycles cannot perform - at least not efficiently - in the realm of Canada. Partially due to this reason, in Canada heat pump technologies are less adopted than in Europe where the ambient temperature rarely drops below $-10{ }^{\circ} \mathrm{C}$. Chapter 2 provides an overview of the issues associated with the performance of the ASHP under extreme temperature conditions, as well as existing approaches to mitigate them by modifying either components or the vapour-compression cycle of the heat pump. These problems are not common for ground-source heat pumps and solar-assisted heat pumps with thermal storage. Thus, instead of altering the heat pump design, it could be beneficial to modify the heating/cooling system in a novel way by coupling the ASHP to a thermal energy storage (TES). In the proposed system, a buried uninsulated short-term rock-bed thermal store enables air tempering at the source side of the ASHP so that the heat pump operates under more favourable temperature conditions during extremely cold or hot days. If this concept proves 
to be functional, it will potentially eliminate the above-mentioned shortcomings of the ASHP systems. This will also contribute to reducing the long-term impact on Canadian energy consumption and GHG emissions.

\subsection{Research objectives}

The overall goal of this research was to assess the concept of coupling an airsource heat pump to a diurnal rock-bed thermal store as a strategy to improve the heat pump performance during periods of extreme conditions. To meet the goal, the research had the following objectives:

- develop an experimental facility to study the performance of the proposed system

- develop an experimental test procedure to characterize the performance of the heat pump

- evaluate the performance of the heat pump when it operates as a conventional heat pump and when it is coupled to the rock bed

\subsection{Contribution to research}

This work contributed the following:

- Design, construction, instrumentation, and commissioning of a full-size experimental setup

- Completion of the experimental tests to collect performance data 
- Determination of the cooling capacity and coefficient of performance of the heat pump with and without the rock bed

- Completion of an uncertainty analysis on the cooling capacity and coefficient of performance of the heat pump

- Development and evaluation of charging and discharging strategies

- Evaluation of the tempering potential of a rock-bed thermal store and its impact on the heat pump performance

\subsection{Outline of thesis}

The remainder of the thesis includes the following chapters:

- Chapter 2 - Literature Review: A review of literature on various approaches to improve the performance of the ASHP systems under severe weather conditions, classification and applications of thermal energy storages.

- Chapter 3 - Design and Commissioning of Experiment: A detailed description of the design of the experimental setup, instrumentation used, and calibration of the thermocouples and a thermopile.

- Chapter 4 - Uncertainty Analysis: A description of the uncertainty analysis of the derived quantities.

- Chapter 5 - Experimental Results and Discussion: A summary of the experimental results with uncertainty margins and a discussion of the obtained results. 
- Chapter 6 - Conclusions and Recommendations: A summary of the findings from this research. 


\section{Chapter 2}

\section{Literature Review}

\subsection{ASHP systems}

ASHP systems are a promising technology in terms of energy savings, energy efficiency, reliability, and environmental impact. However, during periods of extreme cold and hot conditions, they have serious drawbacks. The performance of the heat pump deteriorates so that the heat pump cannot satisfy the heating/cooling requirement without the assistance of a back-up system and the coefficient of performance ${ }^{1}$ (COP) drops below 1, which defeats the benefits of the heat pump in comparison with conventional systems. Moreover, there is a high risk of compressor damage due to increasing refrigerant temperature. A built-in safety lockout mechanism, aimed to prevent operation under high pressure or high temperature of the refrigerant, results in frequent on and off cycling of the heat pump which negatively affects the lifespan of the compressor. Overall, it is a challenge to develop an air-to-air heat pump which

\footnotetext{
${ }^{1}$ The COP is defined as the ratio of heating or cooling provided to the electrical energy consumed.
} 
can maintain the sufficient capacity and reasonable COP when operating under extreme temperatures.

Different approaches have been undertaken to improve heat pump performance. The studies can be classified into two categories: component-level research and system-level research. The former mostly focuses on compressor design and new refrigerants. The latter focuses on improved cycle configurations.

From a performance and economic perspective, the main component of the heat pump system and its largest power consuming element is the compressor. That is why compressor design plays an important role in many performance-improving strategies. At the component level, research work focuses on studying different types of compressors, as well as refrigerants which are intended to be used with certain compressor types. The design of the compressor in conjunction with the thermodynamic properties of the refrigerant used are the decisive factors for the system performance. A scroll compressor is often used in heat pumps for operating more quietly, smoothly, and reliably partially due to multiple independent compression chambers, lower compression gradients, and a fewer number of the moving parts. The ASHP with a variable capacity or variable speed scroll compressor with liquid injection demonstrates good performance under extreme conditions. However, the heat pump with a variable speed scroll compressor can experience resonance vibration under high load and the heat pump with a variable capacity scroll compressor experiences a loss of efficiency at the lower range of the capacity. In terms of the refrigerants, the research has been driven by the regulations under the Montreal Protocol and the Kyoto Protocol that dictate the phasing out hydrochlorofluorocarbons (HCFCs) due to their negative impact on the ozone layer and hydrofluorocarbons for 
being GHG. The refrigerant R-410A became more common as it has been used to replace HCFC 22 (R22) which earlier was primarily utilized in air conditioners and heat pumps.

At the system level, studies are aimed to evaluate different modifications of the vapour-liquid compression cycle, e.g., cascade cycle, multi-stage cycle, auto-cascade cycle, carbon dioxide cycle, etc. An in-depth analysis on the different compression cycles was conducted by Mackintosh (2016). The cascade cycle consists of two or more single stage vapour-compression cycles. This allows using multiple refrigerants each at their optimum operating range which ultimately increases the overall system performance. The multi-stage cycle allows incorporating injection technologies:

- where a portion of the refrigerant at the outlet of a condenser is injected back to the compressor (systems with a flash tank)

- where an additional expansion valve and heat exchanger (i.e., subcooler or economiser) are used to increase the sub-cooling of the main refrigerant flow and inject a portion of it back to the compressor (systems with a subcooler)

The injection technologies are known for improving the performance and reliability of the vapour-compression system by increasing the amount of refrigerant in compression. This allows reducing under-compression loss and increasing the heating capacity. A compressor with a variable-speed drive further improves the COP of the system with a vapour injection. The injection technologies offer significant advantages for applications with high-temperature lift such as water heating; however, the benefits are smaller for the residential forced-air heating and air conditioning applications where the temperature lift is smaller. 


\subsubsection{Bivalent heat pump systems}

The discussed strategies to improve the performance of ASHP do not necessarily offer the most suitable or effective solutions for regions with an annually wide range of ambient temperature. Instead of modifying the vapour-liquid compression cycle and its components, the effectiveness and reliability of the heat pump could be improved if the heat pump is driven by two sources of heat as in so-called bivalent heat pump systems. The most studied example of a bivalent system is a heat pump assisted by solar thermal collectors. Bivalent heat pumps can be classified into two categories. The first category is a series system where the two sources are connected in series and heat is taken from the source with the highest temperature which results in a decreased compressor energy and improved COP. The second category is a dual system where the heat can be taken from either of the sources with respect to the temperature levels. The third category could be included to describe a parallel arrangement of the heat pump and a solar thermal collector where the systems work independently to satisfy the building demand.

The series system can be assembled in a direct or indirect configuration. In the direct configuration, the solar collectors are integrated into the ASHP on the evaporator side, and the fluid circulating in the solar collector also serves as a refrigerant of the heat pump. Although direct systems demonstrate promising performance results, they are typically installed in climates milder than those of Canada (Chu, 2014). Contrarily, an indirect configuration is suitable for cold climates because the solar collector and heat pump form separate loops with an antifreeze solution and refrigerant, respectively. Theoretically, the indirect configuration can be implemented by exploiting a solar collector to preheat ambient air which is used as a heat source 
for the ASHP (Kegel et al., 2012). In practice, indirect systems often include a water-based heat pump where the solar loop and heat pump loop are interconnected via a liquid-to-liquid heat exchanger.

The dual systems are the systems with either two heat sources or two storages (Chandrashekar et al., 1982). A dual-source system represents the most complex arrangement (Lazzarin, 2012) as the heat pump incorporates two evaporators: a liquid evaporator which receives energy from the solar collector via thermal storage and an air evaporator which receives energy from the outside air. In this configuration, the heat pump selects the most favourable source in order to achieve the highest COP. There are three operation modes of the heat pump in dual systems:

1. The heat pump is off while the solar collector charges the storage.

2. The heat pump discharges the storage when its temperature is higher than the outside air but lower than required for direct heating.

3. The heat pump works as a conventional ASHP system and the solar collector charges the storage in order to raise the temperature of the storage above the temperature of the outside air.

The dual-source system can be simplified by having a single evaporator and eliminating thermal storage in the configuration with a tube-in-tube finned heat exchanger that enables the heat pump to receive heat from the solar collectors and ambient air simultaneously (Liu et al., 2011). This simplification can be counterproductive since the efficient operation of the heat pump becomes limited by frequent occurrences of insufficient solar radiation. 
The challenges associated with period of poor performance of ASHP originated in its exposure to a wide ambient temperature range. The challenges may be addressed by modifying the heat pump components and vapour-compression cycle or they can be overcome by minimizing the temperature range at the outdoor unit of the heat pump. These issues are not inherent for a ground-source heat pump since the ground temperature is relatively stable during the entire year, moreover, the ground can be used as both source of heat and thermal storage. In this perspective, the ultimate solution potentially can be offered by a modified dual configuration where an ASHP receives energy alternatively from the ambient air during the periods of moderate temperatures and from a thermal storage during the periods of extreme ambient temperatures. The following section provides an overview of different types of thermal storages, their advantages and disadvantages, as well as their potential to be coupled with an ASHP in order to develop a more efficient heating and cooling system for the residential sector in Canada.

\section{$2.2 \quad$ TES systems}

A TES system is essential for harnessing the intermittent energy of renewable sources and for efficient utilization of waste heat. TES systems can assist in reducing the demand for electricity and increase the flexibility of operation of energy systems which may also reduce the peak-demand loads as well as energy costs. TES is used in both high-temperature applications, e.g., solar power plants and industrial heat recovery systems, and low-temperature applications, e.g., heating, ventilation, and air conditioning. At cogeneration plants, TES is used to decouple heat and power 
generation. At wind and hydro plants, TES accumulates and stores energy around the clock which is then used during the peak hours. This increases the generation capacity of the system, enhances its economic value, and strengthens its demand reliability.

The potential of TES for different applications is assessed based on a list of criteria. Fernandes et al. (2012) and Gutierrez et al. (2016) emphasized some of the main selection criteria:

- thermophysical properties: density, specific heat, conductivity;

- heat transfer rate between heat transfer fluid (HTF) and storage material;

- thermomechanical and chemical properties: stability, reversibility in multiple charging and discharging cycles, compatibility between HTF and storage material;

- operating conditions: temperature range, heat losses, ease to control, storage period required; and

- economic properties: cost and availability of storage material.

\subsubsection{Thermal storage mechanisms}

There are three main mechanisms of storing thermal energy: sensible, latent, and chemical. In sensible TES, energy is accumulated by changing the temperature of a storage medium. Latent TES utilizes latent heat released or absorbed in the process of storage medium transitioning from one phase to another. In chemical TES, heat is generated in the process of exothermic reactions of chemicals. 
Chemical TES is known for its high energy density and ability to store energy at the ambient temperature which eliminates the self-discharging process. However, chemical TES is expensive as this technology is still in development and lacking commercial production which makes it difficult to conduct large-scale building studies.

Latent TES demonstrates a relatively high energy density. Energy can be stored and released at a constant temperature which can be beneficial, for example, in providing thermal comfort when used in building heating/cooling applications. To fully exploit the potential of latent TES, the storage material must be cooled down to a certain temperature so that it can completely solidify. This is not always achievable due to the properties of the phase change material (PCM), which results in inconsistent performance. For instance, systems with certain PCM operate well during fall and spring but underperform during summer when the overnight temperature is not low enough for the solidification of the PCM. Other drawbacks of latent TES is that it is relatively expensive and it has a low thermal conductivity causing low charging and discharging rates. Overall, further research is required to find suitable PCMs.

Finally, sensible TES is relatively simple and inexpensive. The sensible storage medium has good thermal conductivity and moderate specific heat, it is nonflammable and non-toxic. Since sensible TES has a low energy density, it has to be larger than the other two types of TES in order to store an equal amount of energy. Pinel et al. (2011) presented an in-depth comparison of all three types of TES and concluded that albeit chemical and latent stores have large potential, they require further research and development to become as reliable and economically feasible as sensible TES. 


\subsubsection{Sensible TES}

Storage mediums of sensible TES are typically liquids (e.g., water, oil, organic liquids, molten salts, and liquid metals) or solids (e.g., sand, rocks, concrete, metal

pellets, and ceramics). Common solid and liquid materials used in sensible TES are summarized by Fernandes et al. (2012) and Ataer (2006). Solid materials are easier to contain, while liquids are better at absorbing and releasing heat due to convective heat transfer.

\subsubsection{High- and low-temperature applications}

Typical HTF used in high-temperature sensible TES are water, thermal oil, molten salt, and air. Among them, water has the highest specific heat and thermal capacity but its drawback is high vapour pressure and corrosiveness. Thermal oils can withstand higher, yet limited, operating temperatures but they are costly and hazardous. Molten salts have high thermal stability and can be used at even higher operating temperatures. They have high thermal conductivity, low vapour pressure and viscosity, they are non-toxic and non-flammable; however, they are corrosive and require complex equipment. On the other hand, air is a cheap, easily available, non-toxic, non-flammable, environmentally friendly, and non-degradable HTF that can operate under high and low temperatures.

Sensible TES is commonly used for high-temperature applications in solar thermal power plants in order to increase the efficiency of a plant and its generation capacity. About half of the concentrating solar power plants in the world have integrated sensible TES (Esence et al., 2017). Concentrating solar power plants have a maximum operating temperature of about $400{ }^{\circ} \mathrm{C}$ when based on parabolic trough 
concentrators with oil as $\mathrm{HTF}$ and $565{ }^{\circ} \mathrm{C}$ when based on a field of heliostats that use molten salts (Almendros-Ibáñez et al., 2018). These operating temperatures can be increased if air is used as HTF; however, air-based systems require higher mass flow rates and larger surface area as a result of lower heat capacity and conductivity of air. The solar energy collected by HTF is stored in a tank filled with either HTF or solid particles or a combination of both. Typical solid storage materials are stone, brick, and concrete. Rock is often chosen for its availability, good thermal conductivity, low thermal expansion coefficient, high melting point of above $900{ }^{\circ} \mathrm{C}$, thermal and chemical stability under a wide temperature range, non-toxicity, and non-flammability. In addition, rocks serve as both a storage medium and a heat transfer surface and demonstrate good heat transfer with such inexpensive HTF as air. Tiskatine et al. (2017) and Allen et al. (2014) presented thermophysical properties of a number of different rock types and their advantages and disadvantages when used in TES.

Daschner et al. (2013) built and tested a pilot pebble-heater to evaluate its potential for a combined heat and power biomass plant where operating temperatures reach $1200{ }^{\circ} \mathrm{C}$. Alumina oxide pebbles were used as a storage material. When integrated into the plant, TES would be charged by a flue gas during low power demand and discharged by circulating fresh air to provide thermal energy to the customers when the power plant generates mainly electricity during high electricity demand. More case studies of high-temperature TES used at power stations are discussed by Medrano et al. (2010).

Low-temperature applications include solar air heaters, crop dryers, and greenhouses; however, Dincer and Rosen (2011) argue that one of the most promising 
application is the one related to solar heated residential and commercial buildings. In solar air heaters, solar energy is typically absorbed by flat-plate collectors. Although liquid-based solar energy systems have a higher energy density, air-based systems are sometimes preferred due to their simpler design and low cost. As a storage material, stones are often used because of availability and low cost. The size of rocks varies between $0.01 \mathrm{~m}$ and $0.05 \mathrm{~m}$ (Almendros-Ibáñez et al., 2018). In terms of design, a rock bed is typically contained within an insulated tank which has two openings - one at the top and one at the bottom section. The top section usually maintained the warmest, and thus TES is discharged with upwards flow from the top and charged by downwards flow. Due to poor heat conduction between rocks, packed-bed storage can remain stratified for an extended period of time.

Choudhury and Garg (1995) analyzed a residential heating system where the rock bed and water tank form a water-to-air heat exchanger connected to solar water heating collectors. In this configuration, as known as Harry Thomason's method (Dincer et al., 1997), a cylindrical stainless steel water tank was enclosed within an insulated rectangular tank filled with rocks.

Persons et al. (1980) experimentally tested a rock bed used for air-based space heating of a detached single-family house of $210 \mathrm{~m}^{2}$ floor space. The storage was represented by an insulated box of $3.4 \times 3.6 \times 1.6 \mathrm{~m}$ filled with rocks of $2 \mathrm{~cm}$ in diameter. The rock bed was installed in the basement of the house, it was charged by either solar thermal collectors or electric heaters. The flow rate across the rock bed varied between $1400 \mathrm{~m}^{3} / \mathrm{h}$ and $2200 \mathrm{~m}^{3} / \mathrm{h}$, and the maximum pressure drop during charging and discharging processes was 11.2 $\mathrm{Pa}$ and 1.74 Pa, respectively (Persons, 1978). The issue of maldistribution of the airflow was discussed. It was mentioned that 
short circuiting where air flows along the wall directly between the top and bottom plenum ports was occurring until it was fixed. Short circulating disengaged most of the store and hindered the charging and the discharging processes. It was observed that a more uniform flow through a rock bed can be organized if the pressure drop across the rock bed is greater than the inlet air velocity pressure.

\subsubsection{Cooling applications}

While sensible TES, e.g., underground TES and large water tanks, are often used for building heating purposes, PCM technologies, e.g., ice store and passive cooling PCM systems, are typically used for air conditioning purposes (International Renewable Energy Agency, 2013). Dincer and Rosen (2011) discussed three main storage mediums used in cold TES, such as chilled water, ice, and eutectic salts.

Moreno et al. (2014) experimentally compared the performance of a water-towater heat pump coupled to a water tank and a PCM tank of identical volume for space cooling application. The PCM tank was able to store and then supply more energy, yet the charging time was 4.6 times higher and the discharging efficiency ${ }^{2}$ was worse than that of a water tank.

The available literature provides a limited number of examples of rock-bed TES used in cooling applications. However, some research has been done. For instance, Kürklü and Bilgin (2004) conducted an experiment cooling a $15 \mathrm{~m}^{2}$ greenhouse by recirculating air from the greenhouse through two insulated rock-bed canals of $3 \times 1.25 \times 0.75 \mathrm{~m}$ buried in the soil underneath the greenhouse. At night the rock-bed canals were cooled down by circulating fresh outside air through. The flow rate was

\footnotetext{
${ }^{2}$ Ratio between energy supplied and energy stored.
} 
maintained at $1100 \mathrm{~m}^{3} / \mathrm{h}$. Such a cooling system demonstrated the best results in maintaining lower temperature and relative humidity in the greenhouse under hot sunny conditions. Overall, the authors concluded that the rock-bed system has a significant potential for cooling applications in greenhouses.

\subsubsection{Seasonal and diurnal applications}

In building applications, seasonal TES assists in closing the gap between energy availability and heating/cooling demand. However, storing energy for months is accompanied by long-term self-discharge due to heat losses. This can be mitigated by using a low-temperature store. The system with a low-temperature TES often incorporates a heat pump to adjust temperatures in accordance with the heating demand.

Considering a large amount of energy involved in seasonal store, in-ground installation is recommended as it offers large storage volume at a relatively low cost (Nordell and Hellström, 2000). The different types of underground TES are represented by three major categories (International Renewable Energy Agency, 2013):

- borehole heat store where ground directly serves as the storage medium;

- water-filled rock cavern, water-filled pit, buried water tank; and

- aquifer accessed through wells.

Hesaraki et al. (2015) studied systems that combine heat pump and seasonal TES, such as a hot water tank, water-gravel pit storage, borehole, and aquifer. In all configurations, sensible TES was charged by solar collectors integrated into the system either in parallel, or series, or series-parallel in relation to a heat pump. 
The authors analyzed such systems installed around the world and concluded that seasonal TES is more economical and efficient as part of a community development rather than in single-family houses. More examples of seasonal water-gravel and borehole TES used for space heating and domestic hot water supply implemented in district projects in Germany, Sweden, Canada, Finland, and the Netherlands are provided by $\mathrm{Xu}$ et al. (2014).

Dincer et al. (1997) emphasised that an annual cooling or heating load would require a massive and unacceptably expensive store which makes it more practical to focus on short-term sensible TES.

As part of her study on solar-assisted heat pump system, Chu (2014) provided an extensive survey of different system configurations with integrated diurnal TES used for space-heating and domestic hot water supply in residential applications. It was highlighted that the system proposed in the thesis was unique for satisfying both the heating and cooling demand of a residential house with consideration of the Canadian climate. The designed and built system incorporated two water tanks - hot and cold - to serve as source and load sides of the liquid-to-liquid heat pump. The cold tank was charged by a solar simulator setup. The author discussed thermal stratification in the hot tank and its impact on the system performance.

An example of diurnal rock-bed store used for residential heating purposes was discussed earlier in Section 2.2.2.1.

\subsubsection{In-ground TES}

Dorf (1978) discussed different arrangements of rock bed in an insulated container for low- and intermediate-temperature solar heating applications $\left(0{ }^{\circ} \mathrm{C}-150{ }^{\circ} \mathrm{C}\right)$, as 
well as a buried rock bed used for storing energy at up to $500{ }^{\circ} \mathrm{C}$. Depending on the ground type, a few configurations were recommended. Rock-bed storage can be arranged in deep parallel trenches or large pits filled with stones where air circulates through the pipes installed inside. In the ground formed by porous rocks, the storage can be organized in layers of tunnels used for air circulation. If the ground formation is not porous enough, caverns can be formed by drilling and blasting the underground rock layers. The author mentioned that in dry climates, surrounding soil can serve as an insulation material to reduce self-discharging of buried TES. The insulation value of a $10 \mathrm{~m}$ thick layer of dry soil or $2 \mathrm{~m}$ of very dry soil is equivalent to that of $0.3 \mathrm{~m}$ of polyurethane foam.

As mentioned earlier, the ground itself can be used as TES, for instance, in solarassisted ground source heat pump systems where it serves as an energy sink for solar collectors and an energy source for heat pump (Zhu et al., 2014). The charging and discharging processes are organized by means of boreholes. Duct ${ }^{3}$ TES can also be used without a heat pump. Lundh and Dalenbäck (2008) presented a lowtemperature district heating system with seasonal TES designed and commissioned in Anneberg, Sweden. The system included flat plate solar collectors integrated with 100 boreholes of $65 \mathrm{~m}$ in depth installed in granite bedrock.

Although rock-bed and duct TES are promising components of energy efficient and environmentally friendly heating and cooling systems of a single-family house or district, there is a list of possible constraints in implementing underground stores, especially large ones, in urban areas. The list includes physical constraints, e.g., urban infrastructure, district heating and public utilities, and environmental constraints,

\footnotetext{
${ }^{3}$ Duct TES is used here as a collective term that includes both vertically installed underground pipes, aka boreholes, and horizontally installed underground pipes.
} 
e.g., nature conservation (Navarro et al., 2016).

\subsubsection{Pressure drop in rock-bed TES}

The design of a packed-bed store is a trade-off between multiple factors (Esence et al., 2017). To reduce thermal losses, compact stores with big volume and small surface area are recommended. On the other hand, the efficiency of a packed bed increases with the increase of the store stratification which can be achieved at a large height-to-diameter ratio. However, this raises the pressure losses, which may affect the overall system performance.

Hollands and Sullivan (1984) experimentally studied a pressure drop across rockbed TES of $1.8 \mathrm{~m}$ high. Their apparatus had a diffuser with flow straightening screens to organize a uniform velocity profile. Stones of different shapes and sizes common for Ontario, Canada, were tested to determine a hydraulic resistance of each aggregate. The resulting pressure gradient ${ }^{4}$ along the rock bed in flow direction was presented as a function of superficial mass velocity ${ }^{5}$. For instance, in a rock bed with a "19 mm clear stone" aggregate the pressure gradient increased from $14 \mathrm{~Pa} / \mathrm{m}$ to $53 \mathrm{~Pa} / \mathrm{m}$ as the superficial mass velocity increased from $0.07 \mathrm{~kg} /\left(\mathrm{s} \mathrm{m}^{2}\right)$ to $0.17 \mathrm{~kg} /\left(\mathrm{s} \mathrm{m}^{2}\right)$.

Waked (1986) also experimentally studied characteristics of rock-bed TES when packed with rocks of different sizes and tested at different air flow rates. Obtained

\footnotetext{
${ }^{4}$ The pressure gradient is determined as a pressure drop per meter of rock bed height, $\Delta \mathrm{P} / \mathrm{H}$ $(\mathrm{Pa} / \mathrm{m})$

${ }^{5}$ Superficial mass velocity is determined as a mass flow rate per unit cross-section $G=\dot{m} / A_{R B}$ $\left(\mathrm{kg} /\left(\mathrm{s} \mathrm{m}^{2}\right)\right)$
} 
results demonstrated a linear correlation between the pressure gradient and the superficial air velocity so that it increased from $2 \mathrm{~Pa} / \mathrm{m}$ at $0.01 \mathrm{~m} / \mathrm{s}$ to $65 \mathrm{~Pa} / \mathrm{m}$ at $0.31 \mathrm{~m} / \mathrm{s}$ when the storage was filled with $21 \mathrm{~mm}$ in diameter rocks.

Sagara and Nakahara (1991) conducted simulation work to investigate the performance of a solar heating system consisted of solar collectors, an ASHP, and a rock bed. In the computer model, solar collectors charged a rock bed which was a source of heat for the heat pump. The rock bed with the size $0.63 \times 0.63 \times 1.0 \mathrm{~m}$ filled with gravel as well as large-sized storage mediums, such as bricks and concrete blocks, was experimentally tested and the pressure drop through the store was measured. The obtained measurements for the gravel bed were similar to the ones observed by Hollands and Sullivan (1984): the pressure gradient increased from $7 \mathrm{~Pa} / \mathrm{m}$ to

$65 \mathrm{~Pa} / \mathrm{m}$ as the superficial mass velocity increased from $0.06 \mathrm{~kg} /\left(\mathrm{s} \mathrm{m}^{2}\right)$ to $0.22 \mathrm{~kg} /\left(\mathrm{s} \mathrm{m}^{2}\right)$. The pressure gradient across the rock bed filled with larger materials was lower; however, the store demonstrated a reduction in the amount of collected heat. This made the overall system performance comparable regardless of the size of the storage medium. It was noted that large-sized materials may be more advantageous for the systems with tall rock-bed stores.

\subsection{Rock-bed TES integrated to ASHP}

In addition to Sagara and Nakahara (1991) other authors also studied the systems that combine a rock-bed TES and ASHP.

Nicholls (1980a) modelled thermal behaviour of a seasonal rock-bed TES and surrounding soil as part of a solar heating system in order to obtain approximate optimal 
sizing of system components. The system included air-based solar collectors, gravel bed, and air-to-air heat pump connected in series. The rock bed insulated around its perimeter had the width, length, and depth of $10 \mathrm{~m}, 25 \mathrm{~m}$, and $2 \mathrm{~m}$, respectively. It was placed in a building foundation and filled with gravel with the diameter of $0.05 \mathrm{~m}$. Perforated plastic drainage pipes with 4-inch diameter were placed at the opposite walls of the foundation to serve as air manifolds. The simulations were conducted for Spokane in Washington state, USA. The authors developed expressions for the steady-state heat losses to the ground using shape factors (Nicholls, 1980b). As a retrofit option, Nicholls (1981) suggested a more practical design of the system two $20 \mathrm{~m}$ deep thermal wells filled with gravel instead of a rock bed in the foundation - to avoid altering the foundation. The model of the proposed retrofit system consisted of water-based solar collectors and water-to-air heat pump. The models were not validated.

Ceranic et al. (2018) proposed to incorporate a rock-bed TES into a transportable single classroom pod which intended to improve sustainability and energy autonomy of such a modular building system. A low-temperature diurnal rock bed of $9 \times 6 \times 0.5 \mathrm{~m}$ was designed as an integrated part of the foundation module. When the building required heating, ambient air was drawn through the pre-warmed rock bed and then supplied into the classroom space through the floor grills. Similarly, the rock bed was used for cooling purposes. The store was charged by ambient air, although the required temperature could be maintained by means of an ASHP. The authors were interested to build a prototype of the proposed system. 


\subsection{Gaps in literature}

Earlier in this chapter, it was stated that the performance of the ASHP can be improved when integrated into the system with a thermal energy storage which is periodically charged by some environmentally-friendly means. Later, it was argued that sensible thermal storage is the most simple, inexpensive, reliable, clearly understood, and widely used type of TES. Henceforth, for this research, it was decided to couple the ASHP with a sensible TES, such as a rock-bed storage. It was discussed that depending on the properties, the ground can serve as a thermal storage, heat source or thermal insulation, which makes it a suitable surrounding medium for a rock-bed storage installed outdoors due to its large size.

Nevertheless sensible TES and heat pumps have been broadly studied, little research has been conducted on the systems where a diurnal non-insulated rock-bed store is coupled to an ASHP in order to improve the system performance under ex-

treme temperatures. The systems discussed in the literature are lacking examples of certain

- configuration: an ASHP coupled with a rock-bed TES;

- application: low temperature residential heating and cooling;

- combination of the storage material and HTF in TES: rocks and air;

- boundary conditions of TES: direct contact with the surrounding soil;

- time frame (periodicity of usage): diurnal rock-bed TES; and

- TES charging strategies: charging with ambient air. 
Overall, the existing gap in the literature created an interest to design, build, and test such a system. 


\section{Chapter 3}

\section{Design and Commissioning of Experiment}

The following chapter provides a detailed description of the experimental setup which was designed and constructed by the author ${ }^{1}$ to assess the performance of an ASHP when coupled to a diurnal sensible TES. By the request of the industrial partner, the experimental setup was designed and built with an intention to provide a capability of testing and evaluating various scenarios to operate such a combined system and compare its performance with the performance of the conventional heat pump system. The scenarios include:

1. Tempering the source side of the heat pump by discharging the thermal storage when its temperature is more favourable then the temperature of the ambient air. This scenario can be conducted by pulling air from either top or bottom of the thermal storage.

2. Charging the thermal storage by circulating ambient air through it under the

\footnotetext{
${ }^{1}$ The author would like to acknowledge the assistance of three undergraduate students: Ashley Hooker, Isabelle Kosteniuk, and Keelia LaFreniere.
} 
appropriate temperature conditions ${ }^{2}$. This scenario can be conducted by pushing air to the top or bottom of the rock bed.

3. Recirculating air, which is pulled from the rock bed and through the outdoor heat exchanger of the heat pump back to the rock bed under the appropriate temperature conditions ${ }^{3}$.

\subsection{Overview of experimental setup}

A full-scale experimental setup of the ASHP coupled to the diurnal TES was built at the Urbandale Centre for Home Energy Research (Urbandale CHEeR) at Carleton University. Building of the experimental setup commenced in January 2015, shortly after the construction of the Urbandale CHEeR house had started. Building of the system began with a thermal storage represented by a pit in the ground filled with gravel - a $19 \mathrm{~mm}$ clear stone aggregate. It was the same material which was described in Chapter 2 as the storage medium of a rock bed that demonstrated a low pressure loss (Hollands and Sullivan, 1984).

The 2-meter deep pit with the footprint of six by three meters was excavated ${ }^{4}$ on the North-West side of the research house. The backfill was conducted in stages along with the installation of the sensors and other equipment in the storage. The ductwork above the ground was finished at the end of 2015 after a few design iterations that

\footnotetext{
${ }^{2}$ For example, during the summertime, the appropriate conditions mean that the ambient air is cooler than the thermal storage.

${ }^{3}$ For example, during the summertime, the right conditions mean that the exhaust air after the outdoor heat exchanger is cooler than the ambient air and/or the thermal storage.

${ }^{4}$ The depth of the pit was chosen so that the thermal storage would be located below the frost line, and the footprint of the pit was meant to resemble the footprint of a garage.
} 
led to a switch from motorized airtight dampers to manual single blade ones due to air restrictions which caused incompatibility with the heat pump.

The heat pump was commissioned in August 2015. The rock bed was instrumented at the end of 2015 and the indoor units of the heat pump were equipped with sensors in spring 2016. Temperature sensors before and after the outdoor heat exchanger were replaced in summer 2017 when it was found that they require shielding in order to minimize the effect of radiation component on the temperature readings.

\subsection{Rock-bed storage}

In order to couple the ASHP to the rock bed and enable air circulation between the two, the inlet and outlet of the outdoor heat exchanger of the heat pump were connected to the "discharging" and "charging" duct", respectively (Figure 3.1). Each duct was connected to a set of perforated pipes $^{6}$, where one set was installed at the bottom of the storage and another one was installed at the top of the storage (Figure 3.2).

The bottom pipes were installed on top of a 0.2 -meter thick layer of gravel $^{7}$. The layer of stones serves as a drainage and also distances the pipes from the soil. The top pipes were covered by a 0.5-meter thick layer of stones and a polyethylene sheet. This top layer is aimed to constrain the air circulation within the rock bed, protect the pipes from external damage, and avoid direct penetration of precipitation

\footnotetext{
${ }^{5}$ The quotation marks are used to indicate that both ducts can be alternatively used as either charging or discharging, and here for simplicity one is called charging and another one discharging.

${ }^{6} \mathrm{~A}$ set consists of $12 \mathrm{PVC}$ sewer pipes four inches in diameter; only a horizontally laid section of each pipe is perforated. For simplicity, only 3 discharging and 3 charging pipes are depicted on Figure 3.1.

${ }^{7}$ The soil bottom surface of the storage is regarded as a zero reference level.
} 


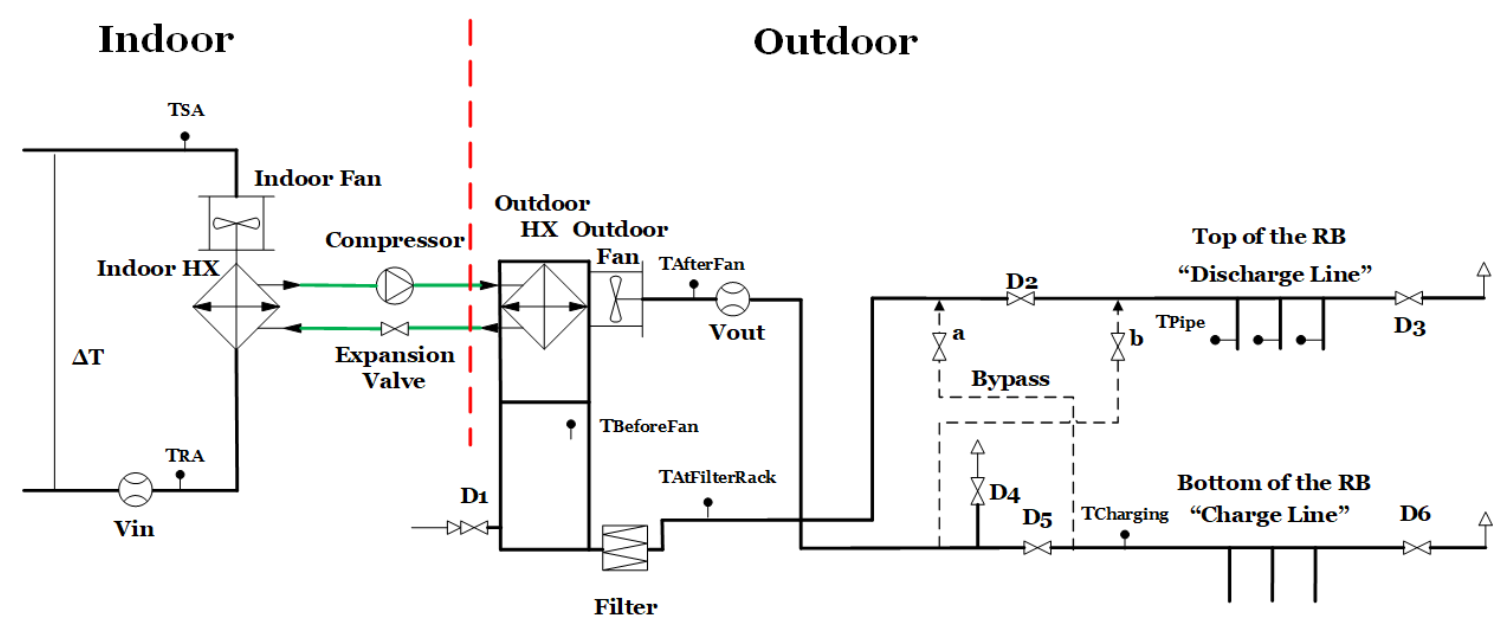

Figure 3.1: Flow diagram of the rock-bed storage coupled to the ASHP

into the storage. However, moisture penetration from the surrounding soil into the storage is not restricted since there is no intermediate layer which would separate the medium of the storage and the surrounding soil. In this setup, soil becomes a beneficial part of the system: it directly cools down the rock bed during the cooling season and warms it up during the heating season. Therefore, due to heat and mass transfer, soil conditions and properties affect the temperature distribution and thermal capacitance of the storage. For instance, thermal conductivity, which directly relates to the temperature distribution, varies with the soil being frozen or unfrozen, saturated or dry, etc. In addition, moisture that migrates from the soil into the rock bed and freezes alters the sensible storage into a latent one and changes its thermal capacitance. This facilitates the discharging process as latent heat of freezing is being released while moisture content in the storage freezes. On the other hand, ice accumulated in the storage slows down the charging process. Similarly, during the cooling season, heavy precipitation can affect charging and discharging 


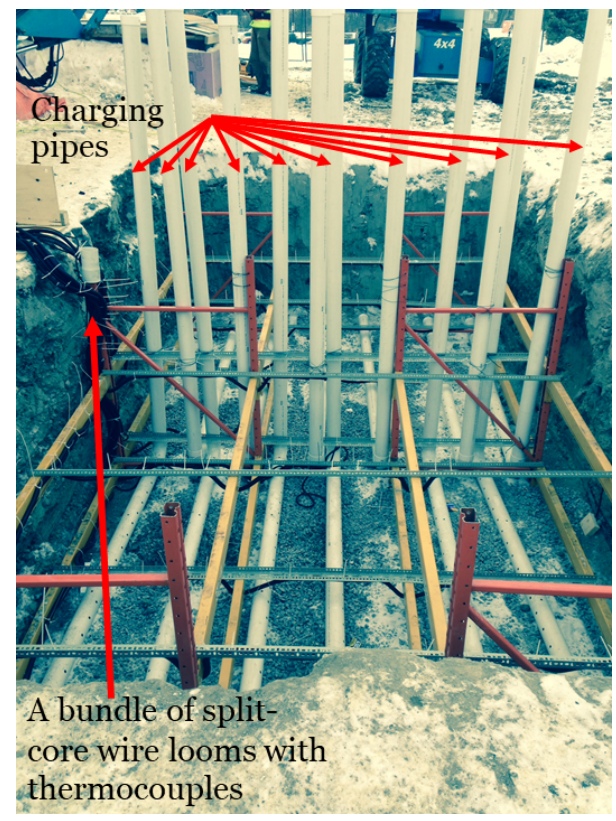

(a) bottom of the rock bed

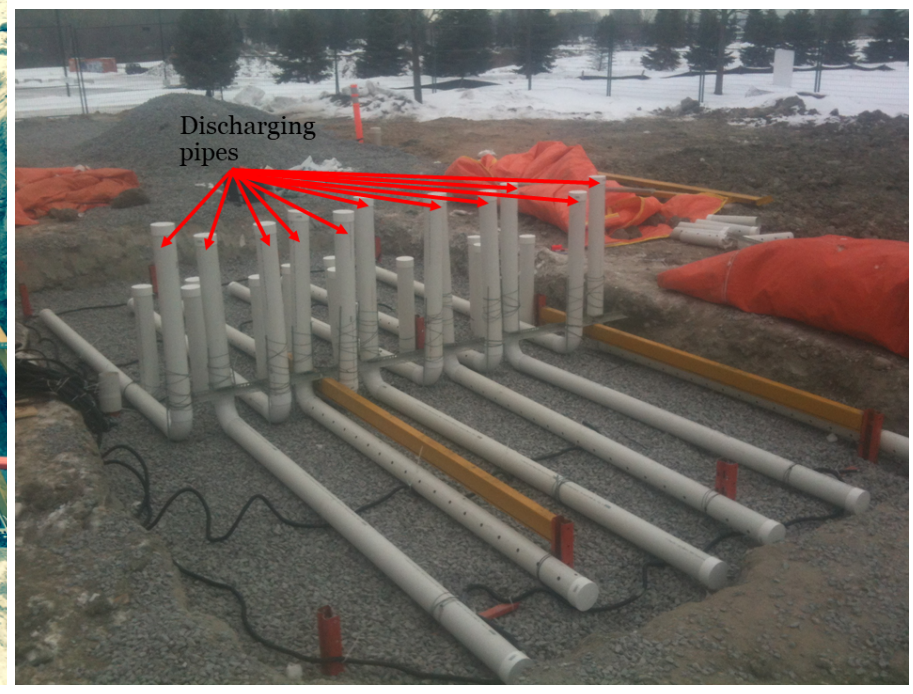

(b) top of the rock bed

Figure 3.2: Rock bed equipment

processes: evaporation of the moisture content benefits the discharging process, yet condensation has a negative impact on the charging process. Hence, the fact that the rock bed can behave as either a sensible or latent storage has both advantages and disadvantages for its diurnal application.

The outdoor unit of the heat pump consists of two compartments. The top compartment contains the heat exchanger and fan that either exhausts the air or sends it to the bottom of the rock bed. The bottom compartment serves as an air intake from either outside or the top of the rock bed. Thus, the heat pump can operate either in a conventional manner using non-conditioned ambient air or in a novel way using the air tempered in the storage. To alternate the flow direction 


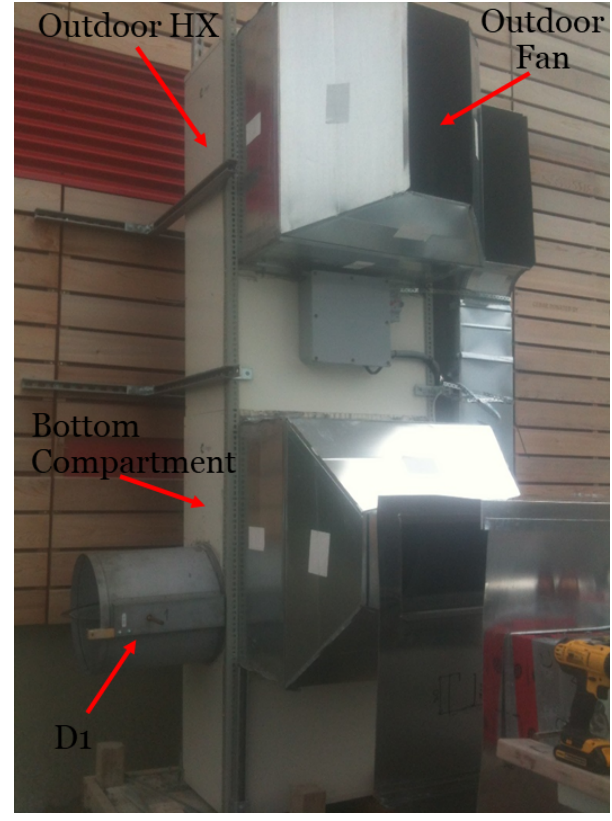

(a) outdoor unit of the HP

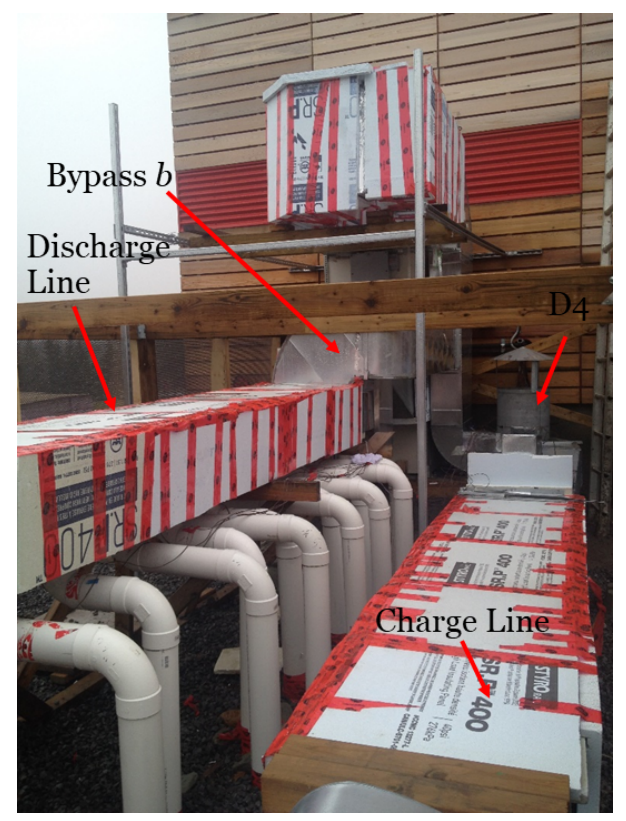

(b) complete ductwork outside

Figure 3.3: Outdoor part of the system

in the system and discharge the rock bed from the bottom instead of the top and charge the top of the rock bed instead of the bottom, two bypass lines connect the discharging and charging ducts. This flow alternation is achieved by opening and closing the appropriate dampers. All dampers are indicated on the flow diagram (Figure 3.1), where the dampers on the main ductwork are labelled as D1..D6 and the dampers installed in the bypasses are labelled as $a$ and $b$. The list of possible charging and discharging scenarios is summarized in the Table 3.1, where a checkmark indicates that the damper is open and a cross means that the damper is closed. Both charging and discharging processes can be conducted by pulling air from either top or bottom of the rock bed so that a temperature gradient across the rock bed can be 
Table 3.1: List of charging and discharging scenarios

\begin{tabular}{|c|c|c|c|c|c|c|c|c|}
\hline Scenario & D1 & D2 & D3 & D4 & D5 & D6 & a & $\mathrm{b}$ \\
\hline (Ia) HP charging the bottom with recirculation & $x$ & $\checkmark$ & $x$ & $x$ & $\checkmark$ & $x$ & $x$ & $x$ \\
\hline (Ib) HP charging the top with recirculation & $x$ & $x$ & $x$ & $x$ & $x$ & $x$ & $\checkmark$ & $\checkmark$ \\
\hline (IIa) HP discharging from the bottom & $x$ & $x$ & $\checkmark$ & $\checkmark$ & $x$ & $x$ & $\checkmark$ & $x$ \\
\hline (IIb) HP discharging from the top & $x$ & $\checkmark$ & $x$ & $\checkmark$ & $x$ & $\checkmark$ & $x$ & $x$ \\
\hline (IIIa) Conventional HP with a lower flow rate & $x$ & $\checkmark$ & $\checkmark$ & $\checkmark$ & $x$ & $x$ & $x$ & $x$ \\
\hline (IIIb) Conventional HP with a higher flow rate & $\checkmark$ & $x$ & $x$ & $\checkmark$ & $x$ & $x$ & $x$ & $x$ \\
\hline (IVa) Conventional charging from the bottom & $\checkmark$ & $x$ & $\checkmark$ & $x$ & $\checkmark$ & $x$ & $x$ & $x$ \\
\hline (IVb) Conventional charging from the top & $\checkmark$ & $x$ & $x$ & $x$ & $x$ & $\checkmark$ & $x$ & $\checkmark$ \\
\hline
\end{tabular}

used advantageously ${ }^{8}$. Charging the rock bed can be conducted by either pushing ambient air straight into the storage or conditioning ambient air when the heat pump is in a reverse mode and then pushing it to the storage. For example, during the summertime, if the house requires heating, the heat pump can be switched to the heating mode so that the outdoor heat exchanger becomes an evaporator which can be used to cool the rock bed.

\subsection{Air source heat pump}

An Ecologix residential air-to-air cold climate air source heat pump was installed in the basement of the CHEeR house. On Figure 3.1, the indoor unit of the heat pump, which consists of a compressor, an expansion valve, an indoor heat exchanger,

\footnotetext{
${ }^{8}$ For example, during the summertime, it is advantageous to discharge the rock bed from its coldest section.
} 
and an indoor fan, is shown on the left-hand side of the vertical red dash line. The outdoor unit, which is shown on the right-hand side of the vertical red dash line, is connected to the indoor unit via a refrigerant line - a green line on Figure 3.1.

The air handler ${ }^{9}$, as part of forced-air heating and air conditioning system, was connected to the ductwork that distributes heated or cooled air to the basement, first, and second floors of the house.

The heat pump was built with a 5-ton variable frequency drive scroll compressor with liquid injection. The compressor is capable of heating and cooling at capacities between $10 \%$ and $100 \%$. This is achieved by changing the duration of the loaded and unloaded states of the compressor. In the loaded state, the compressor delivers full capacity and mass flow. In the unloaded state, there is zero capacity and mass flow through the compressor. Due to the reduced number of compressor starts and stops, the energy consumption decreases and the room temperature maintains at the setpoint value more consistently.

Other than the heating and cooling modes, the heat pump has a test mode when a varying speed outdoor fan is operating while the compressor is not. Test mode remains energized until the call for heating or cooling arises. This mode is designed to enable charging the rock bed with ambient air (scenario IV from Table 3.1). When the rock bed is being charged, the fan speed is set to $100 \%$.

According to the performance map provided by the manufacturer, under an extreme ambient temperature of $-25{ }^{\circ} \mathrm{C}$, the heat pump can provide $5.3-10.3 \mathrm{~kW}$ of heating with the COP of 1.9. The accompanying documentation on the heat pump did not include the cooling performance which could have been used as a reference

\footnotetext{
${ }^{9}$ The air handler consists of the indoor heat exchanger and fan.
} 
for the experimental work.

\subsection{Instrumentation}

To determine the performance of the ASHP in a conventional setup and when coupled to the rock bed, the heat transfer rate from the refrigerant to the airstream in the air handling unit (AHU) must be determined while monitoring the temperature at the outside heat exchanger. The heat transfer rate is calculated based on the measured air velocity at the air handler, the measured temperature difference across the AHU, and the thermophysical properties of the air using standard tables. Another performance criterion is the COP which is calculated using the heat transfer

rate and power consumption. The following sections describe the instruments which were used to determine the performance of the heat pump.

\subsubsection{Thermocouples}

Thermocouples were selected as temperature sensors since they are inexpensive, rigid, fast responding and tip-sensitive within a wide temperature range. Thermocouples were installed in the various locations for different purposes:

- throughout the rock bed to monitor the temperature distribution in the storage,

- in the outdoor ductwork and pipes for troubleshooting purposes,

- across the air handler in conjunction with a thermopile, and

- on the first floor at the CHEeR house for control purposes. 
The environment where the thermocouples are installed dictates whether the sensors require any protection. For instance, the sensors placed throughout the rock bed were inserted into a heat-shrink tube in order to protect the tip from corrosion if soil is acidic (Figure 3.4). In addition, the entire length of the thermocouples in the rock bed was mechanically protected by keeping the wires in a split-core wire looms as can be seen in Figure 3.2. Within the rock bed, the sensors were placed in an X-shape, where one sensor is in the centre of the footprint of the storage, four sensors are in the corner areas, and other four are between the central sensor and corner ones as it is shown in Figure 3.5. In such arrangement, the thermocouples were installed in three horizontal layers: at the bottom $(0.2 \mathrm{~m}$ above the soil bottom surface), at the middle $(0.9 \mathrm{~m})$, and at the top $(1.65 \mathrm{~m})$ of the rock bed.

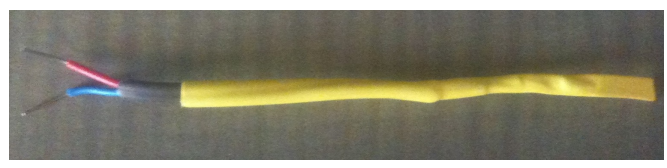

Figure 3.4: Thermocouple in a heat shrink tube

The thermocouples in the pipes and ductwork did not require any particular protection. The important requirement was to centre the sensors in the orifice which was achieved by using the fish wire (Figure 3.6a, Figure 3.6b, Figure 3.7a).

The thermocouples before and after the outdoor unit of the heat pump were shielded so that the sensors were not exposed to the thermal radiation emitted by the hot surface of the heat exchanger. The shielding included a plastic pipe wrapped in a reflective bubble insulation (Figure 3.7). The dimensions of shielding were not optimized. In the future, a pipe with a bigger diameter can be possibly selected as 


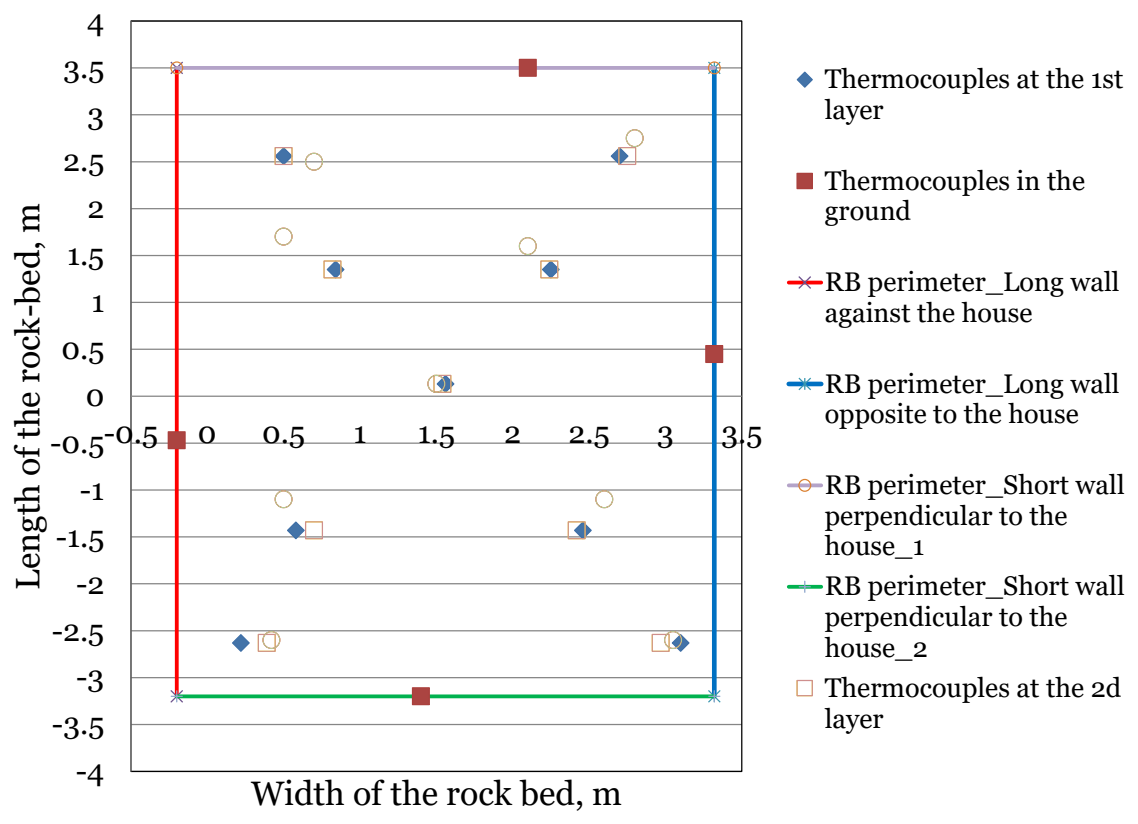

Figure 3.5: Location of the thermocouples in the rock bed

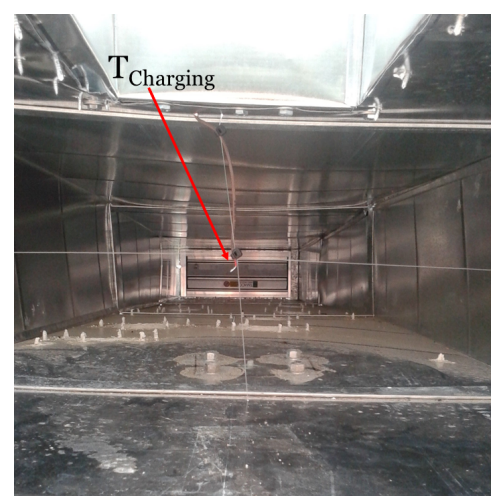

(a) in the duct

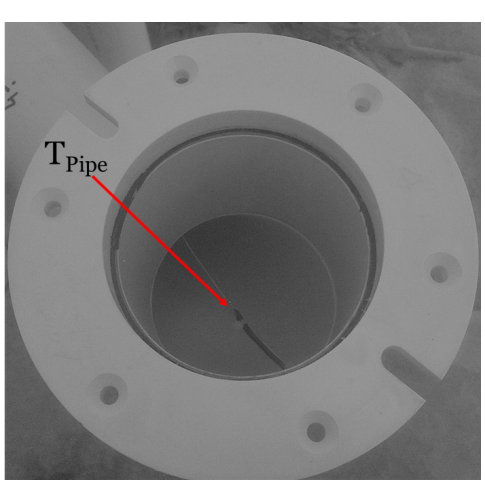

(b) in the pipe

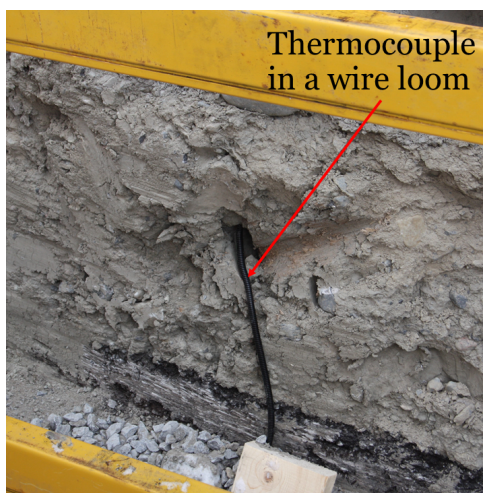

(c) in the soil

Figure 3.6: Thermocouple installation 
a more suitable one.

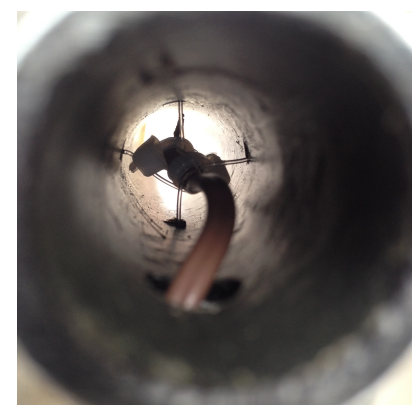

(a) thermocouple inside shielding

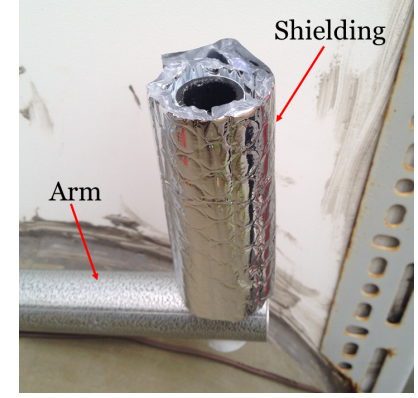

(b) arm and shielding

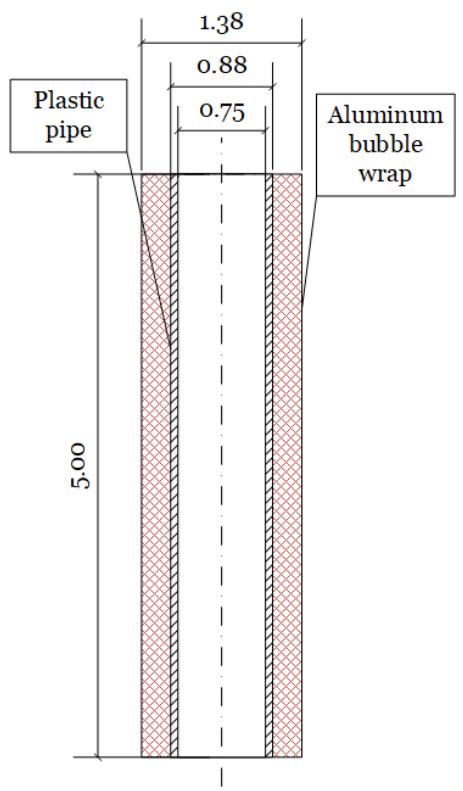

(c) cross section of shielding (the dimensions are in inches)

Figure 3.7: Shielded thermocouple

Thermocouples were constructed using a Type-T (copper-constantan) thermocouple wire. A thermocouple junction - soldered together copper and constantan conductors - produces an electromotive force (emf) which generates the potential difference in a thermocouple circuit. The generated voltage signal is proportional to the temperature between the measurement junction and a reference junction (so-called cold junction). A built-in thermistor in the DAQ establishes the reference temperature. The conversion between the voltage signal and the temperature of the junction can be obtained using tables created by the National Institute of Standards and Technology; however, to achieve a smaller measurement bias error, 
thermocouples need to be calibrated.

\section{Calibration}

Each spool of thermocouple wire used in this project was calibrated against a platinum resistance temperature detector, RTD (Fluke 5615 Platinum Resistance Thermometer, Secondary Standard), factory calibrated to $0.02{ }^{\circ} \mathrm{C}$. The list of the calibrated thermocouple-wire spools, their applications, and the calibration temperature ranges is summarized in Table 3.2. The calibration was performed using a glycol solution bath (Fluke 7102) and a silicon oil bath (Fluke 7340) under the positive and negative temperature range, respectively.

Table 3.2: Thermocouple calibration

\begin{tabular}{llc}
\hline \hline Spool & Sensors & Range, ${ }^{\circ} \mathrm{C}$ \\
\hline \hline Spool A & RB (bottom, middle), Duct (at filter rack) & $-5-90$ \\
Spool B & Soil, RB (top), Zone, Duct (charging) & $-5-90$ \\
ZCL Spool 1 & Duct (shielded BF, AF) & $-5-95$ \\
20 AWG Spool 2 & AHU (SA, RA) & $5-95$ \\
\hline Spool A & RB (bottom, middle), Duct (at filter rack, BF, AF) & $-35-0$ \\
Spool B & Soil, RB (top), Zone, Duct (charging) & $-35-0$ \\
\hline
\end{tabular}

The calibration was carried out by submerging the RTD probe and thermocouples into a filled bath where the temperature was maintained constant $\left( \pm 0.02{ }^{\circ} \mathrm{C}\right)$ and uniform throughout the bath. The resistance signal generated by the RTD was measured by a digital multimeter (DMM) which has an error of $\pm 0.011 \%$ on 4 -wire 
resistance measurements. In order to convert the resistance readings into the temperature, Equation 3.1 (Baldwin, 2011) was developed based on the manufacturer's data:

$$
T=0.000997 R^{2}+2.308 R-240.845
$$

The error resulting from the regression was an order of magnitude smaller than that of the RTD and as such considered negligible. The temperature error due to the resistance reading is calculated as a product of the resistance error in $\Omega$ and the sensitivity parameter in ${ }^{\circ} \mathrm{C} / \Omega$, where the resistance error is a percentage of the maximum resistance reading and the sensitivity parameter is the value of the derivative $\mathrm{dT} / \mathrm{dR}$ derived from Equation 3.1 at the maximum resistance reading. At the maximum measured resistance during the calibration process of $139.67 \Omega$, the resistance error and sensitivity parameter were determined to be $0.0154 \Omega$ and $2.59{ }^{\circ} \mathrm{C} / \Omega$, respectively. This resulted in the error in the temperature reading of $0.04{ }^{\circ} \mathrm{C}$.

The cold-junction temperature was measured by a built-in thermistor on the National Instrument thermocouple card (NI 9142) which has an error of $\pm 0.25{ }^{\circ} \mathrm{C}$. The calibration procedure is described in-depth by Baldwin (2011). The sixth order polynomial equations were obtained to correlate the voltage produced by the thermocouples from the spools ${ }^{10} \mathrm{~A}$ and $\mathrm{B}$ with the difference in temperature of the bath and cold junction. These regression equations were used to convert the output

\footnotetext{
${ }^{10}$ Both spools are Omega Type T 24 gauge wire with the special limits of error (SLE).
} 
voltage to a temperature:

$$
\begin{array}{r}
T_{R B}^{A}=0.005687 e m f^{6}-0.03889 e m f^{5}+0.065088 e m f^{4}+0.0770713 e m f^{3}- \\
-0.69834 e m f^{2}+24.43511 e m f-0.09881+T_{C J C} \\
T_{R B}^{B}=0.004305 e m f^{6}-0.02713 e m f^{5}+0.031024 e m f^{4}+0.068355 e m f^{3}- \\
-0.59445 e m f^{2}+24.48589 e m f-0.1744+T_{C J C}
\end{array}
$$

There is a regression error associated with the usage of the polynomial fit obtained for each spool which shows the maximum difference between the bath temperature measured by the RTD and the values predicted by Equation 3.2 and Equation 3.3. The regression errors for spool A and B were $0.041{ }^{\circ} \mathrm{C}$ and $0.076{ }^{\circ} \mathrm{C}$, respectively.

In order to determine the error propagation from the voltage reading into the temperature measurement, the sensitivity parameter which represents a rate of change of temperature with respect to voltage was calculated by taking the derivative of Equation 3.2 and Equation 3.3 and finding its value at the maximum produced voltage signal. Both spools A and B produced the maximum voltage of $2.75 \mathrm{mV}$ at $90{ }^{\circ} \mathrm{C}$ which resulted in the sensitivity parameter of $21.86{ }^{\circ} \mathrm{C} / \mathrm{mV}$ and $21.66{ }^{\circ} \mathrm{C} / \mathrm{mV}$, respectively. The product of the sensitivity parameter and the voltage reading error of the NI card of $0.008 \mathrm{mV}$ resulted in a temperature bias of $0.175{ }^{\circ} \mathrm{C}$ and $0.173{ }^{\circ} \mathrm{C}$, respectively. Since a different DAQ was used during the experimental work on-site, a temperature bias due to the voltage reading had to be calculated separately for the CR3000 DAQ.

The CR3000 analogue-measurement error is a sum of gain and offset errors, where 
the gain error is expressed as a percentage of reading ${ }^{11}$ in millivolts. Within the CR3000 module temperature range of $0{ }^{\circ} \mathrm{C}$ to $40{ }^{\circ} \mathrm{C}$, the gain error is equal to $0.04 \%$ of reading. The offset error for differential voltage measurements depends on the input range and resolution. Small thermocouple outputs fall within the smallest CR3000 range of $\pm 20 \mathrm{mV}$ which has the resolution of $0.67 \mu \mathrm{V}$. Using Equation 3.4, Equation 3.5, and Equation 3.6, the voltage error of $0.003 \mathrm{mV}$ was calculated. This voltage error was used to determine the temperature bias of the experiment.

$$
\begin{gathered}
\text { VoltageError }= \pm(\text { Gain }+ \text { Offset }) \\
\text { GainError }=0.04 \% \times \text { Reading }, \mathrm{mV} \\
\text { OffsetError }=1.5 \times \text { Resolution }, \mathrm{mV}+1.0 \times 10^{-3} \mathrm{mV}
\end{gathered}
$$

Regression Equation 3.2 and Equation 3.3 applied a so-called Temperature Addition method for cold-junction compensation. The method is fast and easy but it assumes that the thermocouple temperature is relatively close to the reference temperature. According to Potter (1996), a more accurate way to determine the thermocouple temperature is the Direct Voltage Addition method, which is computationally heavier as it requires two temperature-to-voltage conversions. This method was applied to determine the temperatures before and after the outdoor fan since they can be significantly different from the reference temperature. The method requires converting the cold-junction temperature into an equivalent voltage and adding it to the measured thermocouple voltage. The value obtained by converting the sum into a

\footnotetext{
${ }^{11}$ The percentage varies depending on CR3000 module temperature conditions. The temperature ranges are $0{ }^{\circ} \mathrm{C}$ to $40{ }^{\circ} \mathrm{C},-25{ }^{\circ} \mathrm{C}$ to $50{ }^{\circ} \mathrm{C}$, and $-40{ }^{\circ} \mathrm{C}$ to $85{ }^{\circ} \mathrm{C}$.
} 
temperature is the cold-junction compensated thermocouple temperature.

The thermocouples installed before and after the outdoor fan were built using a different spool of a Type $\mathrm{T}$ thermocouple wire which was labelled as ZCL Spool1. The spool was calibrated together with the spools A and B, and calibration equation (Equation $3.7^{12}$ ) was obtained:

$T_{\text {cal }}^{Z C L 1}=-0.519441204765579 e m f^{2}+24.293157477124836 e m f+24.572572764417377$

Following the procedure of the direct voltage addition method, the left-hand side of Equation 3.7 is first equated to a reference temperature and solved for an $\mathrm{emf}^{13}$ in order to convert the reference temperature into an equivalent emf:

$$
e m f_{\text {ref }}=\frac{-b+\sqrt{b^{2}-4 a\left(c-T_{r e f}\right)}}{2 a}
$$

where $a$ is the quadratic coefficient, $b$ is the linear coefficient, $c$ is the constant of Equation 3.7, and $T_{r e f}$ is the cold-junction temperature. Then the cold-junction compensated thermocouple temperature is calculated using Equation 3.9:

$$
T_{\text {comp }}^{Z C L 1}=a\left(e m f+e m f_{r e f}\right)^{2}+b\left(e m f+e m f_{r e f}\right)+c
$$

Table 3.3 lists the individual bias sources associated with the calibration and measurement processes. The total bias was calculated by taking a square root of the

\footnotetext{
${ }^{12}$ The equation was developed for the calibration temperature range of $-5{ }^{\circ} \mathrm{C}$ to $95{ }^{\circ} \mathrm{C}$, the bias errors listed in Table 3.3 are associated with the operational temperature range of $-5{ }^{\circ} \mathrm{C}$ to $65^{\circ} \mathrm{C}$.

${ }^{13}$ Only one, small root, gives the proper emf; that is why Equation 3.8 does not include a standard for the quadratic formula " \pm " sign.
} 
sum of squared individual errors.

Table 3.3: Thermocouple bias error

\begin{tabular}{lccc}
\hline \hline Source of error & Spool A & Spool B & ZCL Spool 1 \\
\hline \hline Cold-junction temperature (calibration) & 0.25 & 0.25 & 0.25 \\
Thermistor location (experiment) & 0.2 & 0.2 & 0.2 \\
Cold-junction temperature (experiment) & 0.1 & 0.1 & 0.1 \\
Regression prediction error & 0.041 & 0.076 & 0.246 \\
Resistance temperature detector & 0.02 & 0.02 & 0.02 \\
Resistance read error (DMM) & 0.04 & 0.04 & 0.04 \\
Bath uniformity & 0.02 & 0.02 & 0.02 \\
Voltage read error (calibration) & 0.175 & 0.173 & 0.180 \\
Voltage read error (experiment) & 0.068 & 0.067 & 0.057 \\
\hline Total bias & 0.39 & 0.39 & 0.46 \\
\hline
\end{tabular}

The fourth spool of Type T thermocouple wire was of a thicker gauge, 20 AWG, and was used to build two thermocouples installed before and after the air handler. It was separately calibrated as a single-junction thermopile using one RTD submerged in a warm calibration bath and used as a sensor against which the thermocouple was calibrated and another RTD submerged in a cold calibration bath was used as a cold-junction temperature.

The reference thermometer (RT) which was used to measure the resistance of both RTDs has an error of $\pm(0.004 \% \times$ Reading $+0.002 \Omega)$. In order to account for the temperature error caused by the resistance reading, the same process as described for the calibration of the previous spools was followed. Table 3.4 outlines the regression 
equations, the maximum measured resistances, and the sensitivity parameters for both RTDs.

Table 3.4: RTD regression equations

\begin{tabular}{lccc}
\hline \hline RTD & Regression Equation & $\mathrm{R}_{\text {max }}, \Omega$ & Sensitivity, ${ }^{\circ} \mathrm{C} / \Omega$ \\
\hline \hline $\mathrm{RTD}_{\text {cold }}$ & $\mathrm{T}=0.001 \mathrm{R}^{2}+2.309 \mathrm{R}-240.863$ & 108.35 & 2.53 \\
$\mathrm{RTD}_{\text {warm }}$ & $\mathrm{T}=0.001 \mathrm{R}^{2}+2.309 \mathrm{R}-240.843$ & 136.78 & 2.58 \\
\hline
\end{tabular}

Equation 3.10 was obtained as a calibration equation valid for the temperature range of 5 to $95^{\circ} \mathrm{C}$. The direct voltage addition method and Equation 3.10 were used to determine the supply and return air temperatures.

$$
T_{c a l}^{20 A W G}=-0.55424993328296 e m f^{2}+24.7880841345279 e m f+20.965365493252
$$

Table 3.5 summarizes the uncertainty on the temperature measurements across the AHU attributed to the calibration and measurement processes.

\subsubsection{Thermopile}

A thermopile is constructed of several thermocouples in series and used to measure temperature difference. An advantage of a thermopile is that the voltage generated by a thermopile is amplified by the number of pairs of junctions, which reduces the error caused by the resolution of the voltage reading. For this study, a five junction thermopile was built and installed across the AHU, namely in the supply and return 
Table 3.5: Thermocouple bias error

\begin{tabular}{lc}
\hline \hline Source of error & 20 AWG Spool 2 \\
\hline \hline RTD $_{\text {cold bath } / \text { cold-junction temperature (calibration) }}$ & 0.02 \\
Thermistor location (experiment) & 0.2 \\
Cold-junction temperature (experiment) & 0.1 \\
RTD $_{\text {warm bath }}$ & 0.02 \\
Resistance read error $\left(\mathrm{RT}_{\text {warm bath }}\right)$ & 0.019 \\
Resistance read error $\left(\mathrm{RT}_{\text {cold bath }}\right)$ & 0.016 \\
Bath uniformity & 0.02 \\
Bath uniformity & 0.02 \\
Volt bath & 0.170 \\
Voltage read error (experiment) & 0.070 \\
\hline Total bias & 0.37 \\
\hline
\end{tabular}

air ducts. The thermopile was built using the wire from the fourth thermocouple spool, 20 AWG Spool2. A five junction thermopile consists of five pairs of individual thermopile beads where five warm ${ }^{14}$ junctions are placed in the return air side and five cold $^{14}$ junctions are in the supply air side of the air handler. The cold side acts as the cold junction which eliminates an error associated with determining the cold junction temperature. Therefore, it is advantageous to use a thermopile rather than thermocouples to obtain more accurate measurements of the temperature difference. This is important for determining the heating and cooling capacity of the heat pump.

The thermopile was calibrated in a similar manner as the fourth thermocouple.

\footnotetext{
${ }^{14}$ Warm and cold sides of the thermopile are arbitrary chosen since the sign of the differential between the return and supply air temperatures switches as the heat pump switches from a cooling mode to a heating mode.
} 
The calibration setup consisted of two constant temperature baths with the RTDs used in the fourth thermocouple calibration, and a thermopile placed across two baths. The same reference thermometer was used for reading the resistance from both RTDs. The calibration procedure was performed by maintaining the cold bath at a constant temperature while increasing the temperature of the second bath in $5{ }^{\circ} \mathrm{C}$ increments until the temperature reached $95^{\circ} \mathrm{C}$. This process was executed 19 times, each time increasing the temperature of the cold bath by $5{ }^{\circ} \mathrm{C}$, from $0{ }^{\circ} \mathrm{C}$ to $90{ }^{\circ} \mathrm{C}$. Using the Curve Fitting application in Matlab, a polynomial equation of the following form was produced:

$$
\Delta T=a+b \times e m f+c \times T_{\text {cold }}+d \times e m f^{2}+e \times e m f \times T_{\text {cold }}
$$

where $\Delta T$ is the measured temperature difference, emf is the measured thermopile voltage, and $T_{\text {cold }}$ is the cold-side temperature.

As an improvement to the curve fit, the calibration temperature was split into three ranges based on the cold-bath temperature: under $20{ }^{\circ} \mathrm{C}$, between $20{ }^{\circ} \mathrm{C}$ and $70{ }^{\circ} \mathrm{C}$, and above $70^{\circ} \mathrm{C}$. Considering the operational temperature range of the heat pump, the first two regions are sufficient for analyzing the experimental data. The coefficients of both regression equations are listed in Table 3.6. Based on the curve residuals, the maximum error introduced by the regression equations was 0.1219 .

In order to account for the uncertainty on the thermopile measurements, a total bias error was determined by summing the squares of each individual bias source and subsequently taking a square root of the sum. The bias sources are listed in Table 3.7 with the values related to the range $T_{\text {cold }}<20{ }^{\circ} \mathrm{C}$ and $20{ }^{\circ} \mathrm{C}<T_{\text {cold }}<70{ }^{\circ} \mathrm{C}$ on 
Table 3.6: Thermopile regression equations

\begin{tabular}{lccccc}
\hline \hline Application & $a$ & $b$ & $c$ & $d$ & $e$ \\
\hline \hline$\Delta T_{T_{\text {cold }}<20}$ & 0.05699 & 4.254 & -0.0005598 & -0.01406 & -0.007732 \\
$\Delta T_{20<T_{\text {cold }}<70}$ & 0.001934 & 4.232 & -0.0004538 & -0.01342 & -0.006831 \\
\hline
\end{tabular}

the left- and right-hand side of the semicolon, respectively.

The error propagated from the cold-side temperature was calculated as a product of the accuracy of the cold-side temperature sensor and the sensitivity parameter. The sensitivity parameter of $0.05{ }^{\circ} \mathrm{C} /{ }^{\circ} \mathrm{C}$ was determined by finding the value of the derivative $d(\Delta T) / d\left(T_{\text {cold }}\right)$ from Equation 3.11 at the maximum measured emf within the operational temperature range ${ }^{15}$. During the calibration process, the RTD was used to measure the cold-side temperature and therefore the error of the cold-side temperature sensor was attributed to the resolution of the platinum probe and resistance read error, which resulted in the error of $0.026{ }^{\circ} \mathrm{C}$. Thus the error due to the cold-side temperature during the calibration was determined to be negligible at $0.0013{ }^{\circ} \mathrm{C}$. During the experimental work, the cold-side temperature was measured by the thermocouple with its uncertainty of $0.3{ }^{\circ} \mathrm{C}$ (Table 3.5) yielding the cold-side temperature error of $0.015{ }^{\circ} \mathrm{C}$.

Similarly, in order to determine the effect of the voltage reading error on the measured temperature difference, the derivative of Equation 3.11 was taken with respect to emf and the maximum sensitivity parameter ${ }^{16}$ of $4.10{ }^{\circ} \mathrm{C} / \mathrm{mV}$ was obtained. This resulted in the temperature bias of $0.03{ }^{\circ} \mathrm{C}$ and $0.02{ }^{\circ} \mathrm{C}$, considering the NI card

\footnotetext{
${ }^{15}$ Conservatively, it is assumed that the maximum emf is $7.23 \mathrm{mV}$ which occurs at $\Delta T=30{ }^{\circ} \mathrm{C}$ and $T_{\text {cold }}=5{ }^{\circ} \mathrm{C}$

${ }^{16}$ The maximum value was found at $\Delta T=15{ }^{\circ} \mathrm{C}$ and $T_{\text {cold }}=5{ }^{\circ} \mathrm{C}$.
} 
and CR3000 DAQ bias $^{17}$ on the voltage measurements of $0.008 \mathrm{mV}$ and $0.005 \mathrm{mV}$, respectively.

The overall bias error for the thermopile measurements is determined to be $0.14^{\circ} \mathrm{C}$.

Table 3.7: Thermopile bias error

\begin{tabular}{|c|c|}
\hline Source of error & 20 AWG Spool 2 \\
\hline $\mathrm{RTD}_{\text {cold bath }}$ & 0.02 \\
\hline Cold-side temperature (experiment) & $0.018 ; 0.011$ \\
\hline Regression prediction error & $0.122 ; 0.077$ \\
\hline $\mathrm{RTD}_{\text {warm bath }}$ & 0.02 \\
\hline Resistance read error $\left(\mathrm{RT}_{\text {warm bath }}\right)$ & $0.017^{\mathrm{a}}$ \\
\hline Resistance read error $\left(\mathrm{RT}_{\text {cold bath }}\right)$ & $0.016,0.0168^{\mathrm{c}}$ \\
\hline Bath uniformity warm bath & 0.02 \\
\hline Bath uniformity ${ }_{\text {cold bath }}$ & 0.02 \\
\hline Voltage read error (calibration) & $0.033 ; 0.033$ \\
\hline Voltage read error (experiment) & 0.020 \\
\hline Total bias & $0.14 ; 0.10$ \\
\hline
\end{tabular}

a For maximum resistance at $40{ }^{\circ} \mathrm{C}$.

b For maximum resistance at $20^{\circ} \mathrm{C}$.

c For maximum resistance at $40^{\circ} \mathrm{C}$.

\footnotetext{
${ }^{17}$ The CR3000 bias was calculated based on the maximum measured voltage signal of $7.22 \mathrm{mV}$ registered at $\Delta T=30{ }^{\circ} \mathrm{C}$ and $T_{\text {cold }}=5{ }^{\circ} \mathrm{C}$.
} 


\subsubsection{Velocity meters}

A three-cup anemometer (Campbell Scientific 014A) was installed before the AHU to measure the velocity at the indoor unit of the heat pump. The diameters of the device and its cups are $20.8 \mathrm{~cm}$ and $5.1 \mathrm{~cm}$, respectively. The anemometer is designed to measure the velocity range of $0 \mathrm{~m} / \mathrm{s}-45 \mathrm{~m} / \mathrm{s}$ with a threshold of $0.45 \mathrm{~m} / \mathrm{s}$. The sensor generates a pulse signal which is converted by CR3000 into meters per second. The accuracy of the sensor is $0.11 \mathrm{~m} / \mathrm{s}$ or $1.5 \%$, whichever is greater. The operational temperature range is between $-50{ }^{\circ} \mathrm{C}$ and $+70{ }^{\circ} \mathrm{C}$.

A four-blade propeller anemometer (Campbell Scientific 27106T Gill Propeller Anemometer) was installed after the fan ${ }^{18}$ to measure the velocity at the outdoor unit of the heat pump. It is designed to measure an axial flow of $0 \mathrm{~m} / \mathrm{s}$ to $40 \mathrm{~m} / \mathrm{s}$ with a threshold of $0.4 \mathrm{~m} / \mathrm{s}$. The sensor generates an analogue DC voltage which is converted by the CR3000 into meters per second. The accuracy of the sensor is $0.3 \mathrm{~m} / \mathrm{s}$. The operational temperature range is between $-50{ }^{\circ} \mathrm{C}$ and $+50{ }^{\circ} \mathrm{C}$. This device is not restricted to the clean air environment for proper functionality. The velocity meters are shown in Figure 3.8. Both devices are wind sensors and are not designed per se for the HVAC purposes; however, the propeller anemometer was recommended for duct/shaft monitoring.

\subsubsection{Watt Nodes}

The electricity drawn by the heat pump was measured by using energy transducers, ETs (WattNode WNB-3Y-208-P), in conjunction with magnetic coil current

\footnotetext{
${ }^{18}$ Such placement was dictated by the limitations in space and straight run length before the fan.
} 


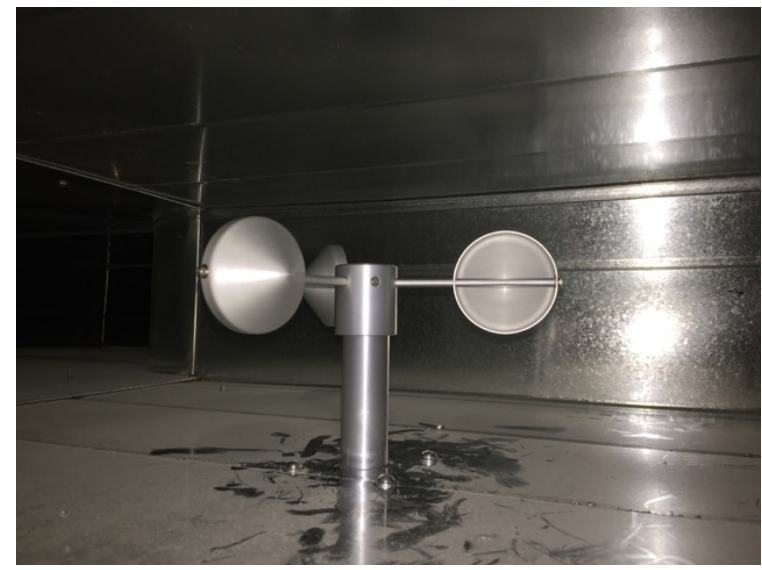

(a) before the AHU indoors

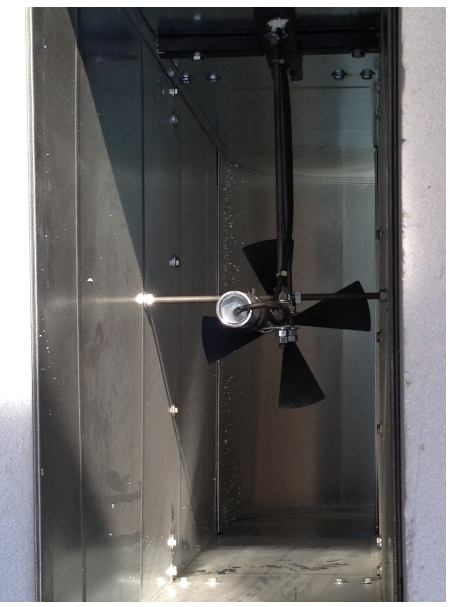

(b) after the fan outside

Figure 3.8: Velocity meters

transformers, CTs, attached to each circuit of interest. The outdoor fan was powered by the compressor unit (230 V circuit, single-phase three-wire configuration), while the AHU was independently electrified (115 V circuit, single-phase two-wire configuration). In consideration of this setup, a pair of 50-ampere CTs (WattNode CTS-0760-050) was used to take measurements of the current flowing through each leg of the split-phase distribution system which provides power to the compressor unit. Similarly, another pair of 30-ampere CTs (WattNode CTS-0760-030) was installed to measure the current flowing to the outdoor fan. Lastly, a single 30-ampere CT was installed in the AHU circuit. Based on the induced current in the CTs and measured voltage in each circuit, the ET emits a pulse once a certain amount of electricity has been consumed. This threshold of energy consumption is a rated value of watt-hours per pulse for each combination of ET and accompanying it CT. The pulse could be converted to the average power draw over a 1-minute interval 


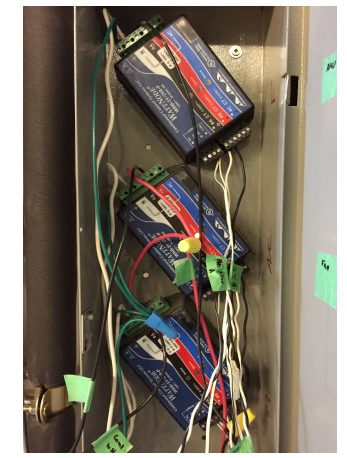

(a) energy transducers

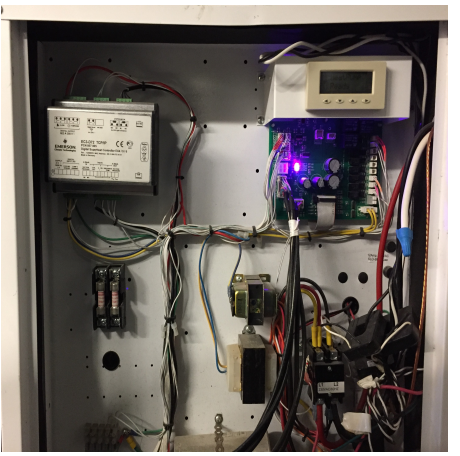

(b) current transformers in the compressor unit

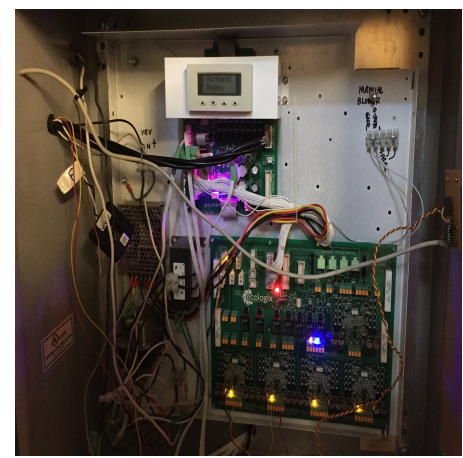

(c) current transformer in the AHU

Figure 3.9: Electrical power measurements

using Equation 3.12:

$$
\text { Power }(k W)=\frac{3600}{60 \times 1000} \text { WattHoursPerPulse } \times \text { PulseCount }
$$

The ETs output a pulse signal which is being received by CR3000 with the accuracy of \pm 1 pulse. 


\section{Chapter 4}

\section{Uncertainty Analysis}

\subsection{Bias and precision errors}

To describe the system performance, two derived quantities - the thermal capacity and the COP - were analyzed. The COP and thermal capacity are the most common metrics used to measure the performance of a heat pump. In this study, the data presented were collected during the cooling season and hence cooling capacity was analyzed. Although heating capacity was equally of interest of this research, no reliable data were obtained since multiple issues with the experimental setup were resolved at the end of the heating season.

In order to ensure the accuracy of the experimental results, it is essential to specify uncertainty margins for the derived quantities. The overall system uncertainty analysis was conducted by propagating errors from the individual measurements to the performance quantities. The uncertainty analysis addresses two types of er-

rors: systematic (also called bias) and random (also called precision) errors. The 
bias error $B$, which could be reduced by calibrating the measuring devices, is constant throughout the experiment. The precision error $S$, which could be reduced by increasing the sample size, has an unpredictable nature and is detected through statistical techniques.

In order to formulate the overall system uncertainty, consider that $Y$ is the function of the performance quantity derived from a group of $M$ independent variables $X_{m}$ (also called subsidiary properties) such as:

$$
Y=Y\left(X_{1}, \ldots, X_{m}, \ldots, X_{M}\right)
$$

Then the total bias for the derived quantity can be determined by summing each of its individual bias components weighted by the respective sensitivity parameter and applying a root mean square approach:

$$
B_{Y}=\sqrt{\sum_{m=1}^{M}\left(\theta_{m} B_{X_{m}}\right)^{2}}
$$

where $\theta_{m}$ is the sensitivity parameter:

$$
\theta_{m}=\frac{\partial Y}{\partial X_{m}}
$$

Similarly, the total precision error is estimated by the root-sum-square (RSS) combination of the precision limits for the measurements of the individual variables:

$$
S_{Y}=\sqrt{\sum_{m=1}^{M}\left(\theta_{m} S_{\bar{X}_{m}}\right)^{2}}
$$


where each $S_{\bar{X}_{m}}$ is the uncertainty associated with the mean value of the measurement sample of the individual variable $X_{m}$ :

$$
S_{\bar{X}_{m}}=\frac{S_{X_{m}}}{\sqrt{N}}
$$

where $S_{X_{m}}$ is the standard deviation of the sample of $N$ readings:

$$
S_{X_{m}}=\left(\sum_{i=1}^{N} \frac{\left(X_{m_{i}}-\bar{X}_{m_{i}}\right)^{2}}{N-1}\right)^{1 / 2}
$$

Alternatively, it was suggested by Stern et al. (1999) that the precision error on the derived quantity can be determined based on the standard deviation of the instantaneous values of the derived quantity (Equation 4.7) rather than the propagation of the individual measurements' precision error (Equation 4.4):

$$
S_{Y}=S_{\bar{Y}}=\frac{S_{y}}{\sqrt{N}}
$$

where $S_{y}$ is the standard deviation of the distribution of $N$ results:

$$
S_{y}=\left(\sum_{i=1}^{N} \frac{\left(y_{i}-\bar{y}\right)^{2}}{N-1}\right)^{1 / 2}
$$

The overall uncertainty for the average derived quantity can be defined as the RSS of the total bias error and the precision error weighted by the Student's t-distribution at $95 \%$ confidence interval, $t_{v, 95}$, as shown in Equation 4.9 (Moffat, 1988).

$$
U_{Y 0.95}=\sqrt{B_{Y}^{2}+\left(t_{v, 95} S_{\bar{Y}}\right)^{2}}
$$


In order to be able to select an appropriate value of the Student's $t$ multiplier to describe the $95 \%$ confidence interval, it is required to calculate the degree of freedom, $v$, using Equation 4.10.

$$
v=N-1
$$

This chapter focuses on determining the systematic error of the cooling capacity and the COP. The cooling capacity was calculated using Equation 4.11:

$$
\dot{Q}=\left.V A\left(\rho c_{p}\right)\right|_{T_{a v g}} \Delta T
$$

where $V$ is the measured velocity of air at the AHU, m/s, $A$ is the cross-section of the area of installation of the velocity meter, $\mathrm{m}^{2}, \rho c_{p}$ is the product of density and specific heat of air, $\mathrm{kJ} /\left(\mathrm{m}^{3} \mathrm{~K}\right)$, evaluated at the averaged supply and return air temperature, $T_{a v g}$, and $\Delta T$ is the temperature differential of air across the AHU, $\mathrm{K}$, measured by the thermopile. The following sections discuss the individual bias components of the cooling capacity.

\subsection{Input quantities of the cooling capacity}

\subsubsection{Velocity at the air handler}

The velocity in the return duct is measured with a pulse count by a 3-cup anemometer using the switch closure configuration. The frequency of closures is linear, thus a linear equation correlates the velocity and frequency:

$$
V_{\text {in }}=0.8 f+0.447
$$


where $f$ is the number of pulses over a logging interval, Hz. Considering the sensitivity parameter $\theta_{f}$ of 0.8 , the frequency resolution of CR3000 of 1 pulse and the scanning interval of 1 minute, the bias due to pulse counting is $0.013 \mathrm{~m} / \mathrm{s}$. The error on the anemometer is $0.11 \mathrm{~m} / \mathrm{s}$.

Additional uncertainty is introduced by the assumption that the velocity profile is uniform and equal to the measurement taken in the centre of the duct. In order to evaluate this assumption, a hand-held rotating vane anemometer (Figure 4.1) with an error of $1 \%$ and resolution of $0.01 \mathrm{~m} / \mathrm{s}$ was used to explore a flow field. Two

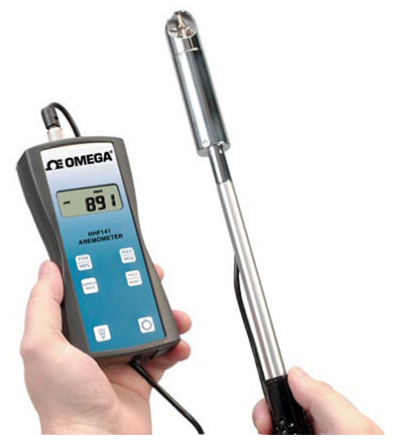

Figure 4.1: Hand-held rotating vane anemometer (OMEGA Engineering, 2018)

holes - one in the middle of the 8-inch side and one in the middle of the 24-inch side - were drilled in the duct downstream from the 3-cup anemometer to insert the hand-held sensor and measure along the height and width of the duct in 1-inch increments to record the velocity. The measurements ${ }^{1}$ were taken along the entire height (measurements in a vertical direction from the 1-inch to 7-inch positions) and

\footnotetext{
${ }^{1}$ The measurements were taken outside of the viscous boundary layer.
} 
a half of the width ${ }^{2}$ (measurements in a horizontal direction from the 1-inch to 12inch positions). Figure 4.2 illustrates the location of the 3-cup anemometer and two locations of the temporarily hand-held anemometer which were used to measure the velocity in a vertical and horizontal directions. It can be noticed that the installation space is limited and the straight run is insufficient. For example, the hydraulic diameter of the duct is 1 foot and the distance between the 3-cup anemometer and a 90-degree bend upstream is about 1.2 feet. Such upstream conditions would have an impact on the symmetry and development of the velocity profile.

To develop a velocity profile, one half of the cross-section of the duct was discretized by applying a $7 \times 12$ grid and assigning a value to each cell of the grid by averaging the appropriate vertical and horizontal measurements. For example, it was assumed that the velocity $v$ in a cell $\left(x_{1}, y_{1}\right)^{3}$ is equal to $\left(\left.v\right|_{x 1, y=4}+\left.v\right|_{y 1, x=12}\right) / 2$, where $x=12$ and $y=4$ are the vertical and horizontal axes of the duct along which the measurements were taken. The resulting half of the symmetrical velocity profile is shown in Figure 4.3 where a long- and short-dashed line represents the vertical centre of the duct. The bold black line outlines the location of the cup assembly of the 3-cup anemometer.

In order to compare the results obtained from both sensors, the uncertainty on both sensors as well as the difference in the readings should be taken into account. The individual bias errors are listed in Table 4.1. Based on the 3-cup anemometer, the

\footnotetext{
${ }^{2}$ The measurements through only a half of the width were taken due to the limited length of the device.

${ }^{3}$ This cell represents the top left corner of the duct in Figure 4.3. The 12th column and 4th row contain the measured values.
} 

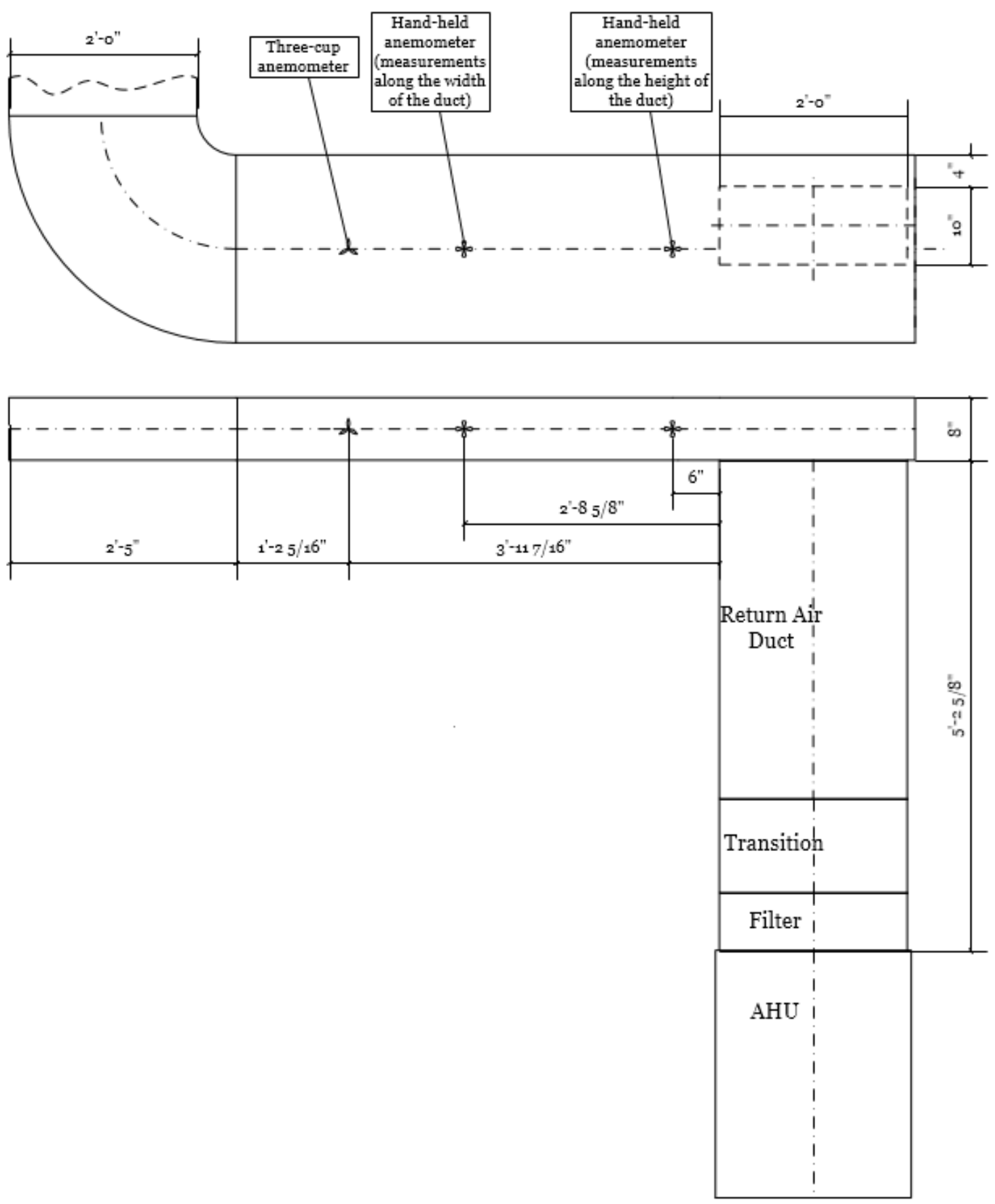

Figure 4.2: Velocity measurements 


\begin{tabular}{|c|c|c|c|c|c|c|c|c|c|c|c|c|}
\hline & 1 & 2 & 3 & 4 & 5 & 6 & 7 & 8 & 9 & 10 & 11 & \\
\hline & 5.1 & 5.2 & 5.3 & 5.5 & 5.4 & 5.3 & 5.0 & 4.9 & 5.1 & 5.1 & 5.3 & 5.0 \\
\hline Z & 5.1 & 5.3 & 5.4 & 5.5 & 5.4 & 5.3 & 5.1 & 4.9 & 5.1 & 5.2 & 5.4 & 5.6 \\
\hline 3 & 5.2 & 5.4 & 5.5 & 5.6 & 5.5 & 5.4 & 5.1 & 5.0 & 5.2 & 5.3 & 5.5 & \\
\hline 4 & 5.2 & 5.5 & 5.7 & 5.9 & 5.9 & 5.5 & 5.1 & 4.8 & 5.2 & 5.3 & 5.7 & b. \\
\hline 5 & 5.2 & 5.3 & 5.4 & 5.6 & 5.5 & 5.4 & 5.1 & 5.0 & 5.2 & 5.3 & 5.5 & \\
\hline 6 & 4.9 & 5.1 & 5.2 & 53 & 5.3 & 5.1 & 4.9 & 4.7 & 4.9 & 5.0 & 5.2 & \\
\hline & 51 & 5.3 & 5.4 & 5.5 & 5.4 & 5.3 & 5.0 & 4.9 & 5.1 & 5.2 & 5.4 & \\
\hline
\end{tabular}

Figure 4.3: Velocity profile in a half of the duct

velocity was $6.2 \mathrm{~m} / \mathrm{s}$; however, based on the developed velocity profile, the average velocity was $5.3 \mathrm{~m} / \mathrm{s}$.

Table 4.1: Velocity profile bias error

\begin{tabular}{lc}
\hline \hline Source of error & Value, $\mathrm{m} / \mathrm{s}$ \\
\hline \hline 3-cup anemometer & 0.11 \\
$\theta_{f} B_{f}$ & 0.013 \\
Vane anemometer & 0.062 \\
Resolution of vane anemometer & 0.005 \\
$V_{3-\text { cup }}-\bar{V}_{\text {vane }}$ & 0.89 \\
\hline Total & 0.9 \\
\hline
\end{tabular}

Overall, considering a non-uniform velocity profile, as well as the original application of the 3-cup wind sensor, and the obstacles ${ }^{4}$ that interfered while taking the measurements with a hand-held anemometer, it was assumed that the error due to the velocity field was $15 \%$. The errors tabulated in Table 4.2 contribute to the total uncertainty of $0.9 \mathrm{~m} / \mathrm{s}$ at the maximum velocity of $6.367 \mathrm{~m} / \mathrm{s}$.

\footnotetext{
${ }^{4}$ Close vicinity to a 90 -degree elbow on one side and the wind sensor on the other side are meant
} 
Table 4.2: Velocity bias error

\begin{tabular}{lc}
\hline \hline Source of error & Value \\
\hline \hline$\theta_{f} B_{f}$ & $0.013 \mathrm{~m} / \mathrm{s}$ \\
Anemometer & $0.11 \mathrm{~m} / \mathrm{s}$ \\
Velocity profile & $15 \%$ \\
\hline Total & $0.96 \mathrm{~m} / \mathrm{s}$ \\
\hline
\end{tabular}

\subsubsection{Air properties}

The ideal gas law can be used to derive a correlation between air density, pressure and temperature, which is described by Equation 4.13:

$$
\rho=P \frac{M}{R T}
$$

where $P$ is pressure, $\mathrm{Pa}, M$ is molecular mass of air, $\left(28.97 \times 10^{-3} \mathrm{~kg} / \mathrm{mol}\right), R$ is the gas constant, $(8.314 \mathrm{~J} /(\mathrm{mol} \mathrm{K}))$, and $T$ is the temperature, $\mathrm{K}$. The pressure measurements were not taken at the CHEeR house, and atmospheric pressure was assumed for all tests. Due to this assumption as well as uncertainty implications of applying the ideal gas law, it was decided to adopt an alternative approach to define air properties by using the tables of thermodynamic properties of air from the U.S. National Bureau of Standards provided in a heat transfer textbook (Holman et al., 2010). Based on the table values, Equation 4.14 and Equation 4.15 were defined to express the temperature dependence of the air density and specific heat within the temperature range of $250 \mathrm{~K}$ to $350 \mathrm{~K}$. Although air properties can be here. 
separately determined at supply and return air temperatures and then averaged under the assumption of a linear correlation with the temperature, it is more accurate to determine both properties at the average temperature since a non-linear behaviour can be observed with the increase of relative humidity.

$$
\begin{gathered}
\rho=1.12 \times 10^{-5}\left(\frac{T_{S A}+T_{R A}}{2}\right)^{2}-0.010868\left(\frac{T_{S A}+T_{R A}}{2}\right)+3.4298 \\
c_{p}=5.8 \times 10^{-7}\left(\frac{T_{S A}+T_{R A}}{2}\right)^{2}-0.000311\left(\frac{T_{S A}+T_{R A}}{2}\right)+1.0468
\end{gathered}
$$

Since the table consisted of coarse-grained values of the air properties, the regression equations were used to predict the values at the smaller temperature intervals and the results were compared against the values in Cengel (2010) with the tabulated intervals of $5{ }^{\circ} \mathrm{C}$ within the temperature range of $0{ }^{\circ} \mathrm{C}-50{ }^{\circ} \mathrm{C}$. The maximum absolute difference between the predicted and tabulated values of the density was $0.0004 \mathrm{~kg} /\left(\mathrm{m}^{3} \mathrm{~K}\right)$ under the operational temperature range of the AHU in a cooling mode. The difference between the values of the specific heat was $0.0017 \mathrm{~kJ} /\left(\mathrm{m}^{3} \mathrm{~K}\right)$.

The specific heat and density vary with the relative humidity, yet that parameter is neither controlled nor monitored at the CHEeR house. According to Tsilingiris (2008) and Wong and Embleton (1984), the difference in the specific heat of the humid versus dry air can be $0.024 \mathrm{~kJ} /(\mathrm{kg} \mathrm{K})$ within the temperature range of $0{ }^{\circ} \mathrm{C}-$ $30{ }^{\circ} \mathrm{C}$.

To determine the error caused by the temperature reading, the bias error on the thermocouple listed in Table 3.5 was multiplied by the sensitivity parameter which was calculated for both density and specific heat by taking a derivative of 
Equation 4.14 and Equation 4.15 with respect to temperature and calculating its value at the maximum operational temperature. The errors associated with the air properties are listed in Table 4.3 and Table 4.4 .

Table 4.3: Density bias error

\begin{tabular}{lc}
\hline \hline Source of error & $10-30{ }^{\circ} \mathrm{C}$ \\
\hline \hline$\theta_{T_{S A}} B_{T_{S A}}=\theta_{T_{R A}} B_{T_{R A}}$ & $0.0008 \mathrm{~kg} / \mathrm{m}^{3}$ \\
Humidity & $0.0167 \mathrm{~kg} / \mathrm{m}^{3}$ \\
Regression prediction & $0.0004 \mathrm{~kg} / \mathrm{m}^{3}$ \\
\hline Total & $0.017 \mathrm{~kg} / \mathrm{m}^{3}$ \\
\hline
\end{tabular}

Table 4.4: Specific heat bias error

\begin{tabular}{lc}
\hline \hline Source of error & $10-30{ }^{\circ} \mathrm{C}$ \\
\hline \hline$\theta_{T_{S A}} B_{T_{S A}}=\theta_{T_{R A}} B_{T_{R A}}$ & $5.3 \times 10^{-6} \mathrm{~kJ} /(\mathrm{kg} \mathrm{K})$ \\
Humidity & $0.024 \mathrm{~kJ} /(\mathrm{kg} \mathrm{K})$ \\
Regression prediction & $0.002 \mathrm{~kJ} /(\mathrm{kg} \mathrm{K})$ \\
\hline Total & $0.024 \mathrm{~kJ} /(\mathrm{kg} \mathrm{K})$ \\
\hline
\end{tabular}

\subsubsection{Cross-sectional area}

The cross-sectional area of the duct connected to the air handler is $0.610 \mathrm{~m} \times$ $0.203 \mathrm{~m}$. Both height and width of the duct were measured by a measuring tape with a resolution of $1 \mathrm{~mm}$. This resolution introduces an error in calculating the area of $0.000321 \mathrm{~m}^{2}$. It was assumed that the duct does not curve inward or outward during 
the heat pump operation. This assumption, as well as the assumption of a perfectly rectangular shape of the duct, should be assessed in the future.

\subsection{Cooling capacity uncertainty}

To calculate the uncertainty of the cooling capacity, the absolute values of its input quantities listed in Table 4.5 were used. The individual bias errors determined earlier are also summarized in the table.

Table 4.5: Independent variables of the derived quantity $\dot{Q}$

\begin{tabular}{llc}
\hline \hline Independent variable & Value & Bias error \\
\hline \hline$V, \mathrm{~m} / \mathrm{s}$ & 6.367 & 0.975 \\
$A, \mathrm{~m}^{2}$ & 0.123871 & 0.0003 \\
$\rho, \mathrm{kg} / \mathrm{m}^{3}$ & 1.21 & 0.017 \\
$c_{p}, \mathrm{~kJ} /(\mathrm{kg} \mathrm{K})$ & 1.005 & 0.024 \\
$\Delta T, \mathrm{~K}$ & 10 & 0.136 \\
\hline
\end{tabular}

The sensitivity parameters were determined by applying Equation 4.2 and Equation 4.3 where derived quantity $Y$ is the cooling capacity calculated using Equation 4.11. The list of the sensitivity parameters is shown in Table 4.6 and the contributing bias errors, as well as the total uncertainty on the cooling capacity, are tabulated in Table 4.7. Although air properties were defined as the functions of the supply air temperature (Equation 4.14 and Equation 4.15) and the regression equation for the temperature difference across the air handler (Equation 3.11) included 
Table 4.6: Cooling capacity sensitivity parameters

\begin{tabular}{llrl}
\hline \hline Parameter & Equation & Value & Units \\
\hline \hline$\theta_{V}=\frac{\partial \dot{Q}}{\partial V}$ & $\theta_{V}=\left.A\left(\rho c_{p}\right)\right|_{T_{a v g}} \Delta T$ & 1.50 & $\frac{k W}{m / s}$ \\
$\theta_{A}=\frac{\partial \dot{Q}}{\partial A}$ & $\theta_{A}=\left.V\left(\rho c_{p}\right)\right|_{T_{a v g}} \Delta T$ & 77.23 & $\frac{k W}{m^{2}}$ \\
$\theta_{\rho}=\frac{\partial \dot{Q}}{\partial \rho}$ & $\theta_{\rho}=\left.V A c_{p}\right|_{T_{a v g}} \Delta T$ & 7.93 & $\frac{k W}{k g / m^{3}}$ \\
$\theta_{c_{p}}=\frac{\partial \dot{Q}}{\partial c_{p}}$ & $\theta_{c_{p}}=\left.V A \rho\right|_{T_{a v g}} \Delta T$ & 9.51 & $\frac{k W}{k J /(k g K)}$ \\
$\theta_{\Delta T}=\frac{\partial \dot{Q}}{\partial \Delta T}$ & $\theta_{\Delta T}=\left.V A\left(\rho c_{p}\right)\right|_{T_{a v g}}$ & 0.96 & $\frac{k W}{{ }^{\circ} C}$ \\
\hline
\end{tabular}

the supply air temperature, it was assumed that the variables are independent.

Table 4.7: Cooling capacity bias error

\begin{tabular}{lc}
\hline \hline Source of error & Value, $\mathrm{kW}$ \\
\hline \hline$\theta_{V} B_{V}$ & 1.44 \\
$\theta_{A} B_{A}$ & 0.02 \\
$\theta_{\rho} B_{\rho}$ & 0.13 \\
$\theta_{c_{p}} B_{c_{p}}$ & 0.23 \\
$\theta_{\Delta T} B_{\Delta T}$ & 0.13 \\
\hline Total & 1.47 \\
\hline
\end{tabular}

As can be seen, the bias error associated with the velocity is the dominating contributor to the total bias error of the derived cooling capacity. The high uncertainty of the velocity measurements is attributed to a non-uniform velocity profile which is difficult to precisely quantify. In this study, an engineering judgement call was made to assume the error of $15 \%$ due to a non-uniform profile. 


\subsection{COP uncertainty}

The COP was calculated using Equation 4.16:

$$
C O P=\frac{\dot{Q}}{P_{H P}}
$$

where $\dot{Q}$ is the cooling capacity, $\mathrm{kW}$, and $P_{H P}$ is the electrical power, $\mathrm{kW}$, required to operate the system.

As it was described in Subsection 3.4.4, the ETs were used to measure the energy consumed by each of the three electric circuits - the combined compressor and outdoor fan circuit, the AHU circuit, and solely the outdoor fan circuit. The energy consumptions were determined by using Equation 4.17:

$$
E=I V \cos \phi \Delta t
$$

where $I$ is the current, $V$ is the voltage, and $\phi$ is the phase angle between the two quantities.

The bias error on the energy measured is attributed to the bias of the ET, the linearity error of the CT, and the bias error of $\phi$ which are all listed in Table 4.8. The bias error of the ET accounts for both the bias of measuring voltage and the pulse resolution bias.

The average power draw was obtained by normalizing the measured electrical energy consumptions over a 1-minute interval using Equation 4.18.

$$
\bar{P}=\frac{E}{\Delta t}=I V \cos \phi
$$


Table 4.8: Energy measurement bias error

\begin{tabular}{ll}
\hline \hline Source of error & \multicolumn{1}{c}{ Value } \\
\hline \hline$B_{I}$ & $1 \%$ of rated current \\
$B_{\phi}$ & $2^{\circ}$ \\
$B_{\text {Epulse }}$ & $0.5 \%$ of reading \\
\hline
\end{tabular}

Applying a root sum squared method, the overall bias error in deriving electric power from the primary measurements was determined as

$$
B_{\bar{P}}=\sqrt{\left(\theta_{I} B_{I}\right)^{2}+\left(\theta_{\phi} B_{\phi}\right)^{2}+\left(\frac{B_{E p u l s e}}{\Delta t}\right)^{2}}
$$

where $\theta_{I}$ and $\theta_{\phi}$ are the sensitivity parameters formulated in Table 4.9. Since the output of the ET is proportional to the power being measured, a sensitivity factor for $B_{\text {Epulse }}$ is not required. It was assumed that the bias associated with $\Delta t$ was negligible. It was also assumed that $E_{\text {pulse }}, I$, and $\phi$ are independent variables.

Table 4.9: Electrical power sensitivity parameters

\begin{tabular}{lc}
\hline \hline Parameter & Equation \\
\hline \hline$\theta_{I}$ & $\frac{\partial \bar{P}}{\partial I}=V \cos \phi$ \\
$\theta_{\phi}$ & $\frac{\partial \bar{P}}{\partial \phi}=-V I \sin \phi$ \\
\hline
\end{tabular}

According to Saldanha and Beausoleil-Morrison (2012), the second term of Equation 4.19 is insignificant even at the field maximum $\phi$ of $28^{\circ}$. Considering this and the bias errors of the measuring devices, Equation 4.19 becomes Equation 4.20a for the single-phase two-wire configuration with a single CT measuring the current, such 
as the AHU circuit in this study. For the power distribution systems with a splitphase configuration where a pair of CTs is installed to measure the current on both live phases, the error introduced by the current measurements is doubled, and hence the total bias is calculated using Equation 4.20b. This is applicable to the combined compressor and outdoor fan circuit, as well as the sole fan circuit.

$$
\begin{array}{r}
B_{\bar{P}}^{A H U}=\sqrt{(0.01 I V \cos \phi)^{2}+\left(\frac{0.005 E}{\Delta t}\right)^{2}}=\sqrt{(0.01 \bar{P})^{2}+(0.005 \bar{P})^{2}} \\
B_{\bar{P}}^{\text {Comp\&Fan }}=\sqrt{2(0.01 I V \cos \phi)^{2}+\left(\frac{0.005 E}{\Delta t}\right)^{2}}=\sqrt{2(0.01 \bar{P})^{2}+(0.005 \bar{P})^{2}}
\end{array}
$$

Both Equation 4.20a and Equation 4.20b would be not complete without one additional source of error. In order to obtain the total bias from the energy measurements, the accuracy of the pulse reading of CR3000 has to be incorporated into the calculations. Considering the watt-hours per pulse resolution of each CT shown in Table 4.10, the accuracy of one pulse per 1-minute interval yields an uncertainty of $45 \mathrm{~W}$ and $75 \mathrm{~W}$ on the measurements taken on the AHU circuit and the combined compressor and outdoor fan circuit, respectively. Similarly to $B_{\text {Epulse }}, B_{C R 3000}$ does not require a sensitivity parameter. All of the errors contributed to the uncertainty on the energy measurements, as well as the total bias $B_{\bar{P}}^{A H U}$ and $B_{\bar{P}}^{\text {Comp\&Fan }}$ calculated using the root sum squared method, are presented in Table 4.11.

The sensitivity parameters for the COP are tabulated in Table 4.12. Taking into account how the measurements of the electricity consumption were taken, the total power draw of the heat pump is the sum of the power draw of the AHU and the 
Table 4.10: Rated and measured outputs

\begin{tabular}{lccc}
\hline \hline CT size, A & Installation location & Rated Wh per pulse & Measured value, $\mathrm{kW}$ \\
\hline \hline 30 & AHU & 0.75 & 0.72 \\
50 & Comp\&Fan & 1.25 & $4.92^{\mathrm{a}}$ \\
\hline
\end{tabular}

a Power draw of the fan is $0.27 \mathrm{~kW}$.

Table 4.11: Energy bias error

\begin{tabular}{lcc}
\hline \hline Source of error & Comp\&Fan, kW & AHU, kW \\
\hline \hline$\theta_{I} B_{I}$ & 0.049 & 0.007 \\
$B_{\text {Epulse }} / \Delta t$ & 0.025 & 0.004 \\
$B_{C R 3000}$ & 0.075 & 0.045 \\
\hline Total & 0.105 & 0.046 \\
\hline
\end{tabular}

combined compressor and fan:

$$
\bar{P}_{H P}=\bar{P}_{\text {Comp\&Fan }}+\bar{P}_{A H U}
$$

Table 4.12: COP sensitivity parameters

\begin{tabular}{llc}
\hline \hline Parameter & Equation & Value, $1 / \mathrm{kW}$ \\
\hline \hline$\theta_{\dot{Q}}$ & $\frac{\partial C O P}{\partial \dot{Q}}=\frac{1}{\bar{P}}$ & 0.177 \\
$\theta_{P}$ & $\frac{\partial C O P}{\partial \bar{P}_{H P}}=\frac{-\dot{Q}}{\bar{P}^{2}}$ & 0.301 \\
\hline
\end{tabular}

Table 4.13 summarizes both thermal and electrical bias in deriving the COP and shows the total uncertainty of $15 \%$. Since the measurements of power draw had the accuracy of $2 \%$, the electrical bias of the COP is insignificant.The high uncertainty in 
the COP is mainly attributed to the thermal component, particularly to its velocity measurement contributor.

Table 4.13: COP bias error

\begin{tabular}{lc}
\hline \hline Source of error & Value \\
\hline \hline$\theta_{\dot{Q}} B_{\dot{Q}}$ & 0.26 \\
$\theta_{P} B_{\bar{P}}{ }^{C o m p \& F a n}$ & 0.03 \\
$\theta_{P} B_{\bar{P}}{ }^{A H U}$ & 0.01 \\
\hline Total & 0.26 \\
\hline
\end{tabular}




\section{Chapter 5}

\section{Experimental Results and Discussion}

\subsection{Methodology}

The experimental setup was designed and built with an intention to provide a capability of testing various scenarios, including charging the top and bottom of the rock bed, as well as discharging from the top and bottom of the rock bed. Experimentally, it was found that some of the charging and discharging scenarios are more practical than others. For instance, discharging from the top of the rock bed was not favourable either in summer, since the top was warmer than the bottom section, nor in winter, since the top was colder than the bottom section. This also led to a realization that charging the bottom instead of the top is more advantageous. In regards to the strategies when the heat pump is used to charge the rock bed by dumping an excess of energy from the house to the rock bed, such scenarios were infrequently feasible. During instances of sunny winter days when cooling was required, the heat pump was switched to a cooling mode in order to provide air conditioning and in parallel to charge the rock bed with the heat extracted from the 
house. However, opportunities to charge the rock bed with the heat pump during summer never occurred: the CHEeR house did not require heating during the cooling season. The scenarios with recirculation, where air after passing the outdoor unit of the heat pump is redirected back to the rock bed instead of being exhausted, were also not practical since the temperature of air exhausted from the outdoor heat exchanger was significantly warmer than the rock bed in summer and significantly colder than the rock bed in winter.

The following chapter will discuss only practical scenarios tested in summer. To assess the impact of the rock-bed storage on the performance of the heat pump, the discharging scenarios were compared against the base case scenario where the heat pump operates in a conventional way and the ambient air is used as an energy source. The flow diagram for the base case scenario is illustrated in Figure 5.1 ${ }^{1}$. Performance of the heat pump is evaluated based on the COP and cooling capacity. Both derived quantities vary as the conditions change at the outdoor heat exchanger and the air handling unit. The conditions were monitored by measuring the ambient temperature $\left(T_{a m b}\right)$ and air temperature after the air handler $\left(T_{S A}\right)$. The ambient temperature was measured by a platinum RTD installed at the weather station which is located on top of the roof at the CHEeR house. Bias error of the sensor is $0.1{ }^{\circ} \mathrm{C}$. Each scenario was tested under a range of the ambient and supply air temperatures. Due to the nature of the experimental setup, the tests were dependent on the weather conditions making each experiment somewhat unique. Each test

\footnotetext{
${ }^{1}$ On this and all following similar diagrams, the red, yellow, and blue colours are used to qualitatively indicate the airstreams of the highest, moderate, and lowest temperatures.
} 


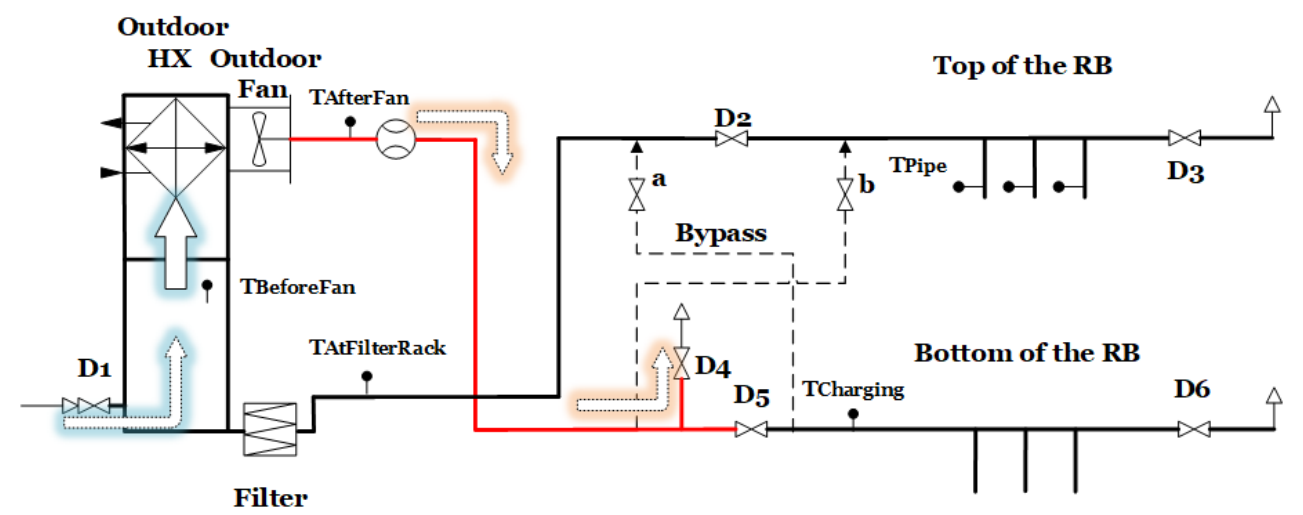

Figure 5.1: Conventional HP (scenario IIIb)

was constrained by the following requirement: the heat pump has to run continuously for at least five minutes under steady-state conditions, i.e., steady-state energy consumption, steady-state flow rates indoors and outdoors, and steady-state temperature conditions. While the indoor temperature conditions are slowly changing, the ambient temperature fluctuates more frequently. Thus, the data collected during, for example, a few hours of a smooth operation with a steady cooling output, had to be discretized over shorter time intervals to match the semi-steady periods of the outdoor temperature conditions. In order to accomplish this, a qualitative judgment was applied to form a sequence of segments of the test where each segment was the closest representation of a steady-state condition. The standard deviation and associated precision error of the measured variables were the auxiliary instruments to the qualitative judgment. Then, for each segment, the measured and derived quantities were time averaged. The population of the averaged values for each scenario composes a dataset which is presented and analyzed in this chapter. 


\subsection{Conventional heat pump scenario}

The base case scenario was tested under a wide range of ambient and supply ${ }^{2}$ air temperatures: from $16{ }^{\circ} \mathrm{C}$ to $33^{\circ} \mathrm{C}$ and from $14{ }^{\circ} \mathrm{C}$ to $20^{\circ} \mathrm{C}$, respectively. Although the temperature range was wider than a typical one for an occupied house, it was exploited to develop a more thorough performance map. As expected, the COP and cooling capacity have a tendency to decrease as the ambient temperature rises, and taking into account the uncertainty of the $\mathrm{COP}$ and $Q$, this pattern remains evident (Figure 5.2). Some variation to this tendency could be explained by the not-identical supply temperature conditions of the tests (Figure 5.3).

The supply temperature is a derivative of the return air temperature, so the increase of the latter leads to the increase of the former. The heat pump cycle is supposed to perform better under higher inlet temperatures at the evaporator (the AHU), i.e., return air temperature. However, based on Figure 5.3, it may appear that the performance of the heat pump improves with the decrease of the supply temperature. This is not the case as the ambient temperature is the factor which has a dominant impact on the heat pump performance. The temperature gradient across the air handler lessens when the cooling output of the heat pump decreases due to high temperatures outside.

In order to better visualize the correlation between the $\mathrm{COP}$ and ambient and supply temperatures, in Figure 5.4 a colour scheme was applied to indicate the region of high ambient temperatures, $H$, where $T_{a m b}>25.5{ }^{\circ} \mathrm{C}$, the region of low

\footnotetext{
${ }^{2}$ Supply air temperature is the temperature of the conditioned airstream at the outlet of the indoor unit of the ASHP as shown in Figure 3.1
} 


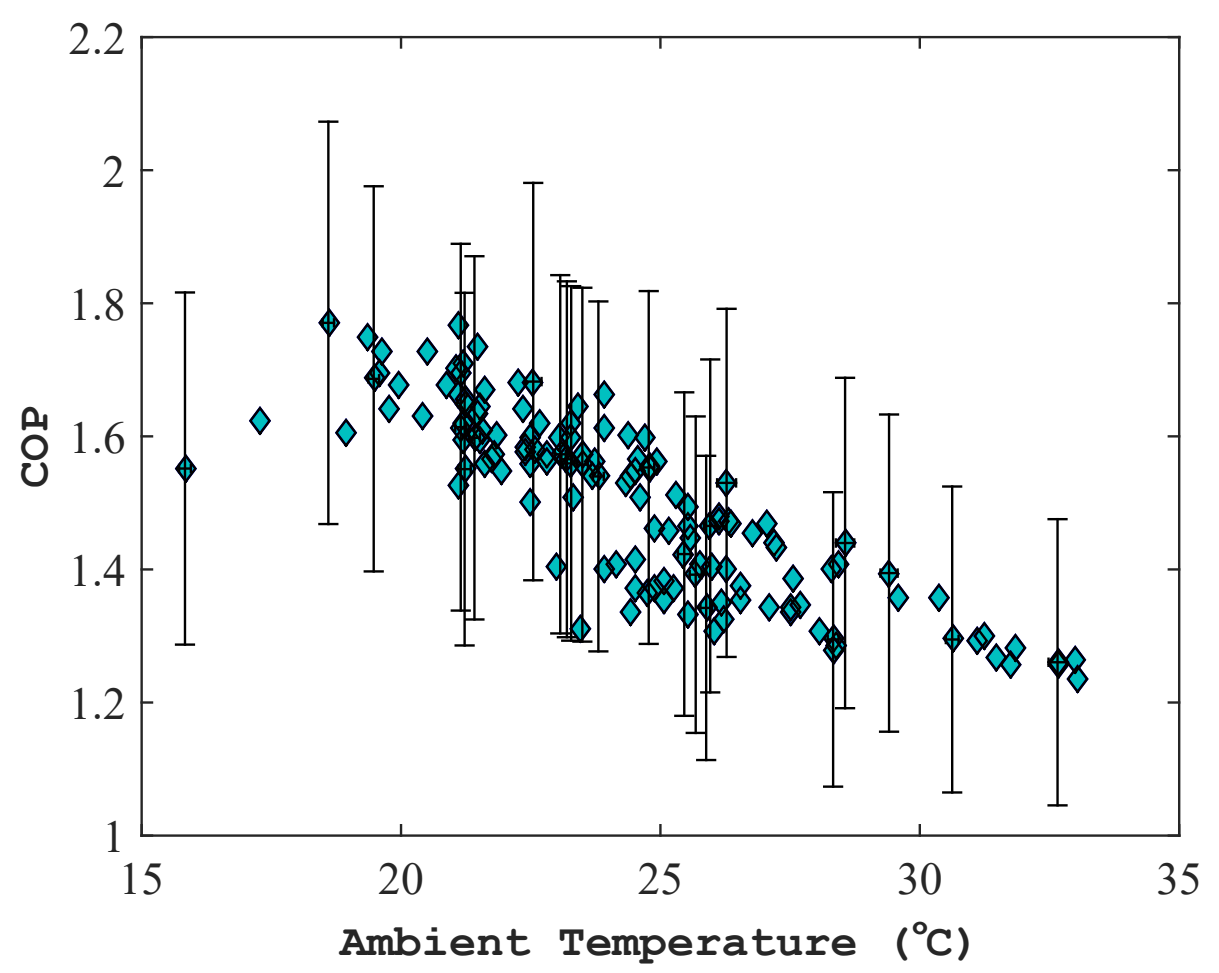

(a)

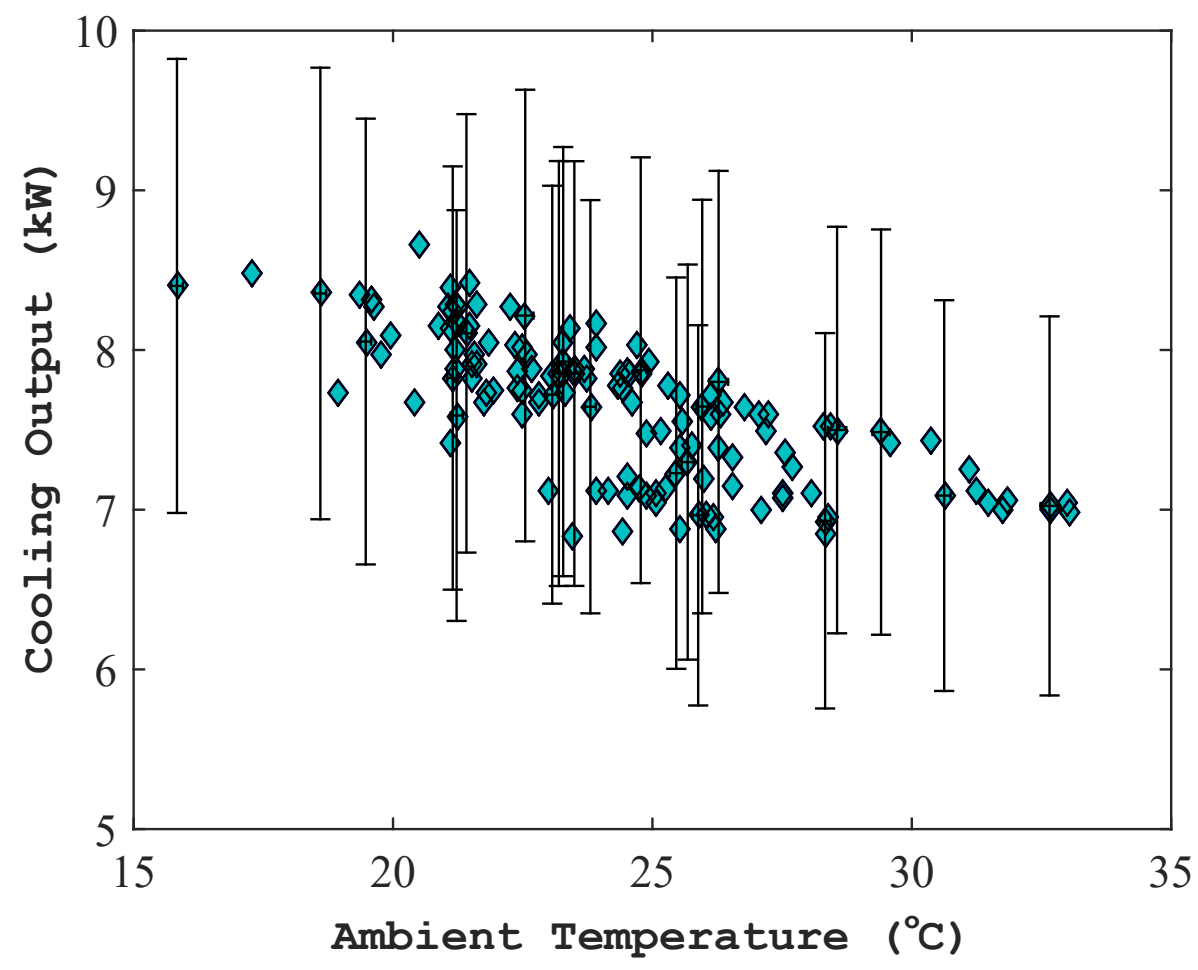

(b)

Figure 5.2: Performance of the heat pump with respect to $T_{a m b}-$ conventional heat pump scenario 


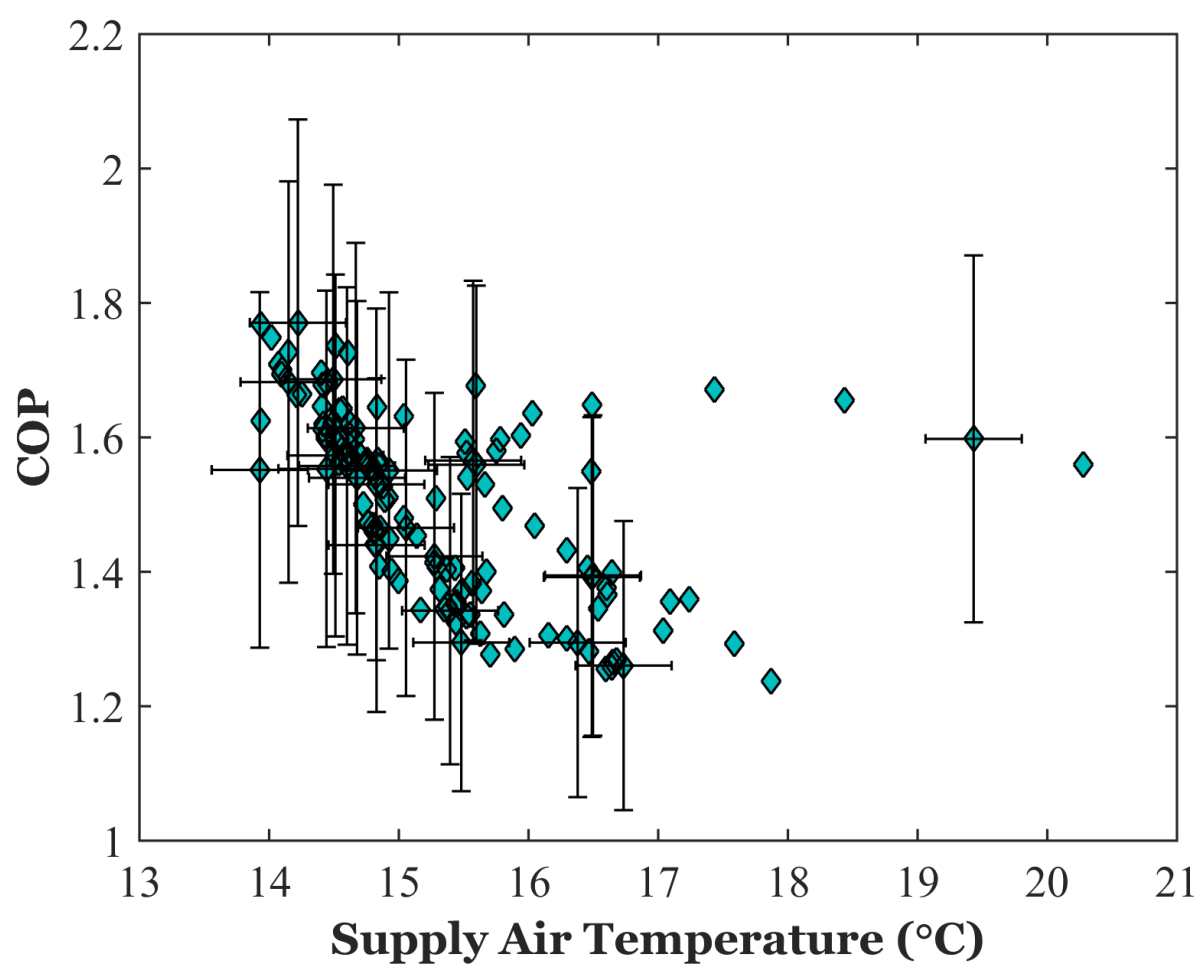

(a)

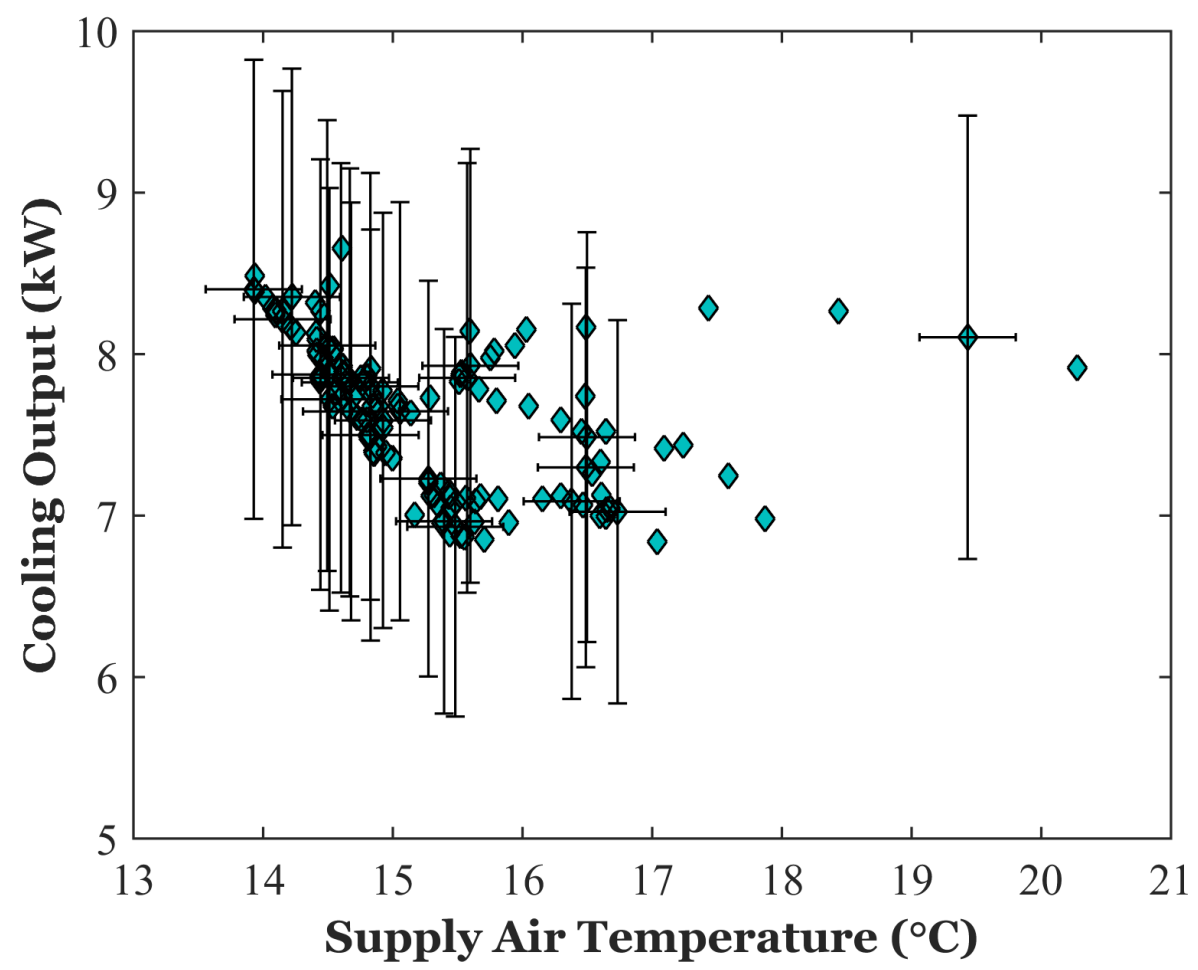

(b)

Figure 5.3: Performance of the heat pump with respect to $T_{S A}$ - conventional heat pump scenario 
temperatures, $L$, where $T_{a m b}<22.5^{\circ} \mathrm{C}$, and the region of moderate temperatures, $M$. This approach enables to plot a $3 \mathrm{D}$ correlation in a $2 \mathrm{D}$ space. The graph illustrates that the high COP value could be reached under a wide range of the supply temperatures as long as the outdoor heat exchanger is not exposed to the extreme temperature conditions.

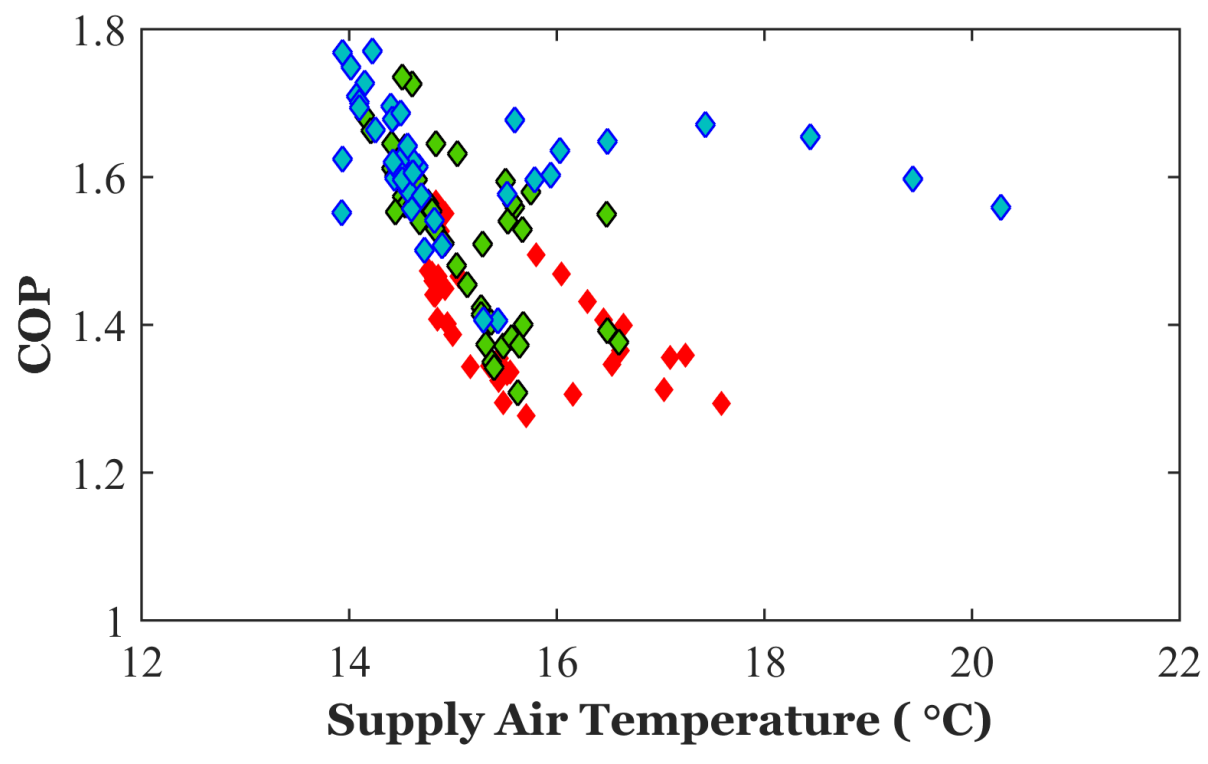

$\diamond \mathrm{H} \diamond \mathrm{M} \diamond \mathrm{L}$

Figure 5.4: $T_{S A}$ vs COP at high, moderate and low temperature ranges of the ambient air - conventional heat pump scenario

It is worth mentioning that often the ambient temperature and the temperature before the fan, $T_{B F}$, do not correspond, especially after prolonged hours of heat pump operation. As it can be seen in Figure 5.5, the $T_{B F}$ is higher than the ambient temperature, which could be caused by the heat transfer from the unit to the upstream air. The error bars indicate that the temperature measurements taken before the fan 
are less accurate than the ambient temperature measurements taken at the weather station. This is partially due to the types of sensors used and also a relatively high

precision error of the $T_{B F}$. It was observed that the $T_{B F}$ is generally less steady, which could be explained by the complications of the temperature measurements taken by a tube-shielded thermocouple in a turbulent environment. Due to all of these nuances, the performance of the heat pump under different scenarios is compared with respect to the ambient temperature rather than $T_{B F}$. Meanwhile, the correlation between the $T_{B F}$ and $T_{a m b}$ provides a valuable insight into the operation of the heat pump. This will be further discussed when comparing different scenarios.

\subsection{Discharging the rock bed}

The experimental setup allows discharging from either the top or bottom of the rock bed; however, during the summer season, the latter one is a more advantageous strategy as the bottom of the rock bed is cooler than the top. The diagram of the discharging scenario is shown in Figure 5.6. As cooled air is pulled from the bottom, ambient air is drawn into the top section. Once cooled air passes through the heat exchanger, it is exhausted since it is too hot to be recirculated back to the rock bed. During the majority of the tests, the supply temperature varied between $14.8^{\circ} \mathrm{C}$ and $16.5^{\circ} \mathrm{C}$ which is a much narrower range than in the previous scenario and thus its insignificant impact will not be discussed here. The average temperature at the outlet of the rock bed - the discharging temperature - was $17.9^{\circ} \mathrm{C}$ with the minimum of $13.8^{\circ} \mathrm{C}$ and maximum of $21^{\circ} \mathrm{C}$. The temperature registered before the 


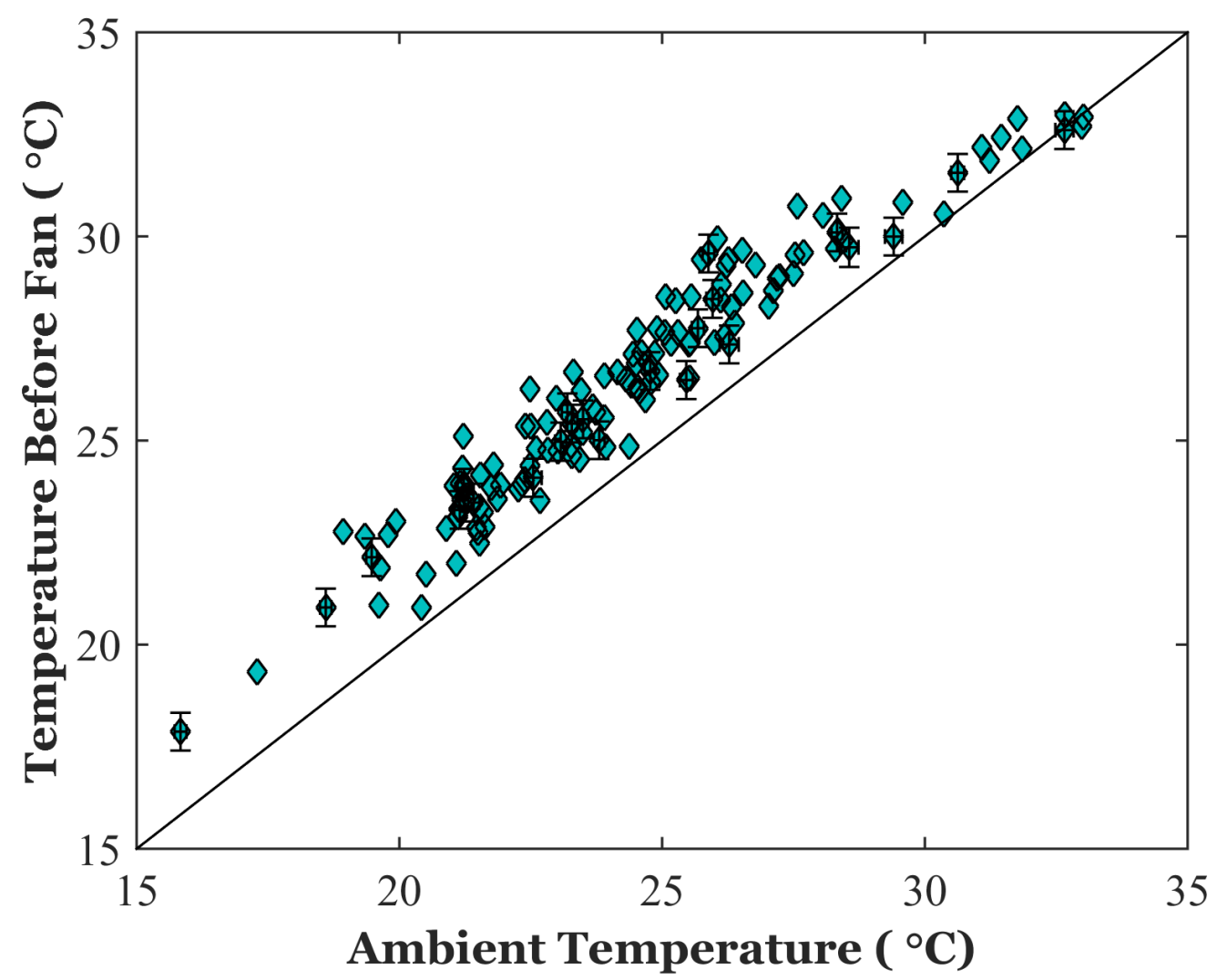

Figure 5.5: $T_{a m b}$ vs $T_{B F}-$ conventional heat pump scenario

fan varied between $17.7^{\circ} \mathrm{C}$ and $26.3^{\circ} \mathrm{C}$ which was close to the temperature range of the ambient air (Figure 5.18b).

Although in this scenario the temperature at the inlet to the heat exchanger was slightly lower than in the base case scenario, it did not improve the performance of the heat pump. At the ambient temperatures above $25^{\circ} \mathrm{C}$, the $\mathrm{COP}$ varied between 1.2 and 1.4 (Figure 5.16b) while the conventional heat pump had the COP of $1.4-$ 1.5. The cooling output was $6.7-7.7 \mathrm{~kW}$ (Figure $5.17 \mathrm{~b}$ ) versus $7.1-7.8 \mathrm{~kW}$ of the conventional heat pump under the ambient air temperature of above $25^{\circ} \mathrm{C}$. At the 


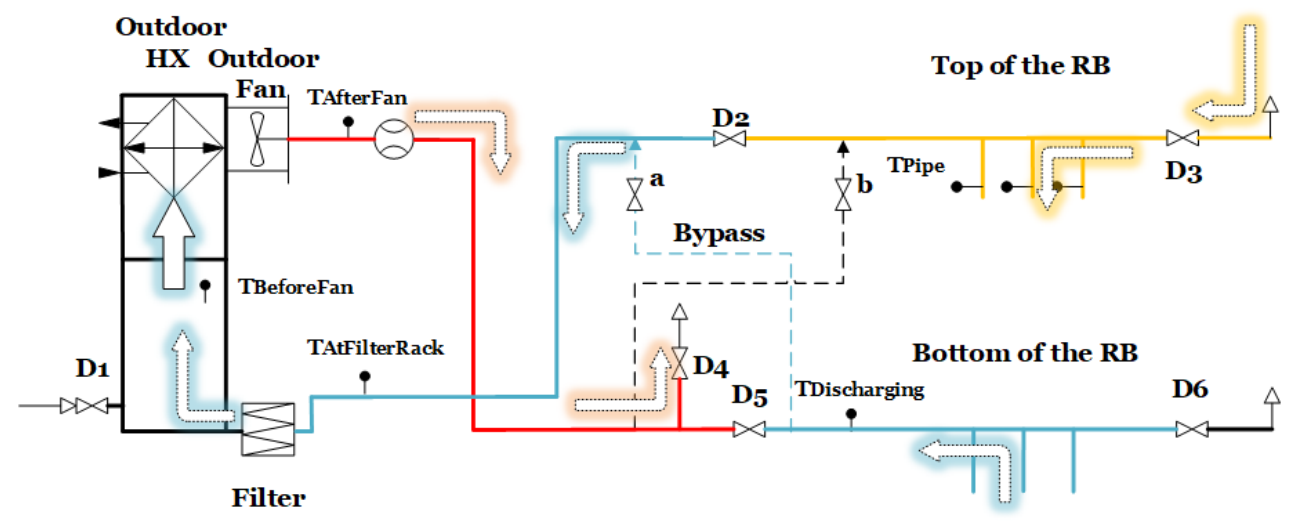

Figure 5.6: Discharging the rock bed (scenario IIa)

lower outdoor temperatures, from $20^{\circ} \mathrm{C}$ to $25^{\circ} \mathrm{C}$, the decline in the cooling capacity was bigger: $6.6-7.7 \mathrm{~kW}$ in comparison with $7.1-8.7 \mathrm{~kW}$ of the conventional system.

The deterioration of the heat pump performance when coupled to the rock bed storage can be explained by the decrease in the flow rate associated with the pressure drop in the system. To verify this, three new scenarios of discharging the rock bed with enhanced flow rates were tested.

\subsection{Discharging the rock bed and adding ambient air}

\subsubsection{Scenario IIa*}

In this modified discharging scenario, the rock bed is also discharged from the bottom but the end of the bottom duct (damper D6) is kept partially open so that the heat pump receives an intake of fresh air combined with the airstream from the 


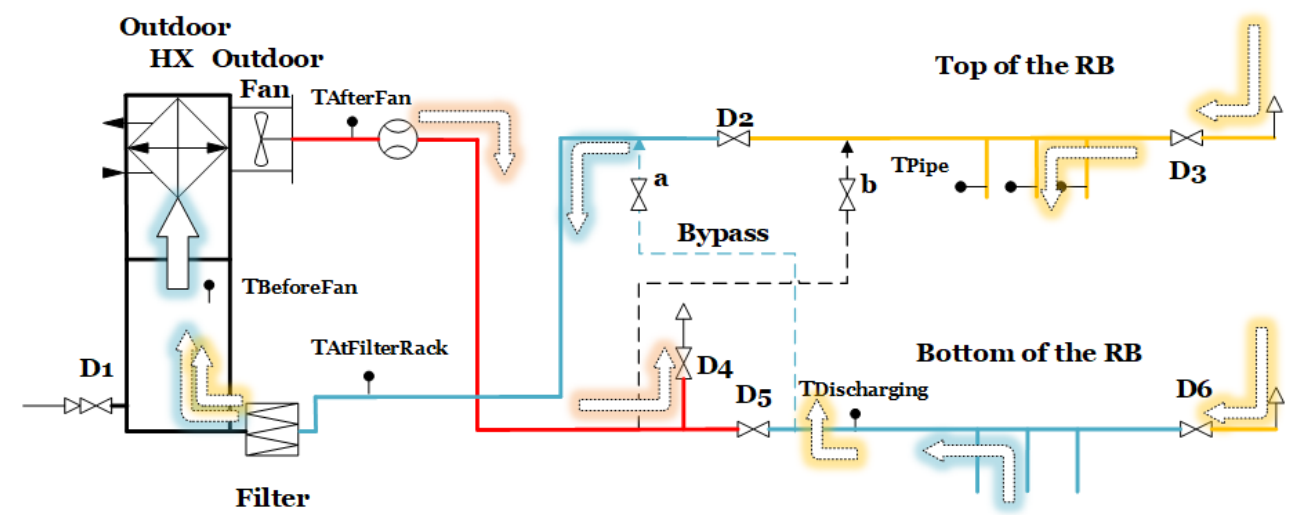

Figure 5.7: Discharging the rock bed and adding some ambient air (scenario IIa*)

rock bed. The diagram of the scenario is shown in Figure 5.7. The objective of the scenario was to increase the flow rate and yet maintain the mixed airstream relatively cool. An example of switching from the pure discharging scenario to the scenario when the ambient air is added to the stream is illustrated in Figure 5.8. The graph demonstrates how similar the discharging temperature, $T_{d i s c h}$, and the temperature at the bottom of the rock bed were before and after a $2 \mathrm{pm}$ spike in the $T_{\text {disch }}$ which occurred as a result of switching between the two scenarios. In almost half an hour, the $T_{\text {disch }}$ increased from $17.5^{\circ} \mathrm{C}$ to $21.5^{\circ} \mathrm{C}$ before the switch back to the pure discharging scenario took place. During this increase, the discharging temperature was still a few degrees lower than the ambient air; however, the temperature before the fan became comparable with the outdoor temperature.

For a more detailed analysis, samples of prolonged tests of each scenario are compared separately. Figure 5.9 presents two scenarios using 6-hour periods of the steady continuous tests under similar temperature conditions. It shows that the discharging temperature is at least $5^{\circ} \mathrm{C}$ higher than the bottom of the rock bed when 


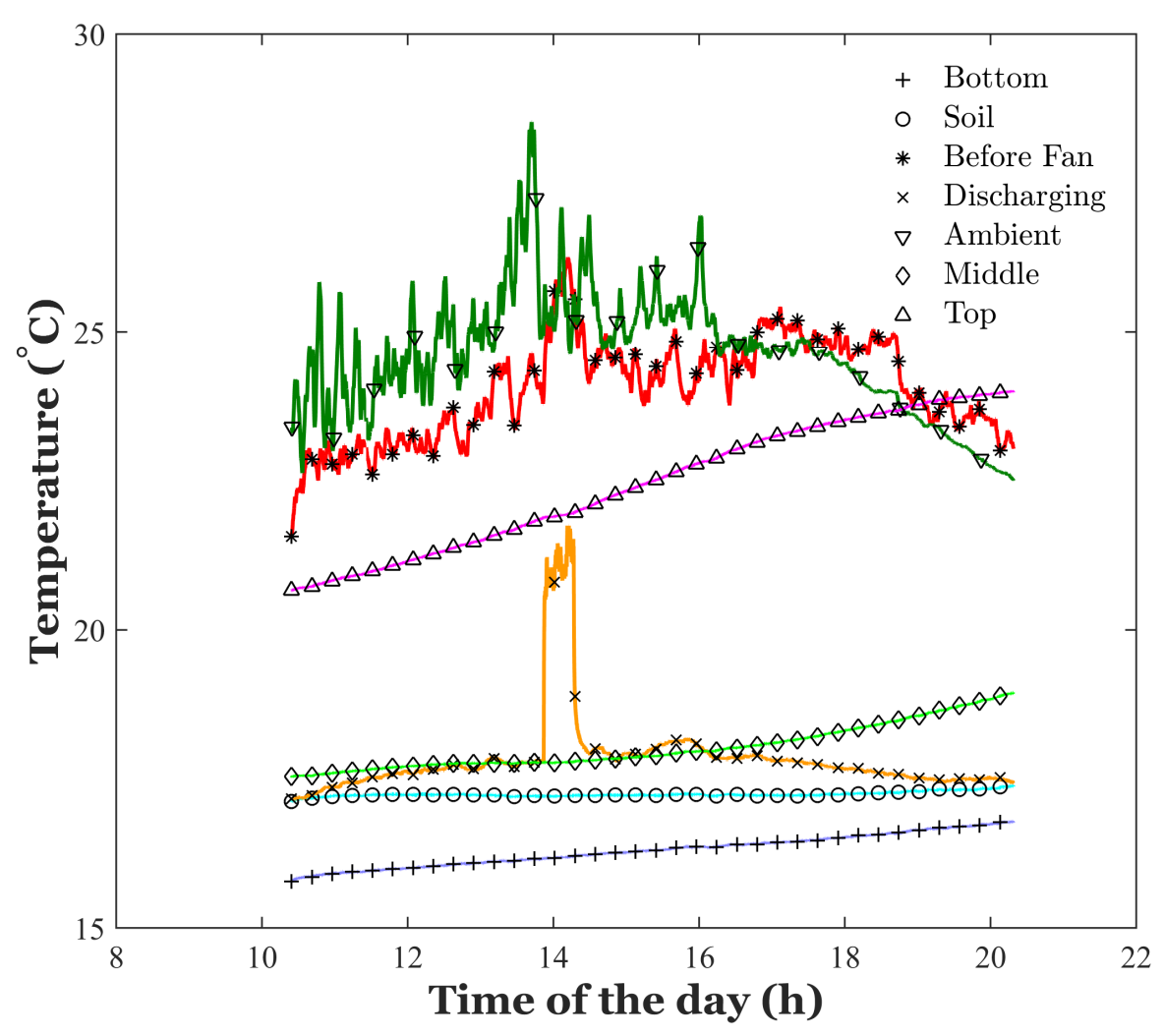

Figure 5.8: Aug 17 - HP discharging the RB w and w/o adding some ambient air ambient air is added to the stream. Meantime the difference is less than $2{ }^{\circ} \mathrm{C}$ when no mixing of the air streams takes place. It also demonstrates a slower temperature increase of the rock bed over time, which suggests that less air circulates through the storage. Although velocity measurements indicate that the flow rate increased by $9 \%$ (from $0.34 \mathrm{~m}^{3} / \mathrm{s}$ to $0.37 \mathrm{~m}^{3} / \mathrm{s}$ ), this value might be too small to justify since the error margins due to a non-uniform velocity profile were not applied.

The comparison analysis of Figure 5.18a and Figure 5.5 suggests that overall the air tempering benefits of the rock bed were somewhat compromised and the increase 
in the flow rate was not sufficient to make a positive impact on either the COP (Figure 5.16a vs. Figure 5.2a) or the cooling capacity (Figure 5.17a vs. Figure 5.2b). However, the most concerning aspect of the operation of the system under both scenarios is that the temperature before the fan does not demonstrate a correlation with the discharging temperature but rather with the ambient temperature (see the behaviour and close vicinity between the data points of "Discharging" and "Ambient" series in Figure 5.9). This may be the main reason why no improvement in the performance of the heat pump was observed.

\subsubsection{Scenario IIa**}

In an attempt to continue increasing the flow rate and study its impact on the performance under extremely high temperatures (above $32{ }^{\circ} \mathrm{C}$ ), a different modification of the discharging scenario with adding ambient air was tested: the fresh air intake was supplied through a fully open damper $D 1$ while $D 6$ was closed. A diagram of a similar test is shown in Figure 5.14. The damper D1 is attached to the outdoor unit and provides immediate access to the fresh air. In addition to this, it has an opening larger than $D 6$ does, which results in a higher flow rate within the system. A 100-minute test generated a single data point which is a far-right outlier in Figure 5.16a, Figure 5.17a, and Figure 5.18a. During the test, the COP of the system was 1.3 and the cooling output was $7.2 \mathrm{~kW}$. The performance of the heat pump when $D 1$ was open versus when $D 6$ was open cannot be compared due to a mere absence of a corresponding data point: the heat pump was shutting off when $D 1$ was closed in attempt to test the respective scenario under extreme temperatures. On the other 


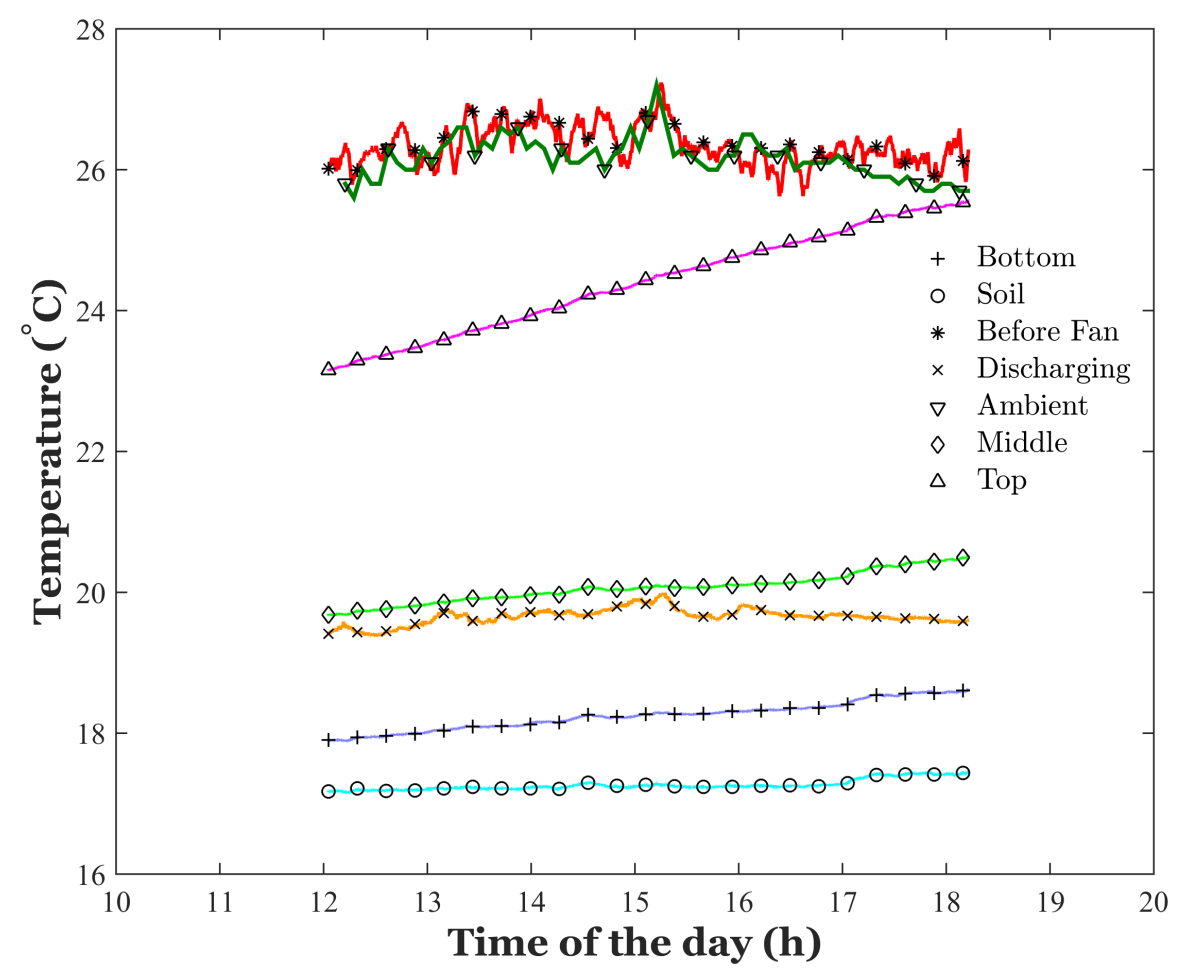

(a) Aug 10 - HP discharging the RB

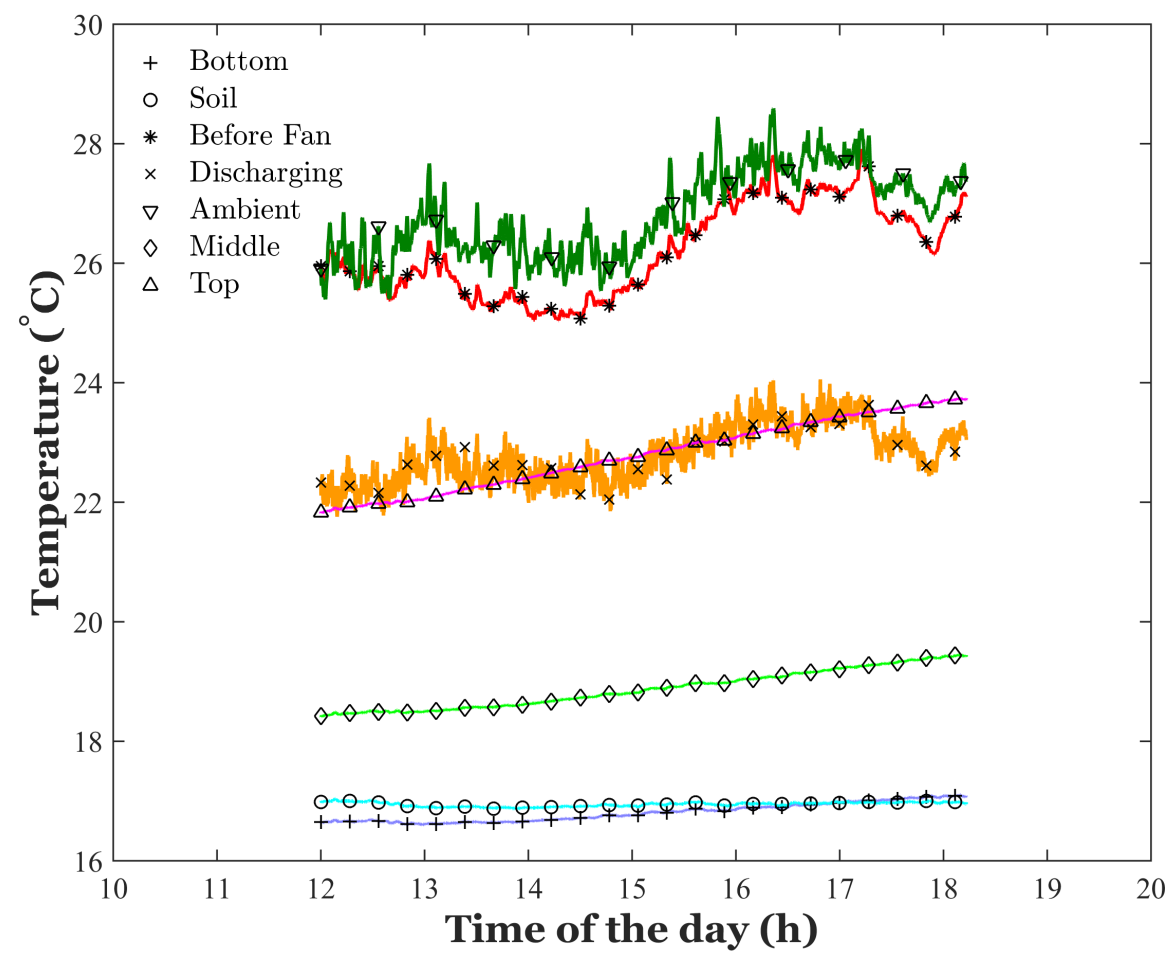

(b) July 30 - HP discharging the RB and adding some ambient

Figure 5.9: Thermal response of the rock bed during different discharging scenarios 
hand, the performance results, as well as the flow rates, are comparable with those obtained when the conventional heat pump scenario was tested. This supports the idea of the importance of a sufficient flow rate for the good performance and smooth operation of the heat pump.

\subsection{Maximizing the flow rate}

The maximum flow rate in the system can be achieved when the fresh air intake is supplied through both dampers $D 1$ and $D 6$ and when the damper $a$ is open to discharge the rock bed as shown in (Figure 5.10). This scenario was tested at the end of the cooling season, September, during a couple of days of a heat wave.

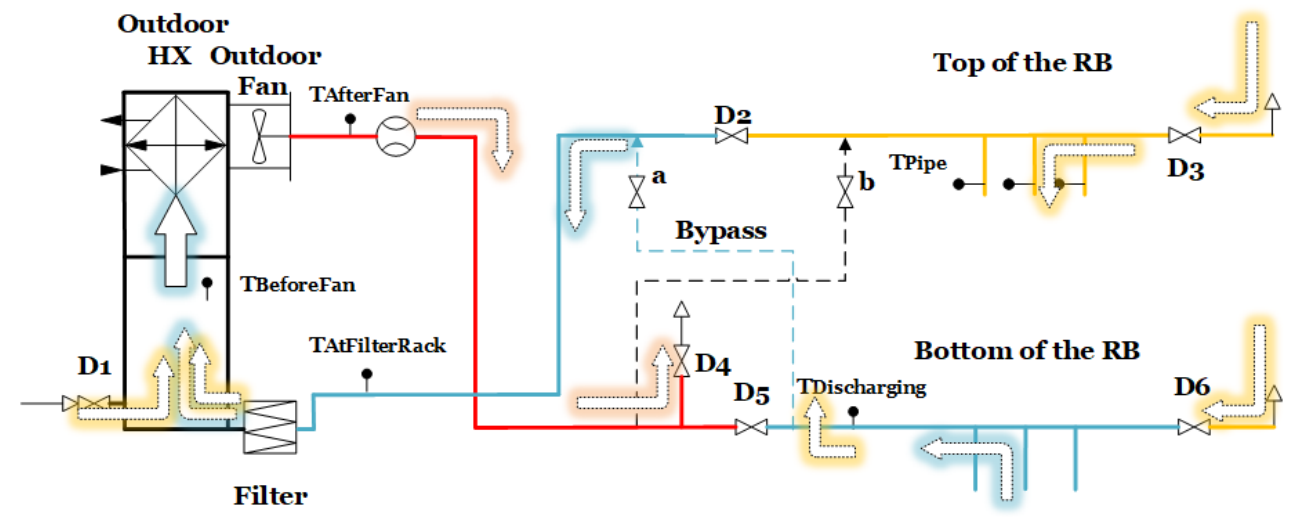

Figure 5.10: Scenario $\mathrm{IIIb}^{*}$ - maximum flow rate

As can be seen in Figure 5.11a, the discharging temperature closely followed the ambient temperature while the temperature of the rock bed remained almost constant. This shows that the airstream in the discharging duct was predominantly delivered from outside via open $D 6$ and the discharging process did not take 
place, which resulted in $T_{B F}$ being equal to or higher than the ambient temperature. All of this makes the scenario similar to the conventional heat pump one. Figure 5.11b compares the two as well as the scenario IIa**. From 10 am till 12 pm, the heat pump was running at the maximum flow rate, $0.55 \mathrm{~m}^{3} / \mathrm{s}$, then starting at $12 \mathrm{pm}$ the heat pump was operating as a conventional system with the flow rate of $0.53 \mathrm{~m}^{3} / \mathrm{s}$, and after $1 \mathrm{pm}$ the heat pump was discharging the rock bed in parallel with taking ambient air through $D 1$ with the total flow rate of $0.54 \mathrm{~m}^{3} / \mathrm{s}$. During the first two periods, the temperature before the fan was rising together with the ambient temperature and then it dropped when the discharging process began. The thermal response of the rock bed can be noticed during the last period.

The performance of the system under the maximum flow rate (Figure 5.16c and Figure 5.17c) was comparable to the performance of the conventional heat pump. During the tests, the supply temperature varied within a range of $4{ }^{\circ} \mathrm{C}$ in accordance with the return air temperature: the tests started when the house was at $27^{\circ} \mathrm{C}$ and continued until it reached the setpoint of $23^{\circ} \mathrm{C}$. The supply temperature was decreasing as the outdoor temperature conditions became moderate. In Figure 5.16c and Figure 5.17c the values of the COP and cooling output under the ambient temperature of $25^{\circ} \mathrm{C}$ and below were obtained when the supply temperature was below $15.5{ }^{\circ} \mathrm{C}$. Analogously, the values of the $\mathrm{COP}$ and cooling output under the ambient temperature above $25^{\circ} \mathrm{C}$ were obtained when the supply temperature was above $15.5^{\circ} \mathrm{C}$. Despite a relatively wide range of the supply temperature, Figure 5.12 reiterates that the outdoor temperature is the dominant factor that affects the heat pump performance. The same three ranges of the ambient temperature as in Section 


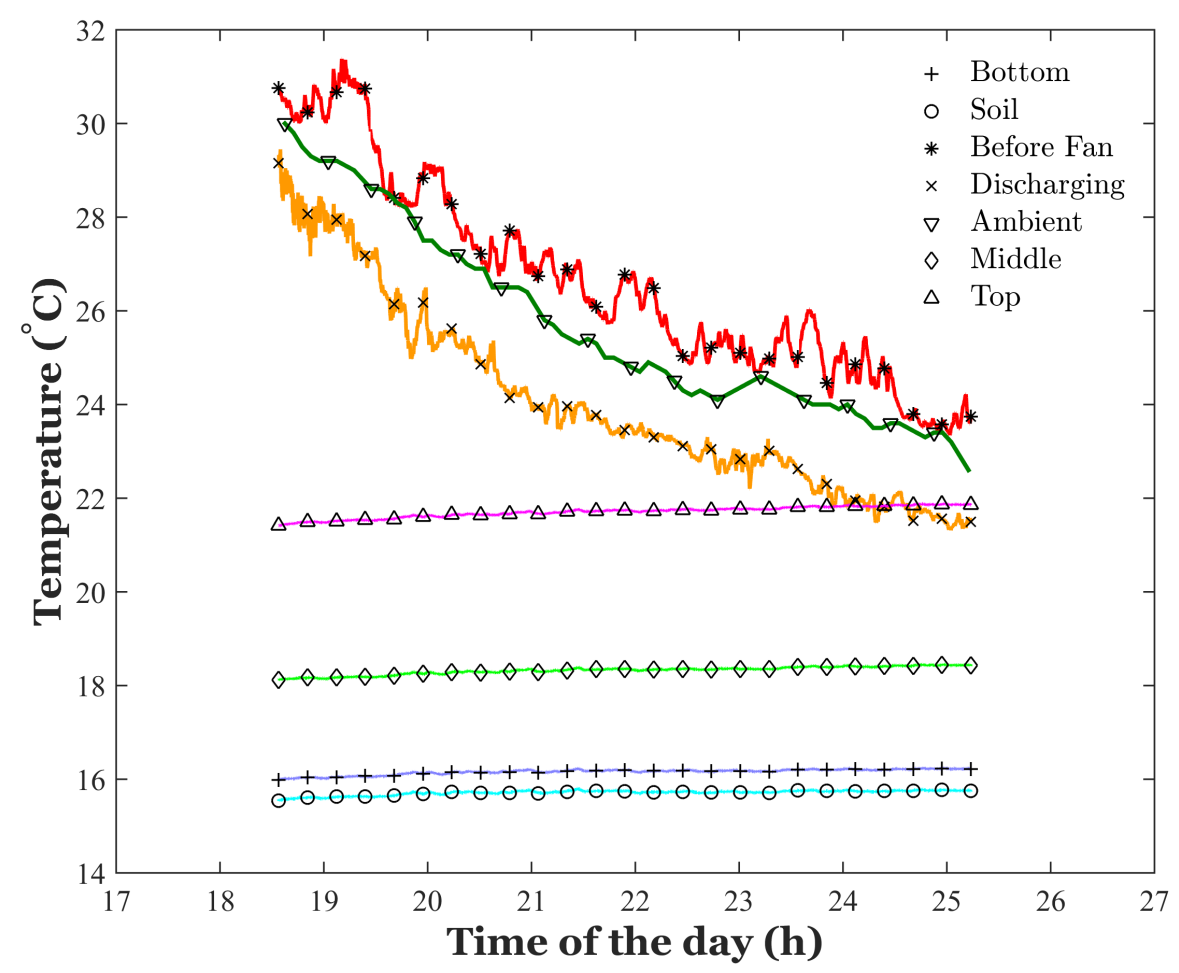

(a) Sep 24 - Maximum Flow Rate

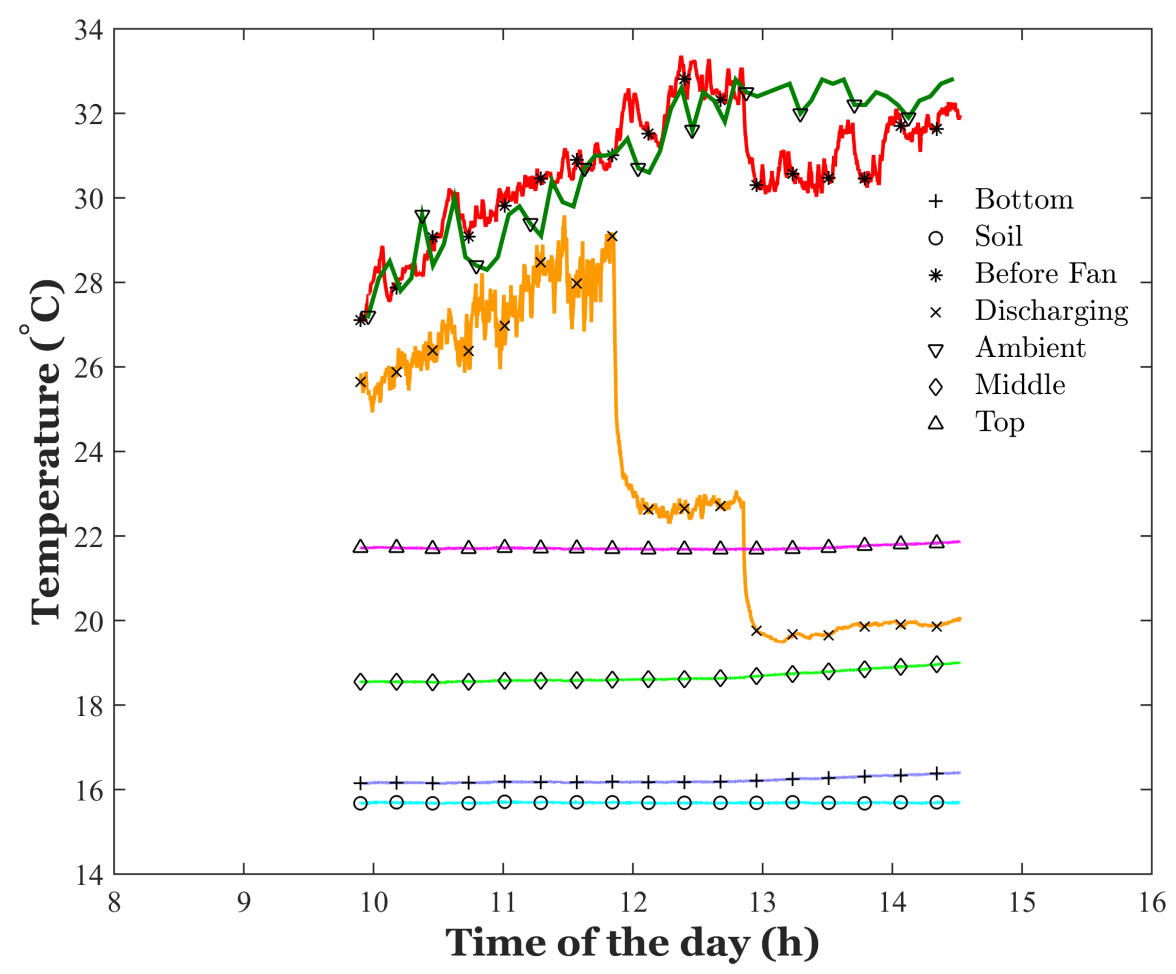

(b) Sep 25 - Max Flow Rate, Conventional HP, D1+Discharging the RB

Figure 5.11: Thermal response of the system under extreme temperature conditions 
5.2 were used here.

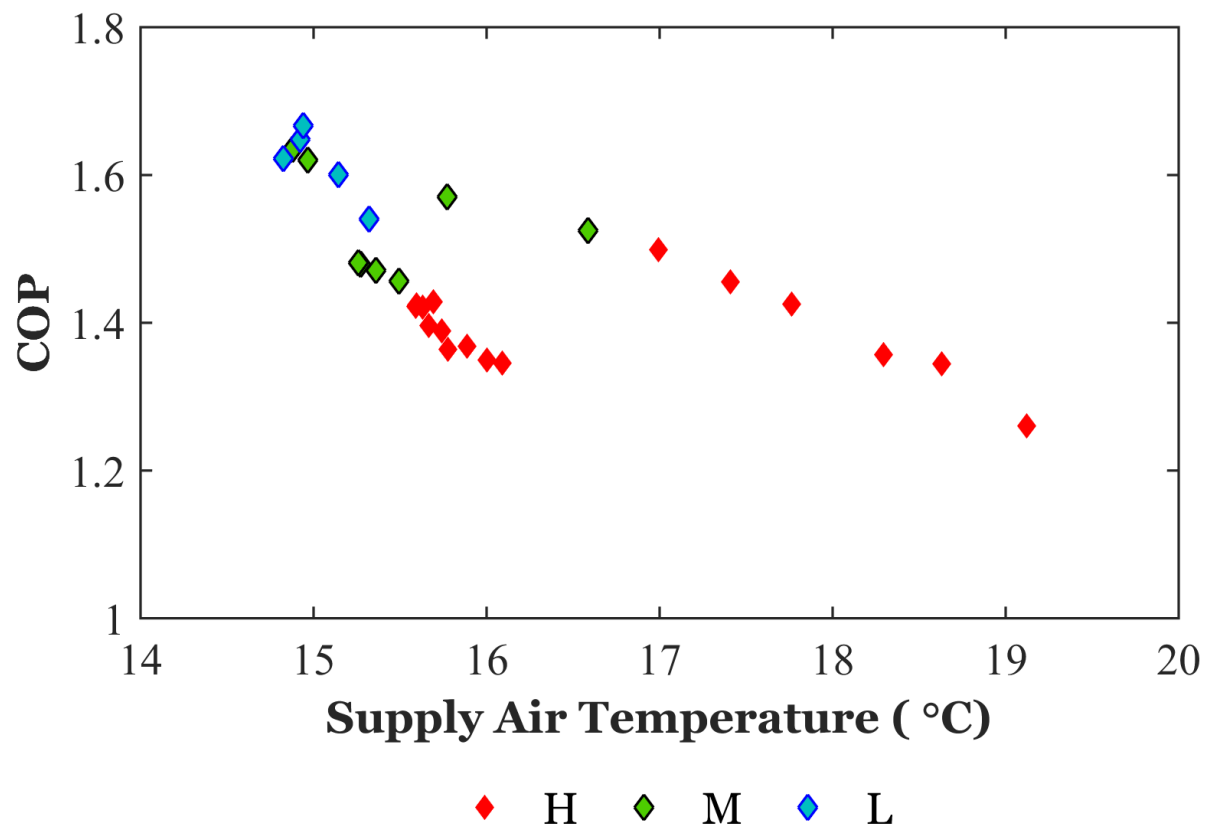

Figure 5.12: $T_{S A}$ vs COP at high, moderate and low temperature ranges of the ambient air - max flow rate scenario

Yet the impact of the supply temperature can be seen in Figure 5.13. The COP of about 1.5 and higher was achieved under lower ambient temperatures. Below and above this value, the heat pump generates more cooling under higher supply temperatures. This means that under extreme outdoor temperature conditions, generating a certain cooling output can be accompanied by a higher COP if the house is kept cool prior to the beginning of the heat pump operation. On the other hand, if cooling is a priority, then it should be taken into account that under the same COP, more cooling will be generated if the house was not conditioned before starting the heat pump operation. 


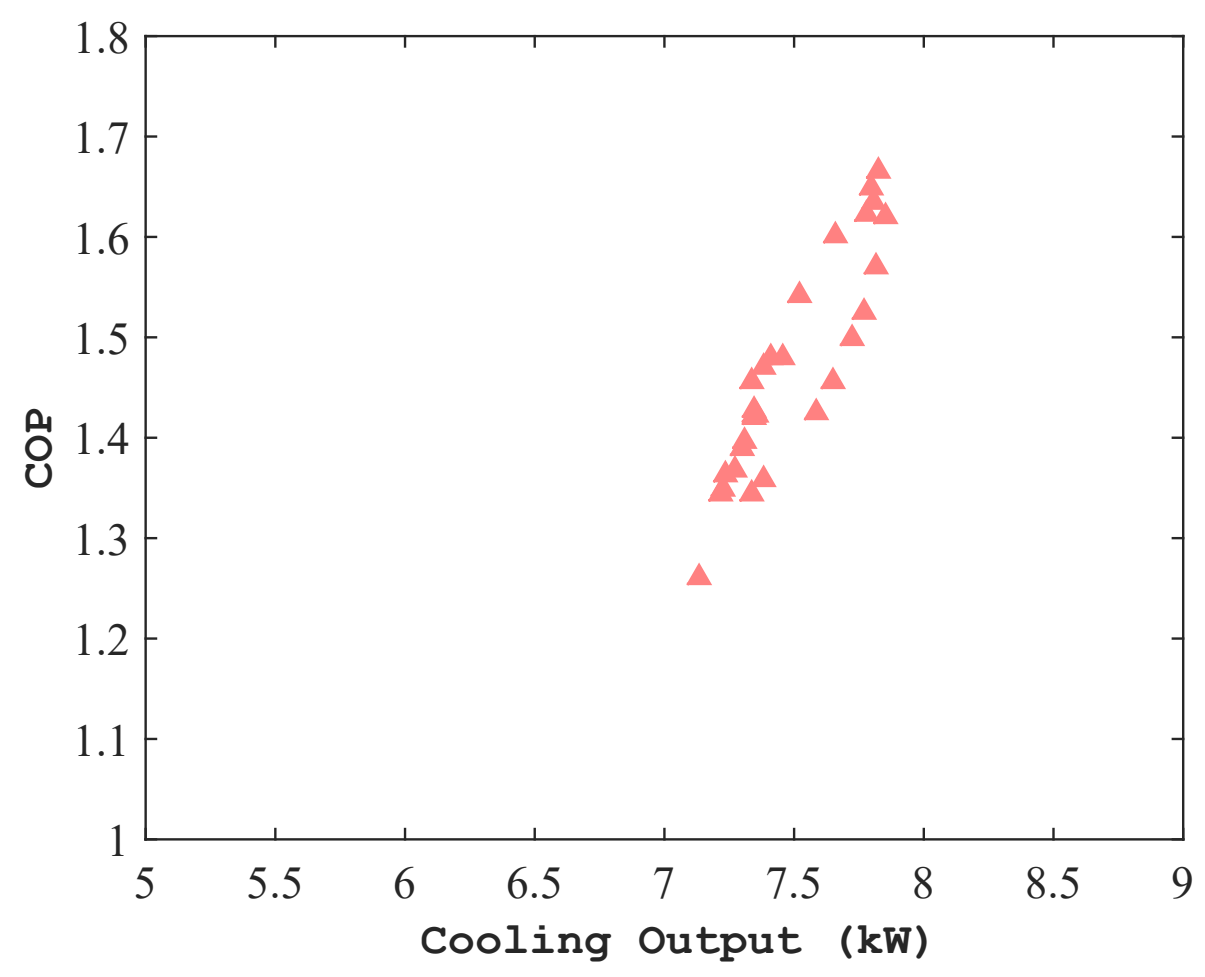

Figure 5.13: $Q$ vs COP - max flow rate scenario

\subsection{Matching the flow rate}

Based on the performance results of the scenario $\mathrm{IIIb}^{*}$ and scenario $\mathrm{IIa}^{* *}$ and operational nuances of the heat pump, it was concluded that:

1. Under extreme temperatures, the heat pump shuts off unless high airflow is maintained.

2. Under moderate temperatures, the heat pump can operate at decreased airflow but it leads to performance deterioration.

To organize a high flow rate, it is important to have the damper $D 1$ open as 
it was in the base case scenario, scenario IIa*, and scenario IIIb*. It was noticed that when the stream of fresh ambient air is added while discharging the rock bed, the discharging process is being compromised so that less air circulates through the store. To address these drawbacks and achieve high performance of the heat pump when discharging the rock bed, it was decided to test a discharging scenario with the flow rate matching the flow rate of the conventional heat pump. In this discharging scenario, D1 was adjusted to a position which enabled the flow rate of the conventional heat pump. The diagram of the scenario is shown in Figure 5.14.

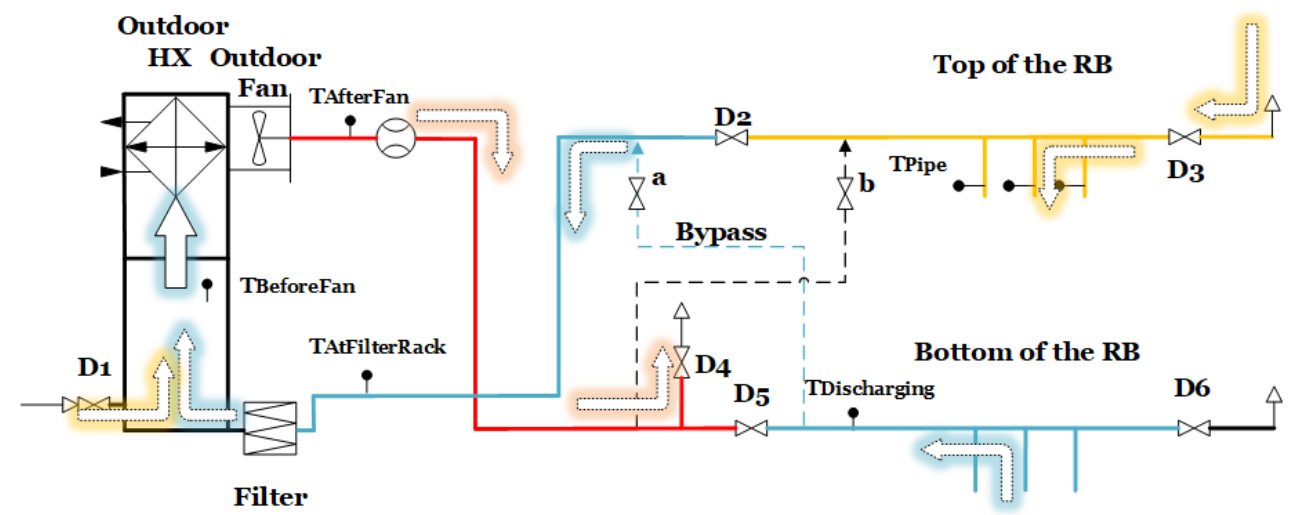

Figure 5.14: Discharging (scenario IIIb**) - matched flow rate

Figure 5.15 illustrates the thermal response of the rock bed during the test. The temperature of each layer of the store was gradually increasing at a similar rate. The discharging temperature was significantly lower than the outdoor temperature since the hot ambient air was added further downstream. However, it can be noticed that the discharging temperature did not follow a linearly increasing pattern of the thermal behaviour of the rock bed, and instead there are some similarities with the pattern of the ambient temperature. The reason for this can be the issues with 
airtightness. On the positive side, the rate of change of the discharging temperature is smaller than the one of the ambient temperature: $\sim 1{ }^{\circ} \mathrm{C}$ and $\sim 8{ }^{\circ} \mathrm{C}$ over a 7-hour period, respectively. Overall, this scenario provides the best combination of a high flow rate and low discharging temperature (Figure 5.18d). Despite that, the performance of the system (Figure 5.16d, Figure 5.17d) did not necessarily improve in comparison with the conventional heat pump. It can be explained by the fact that the low discharging temperature did not result in an equally low temperature before the fan. In some cases, the temperature difference between $T_{B F}$ and $T_{\text {disch }}$ was as high at $10{ }^{\circ} \mathrm{C}$.

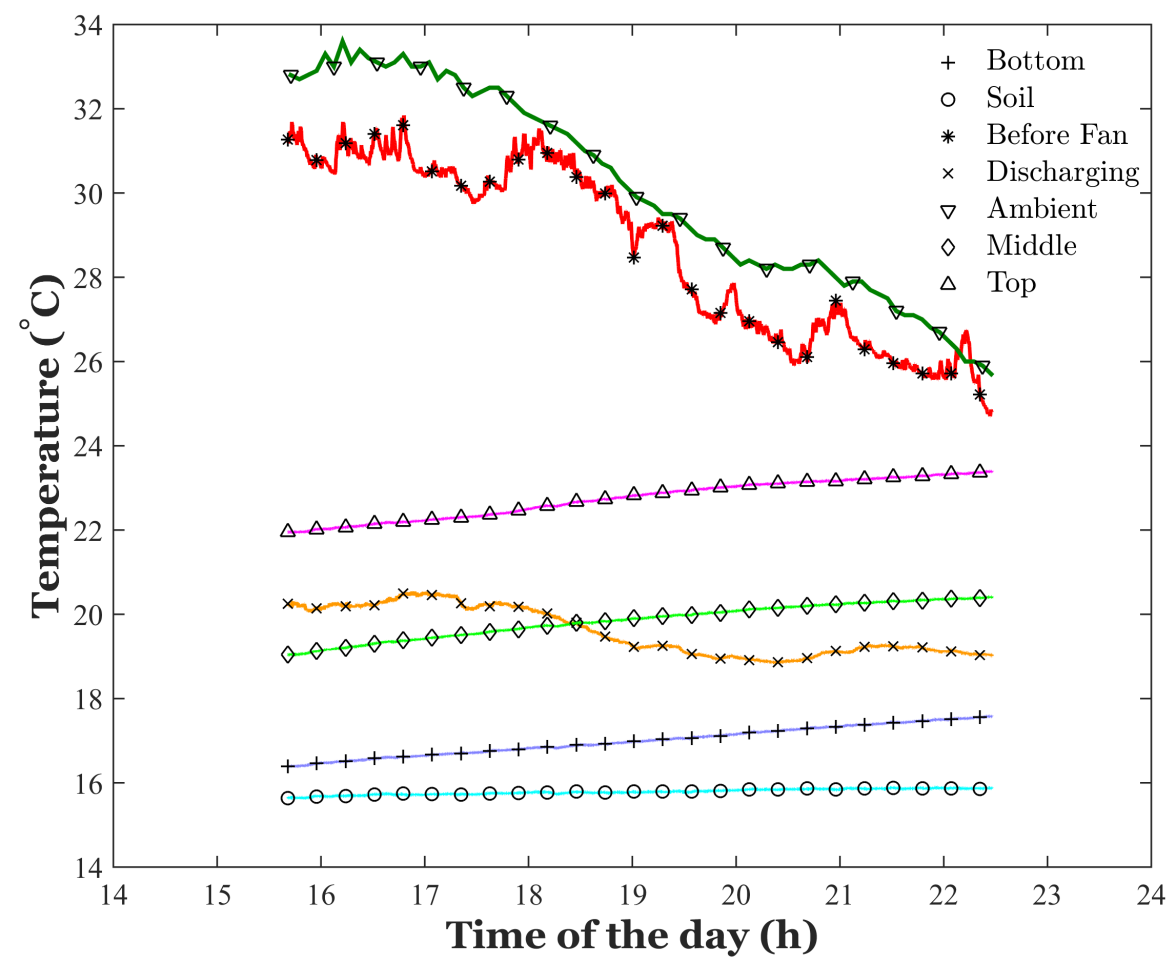

Figure 5.15: Sep 25 - Matched Flow Rate 


\subsection{Charging the rock bed}

In the summertime, the most practical charging scenario is to send cool ambient air to the bottom of the rock bed and let the warm airstream escape through the pipes in the top section of the store. The diagram of the process is shown in Figure 5.19. The charging scenario is strongly dependent on the weather and correspondence between the ambient temperature and the temperature of the rock bed, particularly the bottom section of it. In other words, the requirement for charging to start is that the bottom of the rock bed has to be warmer than the outdoor temperature. In the middle of the summer, when the experimental work started, the bottom of the rock bed and the surrounding soil were at $17^{\circ} \mathrm{C}$. Throughout the summer the soil temperature was fairly stable regardless of the discharging processes, which limited the number of opportunities to test the charging process.

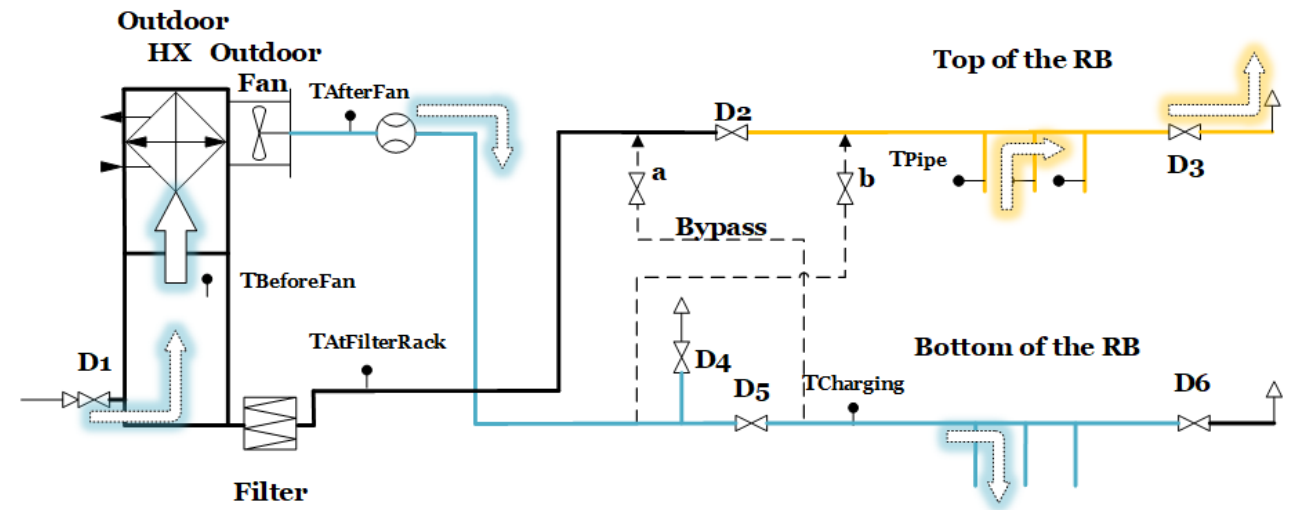

Figure 5.19: Conventional charging the bottom of the rock bed (scenario IVa)

During the charging process, the temperature of the bottom of the rock bed decreases rapidly during the night hours and gradually as dawn approaches. The temperature of the middle section has a smaller rate of change during the first 2 - 
4 hours of charging and then the temperature decreases faster until it equalises with the temperature of the bottom. The thermal behaviour of the top section depends on its correspondence to the temperature of the middle section. If the top section is cooler than the middle, then the temperature change of the top section has a shape similar to a parabola: first, the temperature increases until it evens up with the middle section and then it starts decreasing. Otherwise, an inertial almost linear decrease can be observed (see example in Figure 5.20a).

In order to simplistically evaluate the temperature changes of the rock bed and of the airstream circulating through the store, the heat transfer rate of the airstream was compared to the heat transfer rate of the rock bed using Equation 5.1 and Equation 5.2.

$$
\dot{Q}_{a i r}=\left.V A\left(\rho_{a i r} c_{p a i r}\right)\right|_{T_{a v g}} \Delta T_{\text {air }}
$$

where $V$ is the velocity of the airstream after the outdoor fan, $\mathrm{m} / \mathrm{s}, A$ is the crosssection of the duct where the velocity meter was installed, $\mathrm{m}^{2}, \rho_{\text {air }} c_{\text {pair }}$ is the product of density and specific heat of air, $\mathrm{kJ} /\left(\mathrm{m}^{3} \mathrm{~K}\right)$, evaluated at the averaged inlet and outlet temperature of the rock bed, $T_{\text {avg }}$, and $\Delta T$ is the temperature differential of air across the rock bed, $\mathrm{K}$. The inlet temperature is the charging temperature and outlet temperature is the temperature measured in the pipe connected to the top duct as labeled in Figure 5.19. The flow rate during the charging process varied between $0.47 \mathrm{~m}^{3} / \mathrm{s}$ and $0.49 \mathrm{~m}^{3} / \mathrm{s}$.

$$
\dot{Q}_{R B}=V\left(\rho_{R B} c_{p R B}\right) \Delta T_{R B} / \Delta t
$$




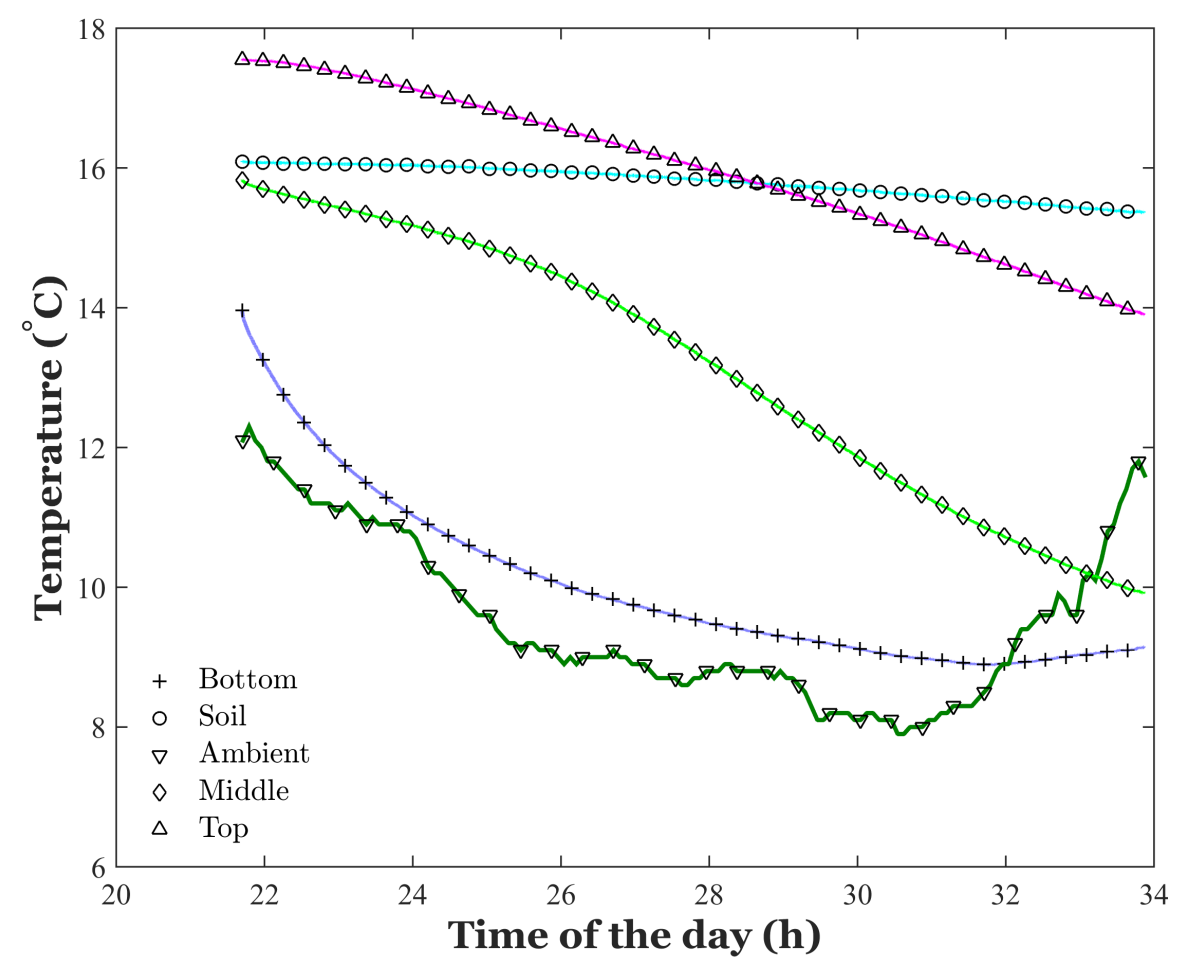

(a) Thermal response of the rock bed

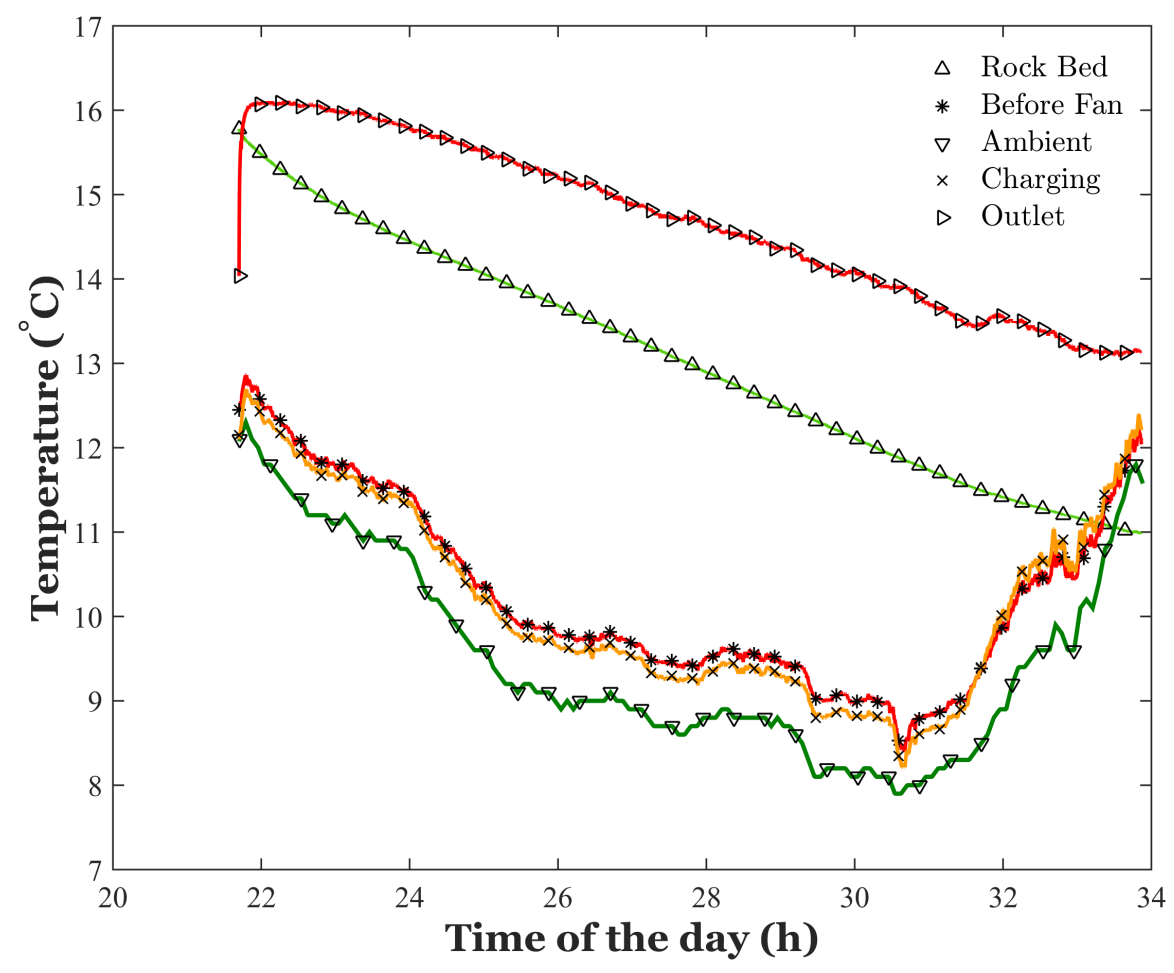

(b) Temperatures within the system

Figure 5.20: Aug 31 - charging the bottom of the rock bed 
where $V$ is the volume of the rock bed, $\mathrm{m}^{3} / \mathrm{s}, \rho_{R B} c_{p R B}$ is the product of density and specific heat of the rock bed, $\mathrm{kJ} /\left(\mathrm{m}^{3} \mathrm{~K}\right)$, and $\Delta T / \Delta t$ is the temperature gradient of the rock bed during a time interval $\Delta t$.

Using formulas proposed by Ismail and Stuginsky Jr (1999) for calculating effective density and specific heat of packed bed with the consideration of the thermophysical properties of both solid storage material (Singh et al., 2010) and HTF, as well as void fraction (Sagara and Nakahara, 1991), it was assumed that $\rho_{R B}=1800 \mathrm{~kg} / \mathrm{m}^{3}$ and $c_{p R B}=0.8 \mathrm{~kJ} /(\mathrm{kg} \mathrm{K})$.

Using instantaneous values at 5 -second measuring intervals, the calculated $\dot{Q}_{a i r}$ is equated to $\dot{Q}_{R B}$ and solved for $\Delta T_{R B}$ for each interval. Then the instantaneous $\Delta T_{R B}$ is integrated over an entire charging period. The integrated value is compared to the temperature measurements taken in the rock bed.

Based on the charging and outlet temperature measurements shown in Figure $5.20 \mathrm{~b}$, from $11 \mathrm{pm}$ till 8 am the average $\dot{Q}_{a i r}$ was $2.8 \mathrm{~kW}$ which resulted in the predicted value $\Delta T_{R B}$ of $2.3{ }^{\circ} \mathrm{C}$; however, as can be seen in Figure $5.20 \mathrm{~b}$ overall the rock bed cooled down by $4.8^{\circ} \mathrm{C}$.

In reality, $\dot{Q}_{a i r}$ is higher than the value calculated since the heat losses through the outlet pipes of the rock bed were not included in the calculations. Thus, the predicted temperature decrease of the rock bed is underestimated. On the other hand, the calculations assumed no heat transfer to the surrounding ground, meantime Figure 5.20a demonstrates that the soil cooled down as a result of the charging process. Overall, the simplified calculations can be used as an indicator of the system performance and for troubleshooting purposes. It is worth mentioning that the uncertainty on $\dot{Q}_{a i r}$ is $1.2 \mathrm{~kW}$ (Appendix B) which implies that the true value of the 
temperature decrease lies between $3{ }^{\circ} \mathrm{C}$ and $7.5^{\circ} \mathrm{C}$ for the given example (August 31). Hence, the predicted values lie within the error margin.

\subsection{Closing remarks}

The results obtained when testing the heat pump with and without the rock bed indicated no improvement introduced by the thermal store. In the preceding sections, it was mentioned that a significant drop in the flow rate is associated with the discharging process when air tempered in the rock bed is pulled from the bottom of the store and supplied to the outdoor heat exchanger. On the other hand, no such effect was observed during charging the bottom of the rock bed.

After testing a few additional scenarios with different flow paths within the outdoor ductwork, it was noticed that the lowest flow rate is attributed to the scenarios when the bypass - either $a$ or $b$ or both - is used. The flow rate can increase by $40 \%$ when air circulation through the rock bed is organized without using the bypass. Figure 5.21 shows three scenarios with the lowest flow rate: recirculation from the bottom to the top section of the rock bed, charging the top section with the ambient air, and discharging the bottom of the rock bed. Although the first scenario has

the highest airflow resistance which must result in the lowest airflow generated by the fan, the measurements are not accurate enough to properly reflect the difference between three scenarios.

Figure 5.22 compares the scenario with recirculation from the top to bottom to the charging scenario, where both do not use the bypass. The former has a higher pressure loss as air is being first pulled from and then pushed to the rock bed. The 
latter has a smaller pressure loss since the fan uses outdoor air. Accordingly, the pressure loss affects the flow rate of each scenario.

Lastly, Figure 5.23 demonstrates two modifications of the conventional heat pump with the highest flow rates. Interestingly, these scenarios have much lower flow rate than the designed value of $8500 \mathrm{~m}^{3} / \mathrm{h}$. According to the specification of the fan (Appendix C), the flow rate of $1900 \mathrm{~m}^{3} / \mathrm{h}$ is outside of the fan curve. This suggests the necessity of a profound simplification of the existing ductwork in order to make the proposed system competitive. 


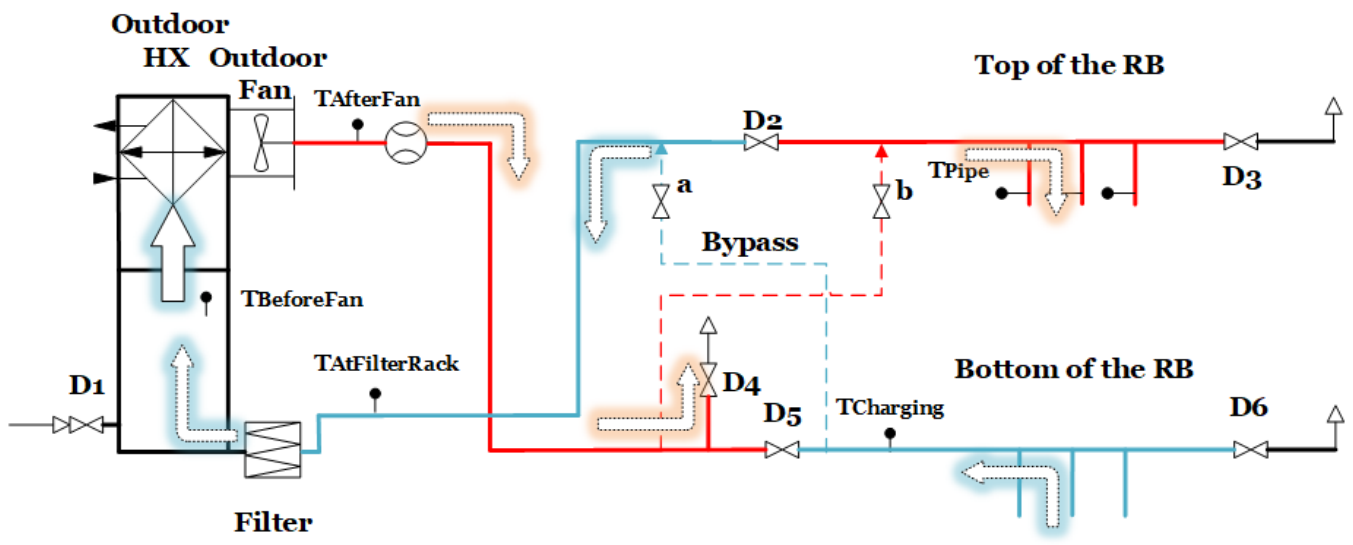

(a) $\dot{V}=1310 \pm 260 \mathrm{~m}^{3} / \mathrm{h}$

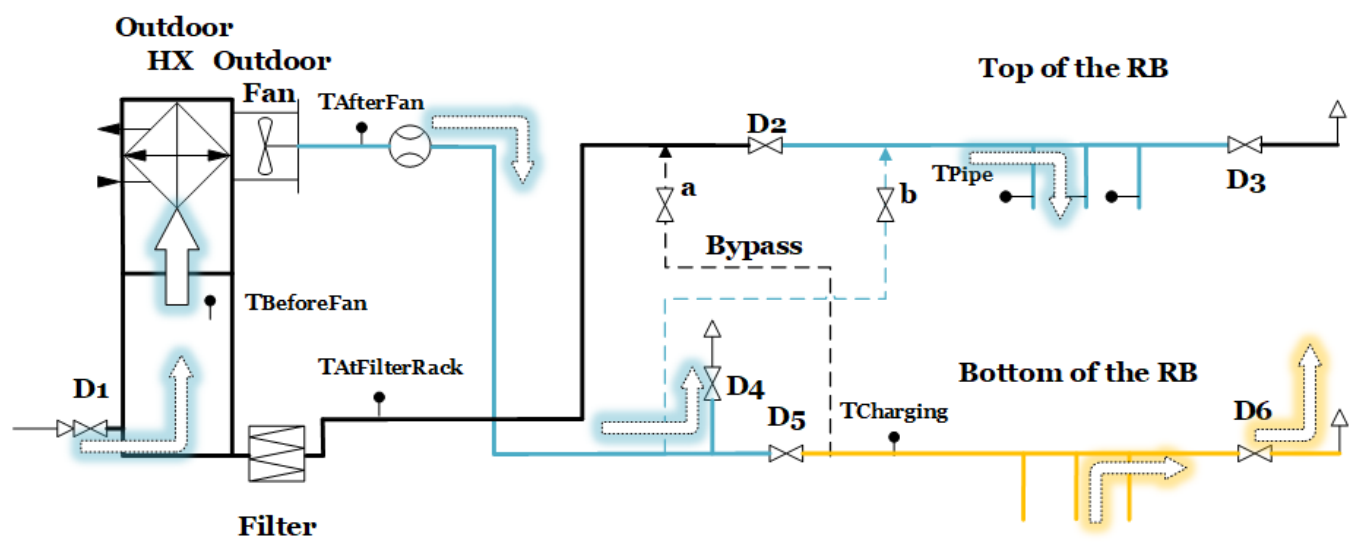

(b) $\dot{V}=1310 \pm 260 \mathrm{~m}^{3} / \mathrm{h}$

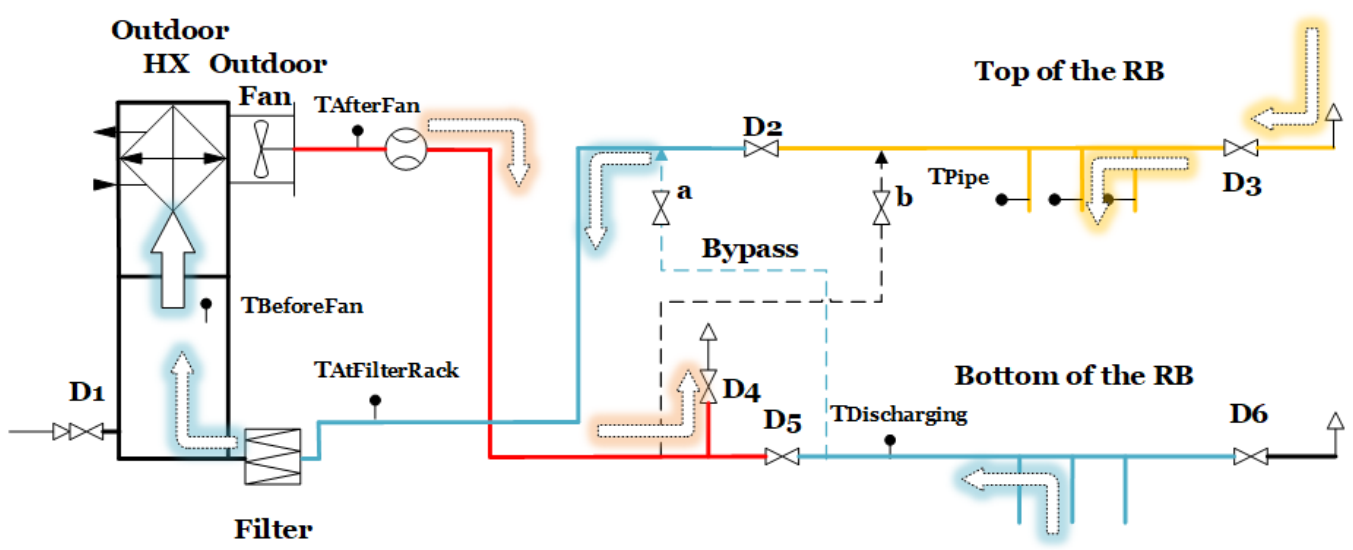

(c) $\dot{V}=1220 \pm 250 \mathrm{~m}^{3} / \mathrm{h}$

Figure 5.21: Charging/discharging scenarios where the bypass was used 


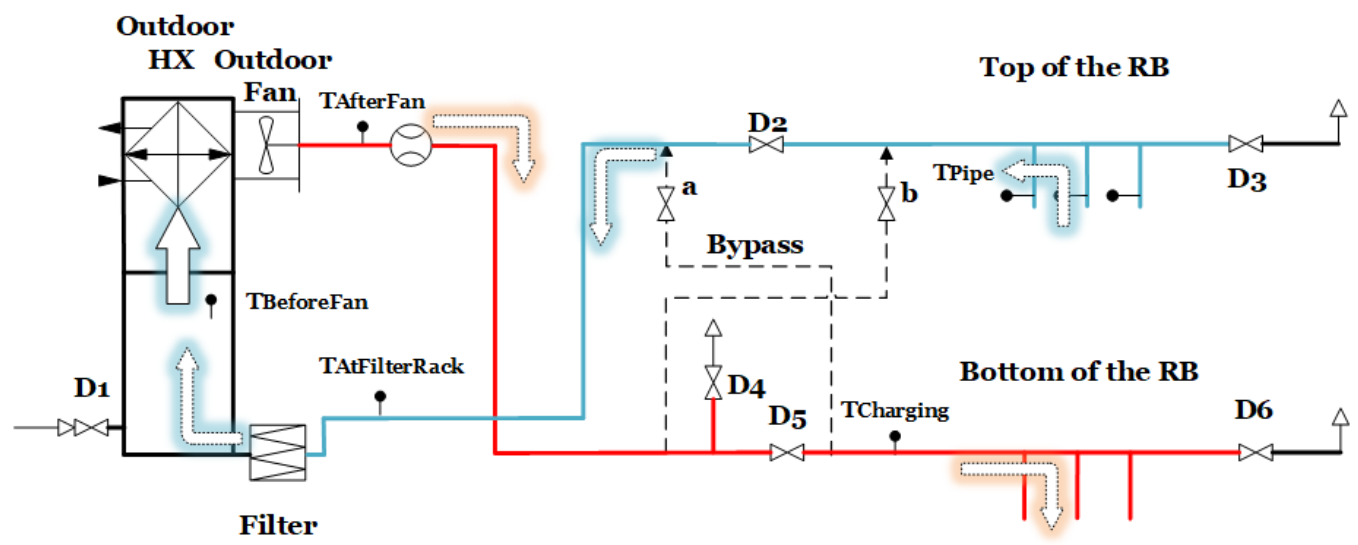

(a) $\dot{V}=1450 \pm 280 \mathrm{~m}^{3} / \mathrm{h}$

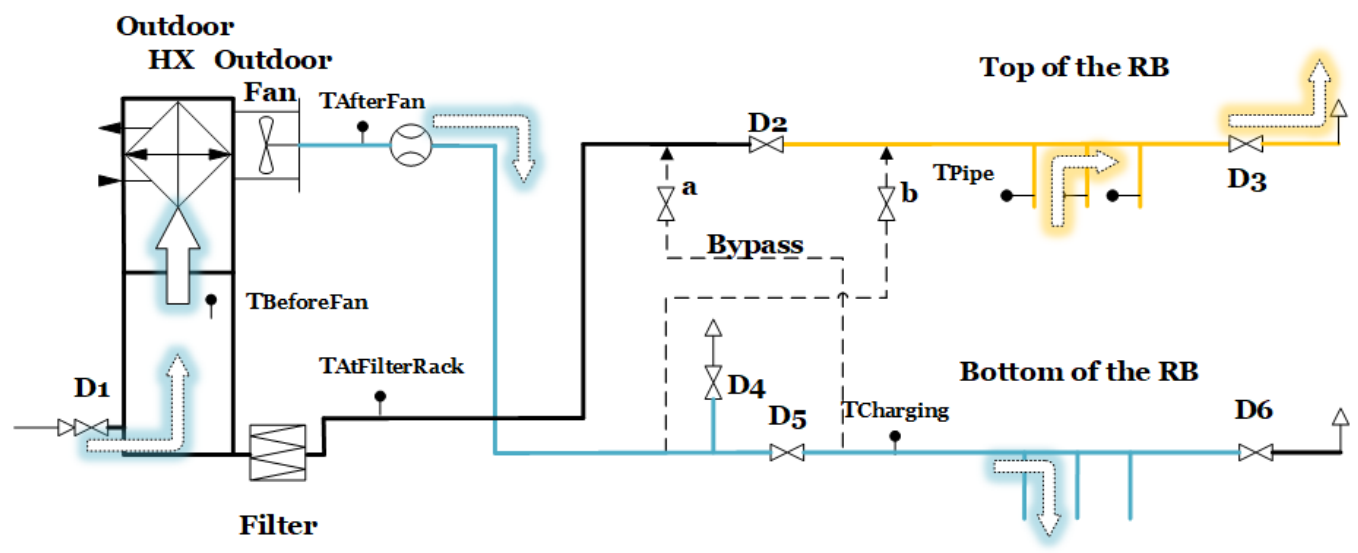

(b) $\dot{V}=1730 \pm 310 \mathrm{~m}^{3} / \mathrm{h}$

Figure 5.22: Charging/discharging scenarios where the bypass was NOT used 


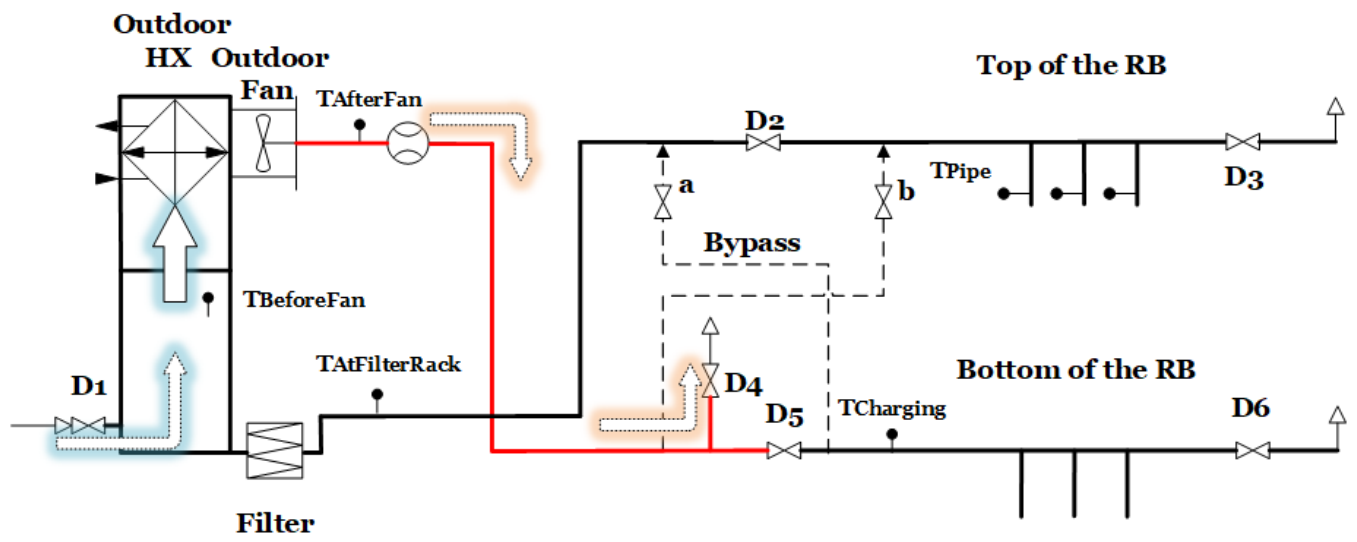

(a) $\dot{V}=1900 \pm 340 \mathrm{~m}^{3} / \mathrm{h}$

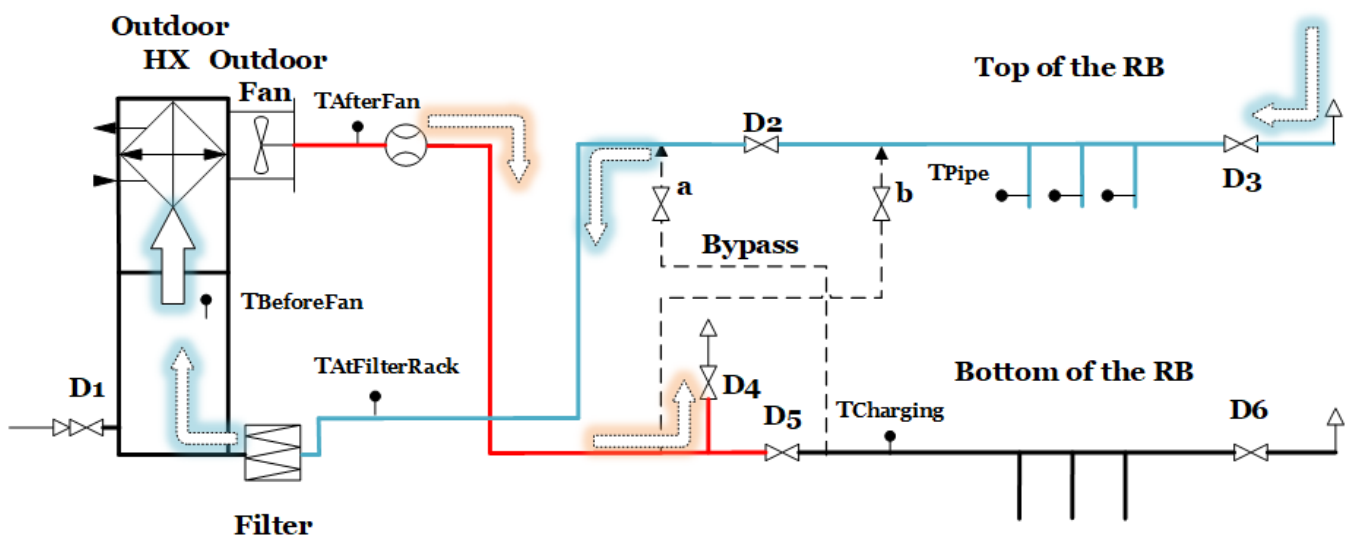

(b) $\dot{V}=1900 \pm 340 \mathrm{~m}^{3} / \mathrm{h}$

Figure 5.23: Conventional heat pump 


\section{Chapter 6}

\section{Conclusions and Future Work}

Air source heat pumps can contribute to reducing the energy consumption in the residential sector; however, for market adoption of this technology in the reality of Canadian climate, it is important to address its biggest technological drawback. The strategy of coupling the heat pump to a short-term rock-bed TES was proposed in this work to approach the issue related to poor performance of the ASHP in extreme temperature conditions. Despite the fact that ASHP and TES have been broadly studied, little research has been conducted on the systems that combine both technologies in the proposed configuration. The goal of this research was to assess the performance of the heat pump when supplying to the outdoor heat exchanger air tempered in the rock bed. The experimental setup was designed, commissioned, and tested at the Urbandale CHEeR house.

Considering the cold climate of Canada, the main motivation for using the rockbed TES was to improve winter performance of the ASHP. However, the heating season was spent conducting exploratory tests as well as troubleshooting and finetuning the experimental setup. Once the obvious issues were resolved, air tightness 
was improved and the temperature sensors across the outdoor heat exchanger were shielded, a protocol for summer testing of the ASHP coupled to the rock bed was developed. A number of experiments were conducted to compare the COP and cooling capacity of the conventional heat pump with those of the heat pump coupled to the rock-bed store. Four discharging scenarios differentiated by the portion of air drawn from the rock bed and ambient air added to the airstream were tested.

\subsection{Conclusions}

Based on the experimental results, the following conclusions can be drawn:

1. The underground rock-bed TES is suitable for tempering ambient air when it is used in the applications as in the proposed ones and in climates similar to those of Canada: the temperature at the outlet of the energy store is moderate even during extremely hot days, and the rock bed maintains cool even if it is charged infrequently during the summer.

2. The system has a few significant design issues:

- high airflow resistance of the ductwork which prevents air tempered in the rock bed from reaching the outdoor unit of the ASHP,

- heat losses through the ductwork which reduce the benefits of air tempering,

- air leaks which result in drawing to the outdoor heat exchanger ambient air instead of tempered air from the rock bed. 
3. The overall system performance is not improved due to the design issues; however, the rock bed has the potential to become an enhancement to the ASHP system if the design issues are resolved: using air tempered in the rock bed should increase the COP by $30-40 \%$ and the cooling capacity by $15-20 \%$.

\subsection{Future work}

To exploit the air tempering potential of the rock bed, the ductwork which connects the outdoor heat exchanger with the rock bed has to be well-insulated and simplified, e.g. with short runs and a minimum number of connections, in order to minimize pressure drop and limit heat losses and leaks. A less complicated ductwork with a smaller pressure drop will enable the fan to provide a higher flow rate. This will eliminate the need to add fresh air to the tempered airstream from the rock bed. In a current setup, the ductwork is too convoluted and has too high a pressure drop and heat losses to be competitive with the conventional heat pump.

The system with its improved outdoor design should be tested in winter to evaluate the COP and heating capacity during periods of extremely cold conditions.

To obtain more accurate results of the COP and capacity of the heat pump as well as the thermal capacity of the rock bed, the measurements of the flow rate through the indoor and outdoor ductwork have to be improved. 


\section{References}

K. Allen, T. Von Backström, D. Kröger, and A. Kisters. Rock bed storage for solar thermal power plants: Rock characteristics, suitability, and availability. Solar Energy Materials and Solar Cells, 126:170-183, 2014.

J. Almendros-Ibáñez, M. Fernández-Torrijos, M. Díaz-Heras, J. Belmonte, and C. Sobrino. A review of solar thermal energy storage in beds of particles: Packed and fluidized beds. Solar Energy, 2018. doi: http://dx.doi.org/10.1016/j.solener.2018. 05.04 .

O. E. Ataer. Storage of thermal energy. Encyclopedia of Life Support, 2006.

C. Baldwin. Design and Construction of an Experimental Apparatus to Assess the Performance of a Solar Absorption Chiller with Integrated Thermal Storage. M.A.Sc., Carleton University, 2011.

Y. A. Cengel. Fluid mechanics. Tata McGraw-Hill Education, 2010.

B. Ceranic, J. Beardmore, and A. Cox. Rapid deployment modular building solutions and climatic adaptability: Case based study of a novel approach to thermal capacity on demand and building management systems. Energy and Buildings, 167:124-135, 2018. 
M. Chandrashekar, N. Le, H. Sullivan, and K. Hollands. A comparative study of solar assisted heat pump systems for canadian locations. Solar Energy, 28(3):217-226, 1982.

C. Choudhury and H. Garg. Integrated rock bed heat exchanger-cum-storage unit for residential-cum-water heating. Energy conversion and management, 36(10): 999-1006, 1995.

J. Chu. Evaluation of a Dual Tank Indirect Solar-Assisted Heat Pump System for a High Performance House. PhD thesis, Carleton University Ottawa, 2014.

R. Daschner, S. Binder, and M. Mocker. Pebble bed regenerator and storage system for high temperature use. Applied energy, 109:394-401, 2013.

I. Dincer and M. Rosen. Thermal Energy Storage: Systems and Applications. John Wiley \& Sons, second edition, 2011.

I. Dincer, S. Dost, and X. Li. Performance analyses of sensible heat storage systems for thermal applications. International Journal of Energy Research, 21(12):1157$1171,1997$.

R. C. Dorf. Energy, resources, and policy. 1978.

T. Esence, A. Bruch, S. Molina, B. Stutz, and J.-F. Fourmigué. A review on experience feedback and numerical modeling of packed-bed thermal energy storage systems. Solar Energy, 153:628-654, 2017.

D. Fernandes, F. Pitié, G. Cáceres, and J. Baeyens. Thermal energy storage:how 
previous findings determine current research priorities. Energy, 39(1):246-257, 2012.

A. Gutierrez, L. Miró, A. Gil, J. Rodríguez-Aseguinolaza, C. Barreneche, N. Calvet, X. Py, A. I. Fernández, M. Grágeda, S. Ushak, et al. Advances in the valorization of waste and by-product materials as thermal energy storage (tes) materials. Renewable and Sustainable Energy Reviews, 59:763-783, 2016.

A. Hesaraki, S. Holmberg, and F. Haghighat. Seasonal thermal energy storage with heat pumps and low temperatures in building projectsa comparative review. Renewable and Sustainable Energy Reviews, 43:1199-1213, 2015.

K. Hollands and H. Sullivan. Pressure drops across rock bed thermal storage systems. Solar Energy, 33(2):221-225, 1984.

J. Holman et al. Heat transfer. 10th, 2010.

Intergovernmental Panel on Climate Change. Climate change 2014: mitigation of climate change, volume 3. Cambridge University Press, 2015.

International Renewable Energy Agency. Technology brief: Thermal energy storage. IEA-ETSAP and IRENAC Technology Brief E1\%-January, 2013.

K. Ismail and R. Stuginsky Jr. A parametric study on possible fixed bed models for pcm and sensible heat storage. Applied Thermal Engineering, 19(7):757-788, 1999.

M. Kegel, J. Tamasauskas, R. Sunye, and A. Langlois. Assessment of a solar assisted 
air source and a solar assisted water source heat pump system in a canadian household. Energy Procedia, 30:654-663, 2012.

A. Kürklü and S. Bilgin. Cooling of a polyethylene tunnel type greenhouse by means of a rock bed. Renewable energy, 29(13):2077-2086, 2004.

R. M. Lazzarin. Dual source heat pump systems: operation and performance. Energy and Buildings, 52:77-85, 2012.

Y. Liu, J. Ma, and G. Zhou. The coupling performance of a solar-air heat pump. Procedia Engineering, 15:4058-4062, 2011.

M. Lundh and J.-O. Dalenbäck. Swedish solar heated residential area with seasonal storage in rock: Initial evaluation. Renewable energy, 33(4):703-711, 2008.

T. Mackintosh. The Design and Experimental Analysis of an Air Source Heat Pump for Extreme Cold Weather Operation. PhD thesis, Carleton University, 2016.

M. Medrano, A. Gil, I. Martorell, X. Potau, and L. F. Cabeza. State of the art on high-temperature thermal energy storage for power generation. part 2case studies. Renewable and Sustainable Energy Reviews, 14(1):56-72, 2010.

R. Moffat. Describing the uncertainties in experimental results. Experimental Thermal and Fluid Science, 1(1):3-17, 1988.

P. Moreno, A. Castell, C. Sole, G. Zsembinszki, and L. F. Cabeza. Pcm thermal energy storage tanks in heat pump system for space cooling. Energy and Buildings, 82:399-405, 2014. 
L. Navarro, A. de Gracia, D. Niall, A. Castell, M. Browne, S. J. McCormack, P. Griffiths, and L. F. Cabeza. Thermal energy storage in building integrated thermal systems: A review. part 2. integration as passive system. Renewable Energy, 85: $1334-1356,2016$.

R. Nicholls. Gravel bed storage analysis for heat pump systems. Building and Environment, 15(2):119-128, 1980a.

R. Nicholls. Gravel bed heat exchange loss and storage functions. Building and Environment, 15(2):129-131, 1980 b.

R. Nicholls. Analysis of thermal well storage for solar collectorheat pump systems. Building and Environment, 16(1):23-34, 1981.

B. Nordell and G. Hellström. High temperature solar heated seasonal storage system for low temperature heating of buildings. Solar Energy, 69(6):511-523, 2000.

OMEGA Engineering. Handheld Rotating Vane Anemometer HHF141. Omega(http://www.omega.ca/pptst_eng/HHF141.html), 2018.

R. Persons, J. Duffie, and J. Mitchell. Comparison of measured and predicted rock bed storage performance. Solar Energy, 24(2):199-201, 1980.

R. W. Persons. Rock bed storage performance: Arlington Solar House. M.A.Sc., University of Wisconsin-Madison, 1978.

P. Pinel, C. Cruickshank, I. Beausoleil-Morrison, and A. Wills. A review of available methods for seasonal storage of thermal energy in residential applications. Renewable and Sustainable Energy Reviews, 15(7):3341-3359, 2011. 
D. Potter. Measuring temperature with thermocouples-a tutorial. National Instruments Corporation, pages 1-15, 1996.

K. Sagara and N. Nakahara. Thermal performance and pressure drop of rock beds with large storage materials. Solar Energy, 47(3):157-163, 1991.

N. Saldanha and I. Beausoleil-Morrison. Measured end-use electric load profiles for 12 canadian houses at high temporal resolution. Energy and Buildings, 49:519-530, 2012.

H. Singh, R. Saini, and J. Saini. A review on packed bed solar energy storage systems. Renewable and Sustainable Energy Reviews, 14(3):1059-1069, 2010.

F. Stern, M. Muste, M.-L. Beninati, and W. E. Eichinger. Summary of experimental uncertainty assessment methodology with example. Technical report, IIHR Report, 1999.

R. Tiskatine, R. Oaddi, R. A. El Cadi, A. Bazgaou, L. Bouirden, A. Aharoune, and A. Ihlal. Suitability and characteristics of rocks for sensible heat storage in csp plants. Solar Energy Materials and Solar Cells, 169:245-257, 2017.

P. Tsilingiris. Thermophysical and transport properties of humid air at temperature range between 0 and 100 c. Energy Conversion and Management, 49(5):1098-1110, 2008.

A. M. Waked. Solar energy storage in rocks. Solar $\&$ wind technology, 3(1):27-31, 1986. 
G. S. Wong and T. F. Embleton. Variation of specific heats and of specific heat ratio in air with humidity. The Journal of the Acoustical Society of America, 76 (2):555-559, 1984.

J. Xu, R. Wang, and Y. Li. A review of available technologies for seasonal thermal energy storage. Solar Energy, 103:610-638, 2014.

N. Zhu, P. Hu, L. Xu, Z. Jiang, and F. Lei. Recent research and applications of ground source heat pump integrated with thermal energy storage systems: A review. Applied thermal engineering, 71(1):142-151, 2014. 


\section{Appendix A}

\section{Performance of the heat pump under five scenarios}

The following graphs demonstrate the experimental results of five tests discussed in Chapter 5, where

- $A$ is the test with the conventional heat pump,

- $B$ is the test with discharging the rock bed and adding some ambient air,

- $C$ is the test with discharging the rock bed,

- $D$ is the test with the maximum flow rate,

- $E$ is the test with matching flow rate.

Figure A.1 compares the measured velocity at the outdoor fan during all five tests. Figure A.2 compares performance of the ASHP under varying ambient and supply air temperatures during all five tests. 


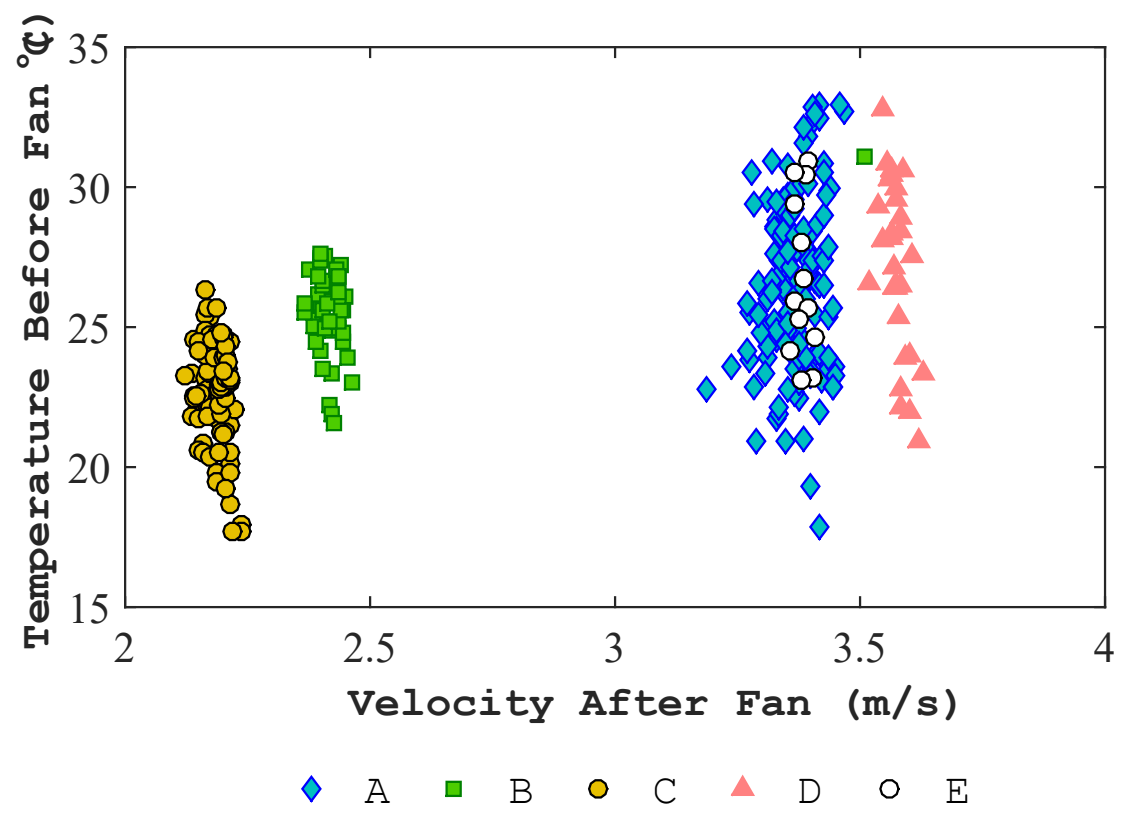

Figure A.1: Velocity 


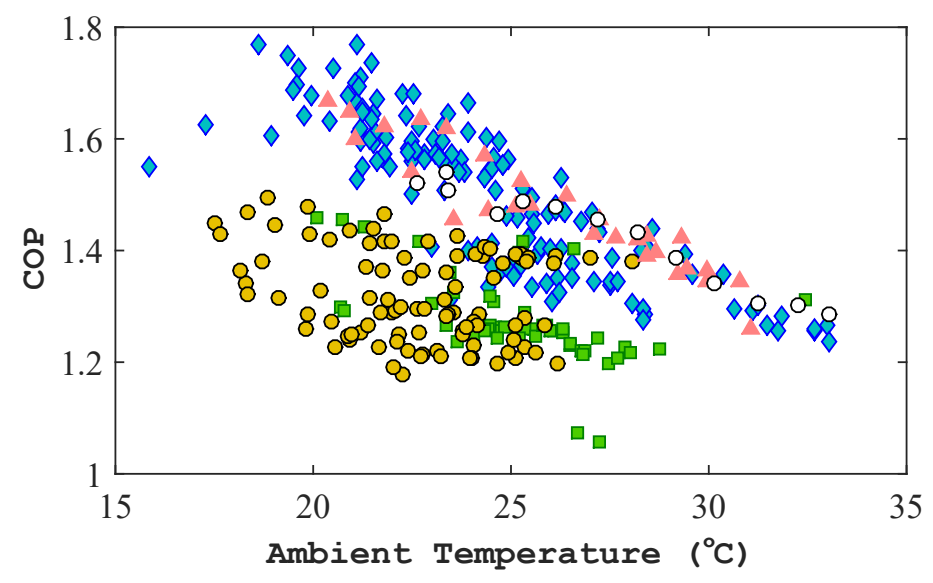

$\diamond \mathrm{A} \quad \mathrm{B} \quad \mathrm{O} \quad \mathrm{C} \triangle \mathrm{D} \quad \mathrm{D} \quad \mathrm{E}$

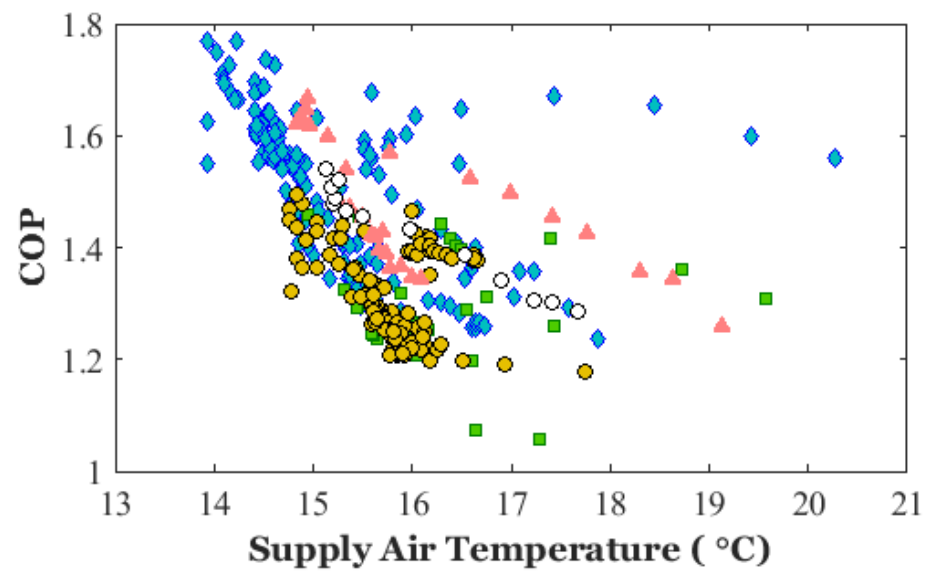

$\bullet \mathrm{A} \square \mathrm{B} \circ \mathrm{C} \wedge \mathrm{D} \circ \mathrm{E}$

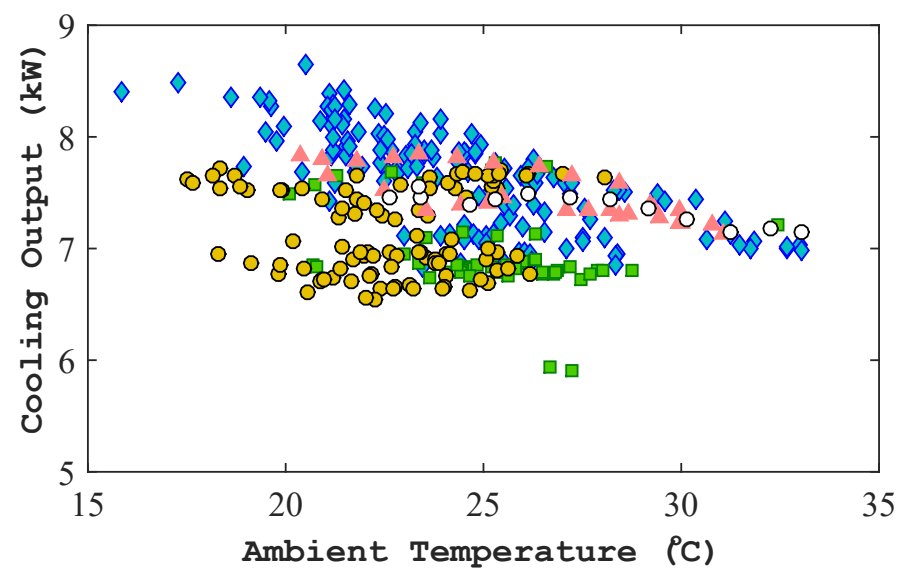

$\diamond \mathrm{A} \square \mathrm{B} O \mathrm{C} \triangle \mathrm{D} \quad \mathrm{O} \mathrm{E}$

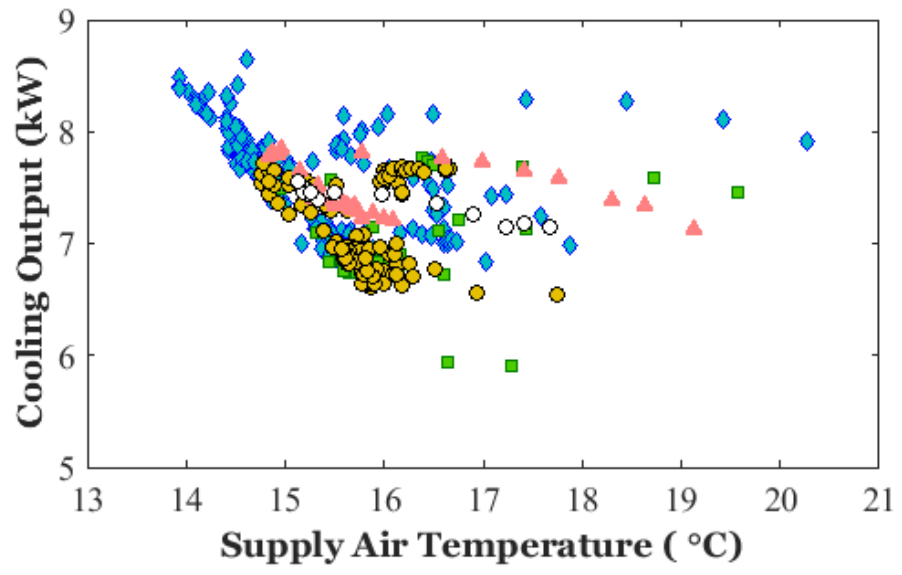

- A $\square$ B C $\triangle \mathrm{D} \circ \mathrm{F}$

Figure A.2: Performance of the heat pump under five scenarios 


\section{Appendix B}

\section{Uncertainty of the heat transfer rate of the rock bed}

\section{B.1 Velocity at the outdoor heat exchanger}

The velocity at the outlet of the outdoor heat exchanger is measured by a propeller anemometer rotation which produces an analogue voltage signal proportional to the air speed:

$$
V_{\text {out }}=0.018 \times \text { Reading }, m V
$$

At the maximum velocity of $3.5 \mathrm{~m} / \mathrm{s}$, the produced voltage lies within a $200 \mathrm{mV}$ range of CR3000 with an associated error of $88.6 \mathrm{mV}$ which results in a negligible bias error due to voltage reading of $0.0016 \mathrm{~m} / \mathrm{s}$. The accuracy of the sensor is $0.3 \mathrm{~m} / \mathrm{s}$. An additional error of $15 \%^{1}$, attributed to a non-uniform velocity profile,

\footnotetext{
${ }^{1}$ The anemometer with the diameter of $20 \mathrm{~cm}$ was installed 2 feet before and after 90-degree elbows in the duct with the hydraulic diameter of 1.17 feet. It was assumed that the velocity profiles at the AHU and outdoor heat exchanger are similarly non-uniform, and the error of the same as in Chapter 5 value was used here.
} 
was added to calculate the total uncertainty. Bias errors associated with the outdoor velocity measurements are listed in Table B.1:

Table B.1: Velocity bias error

\begin{tabular}{lc}
\hline \hline Source of error & Value \\
\hline \hline$\theta_{m V} B_{m V}$ & $0.0016 \mathrm{~m} / \mathrm{s}$ \\
Anemometer & $0.3 \mathrm{~m} / \mathrm{s}$ \\
Velocity profile & $15 \%$ \\
\hline Total & $0.6 \mathrm{~m} / \mathrm{s}$ \\
\hline
\end{tabular}

\section{B.2 Thermocouples}

Both thermocouples $-T_{\text {charg }}$ at the inlet to the rock bed and $T_{\text {pipe }}$ at the outlet of the rock bed (Figure 3.1) - were made of Omega Type T 24 gauge wire with the special limits of error (SLE). Calibration equations used to convert the output voltage of the $T_{\text {charg }}\left(\right.$ spool B) and $T_{\text {pipe }}($ spool TS) to a temperature are listed below:

$$
\begin{array}{r}
T_{\text {charg }}^{B}=0.004305 e m f^{6}-0.02713 e m f^{5}+0.031024 e m f^{4}+0.068355 e m f^{3}- \\
-0.59445 e m f^{2}+24.48589 e m f-0.1744+T_{C J C} \\
T_{\text {pipe }}^{T S}=0.00485 e m f^{6}-0.02733 e m f^{5}+0.039431 e m f^{4}+0.032176 e m f^{3}- \\
-0.60798 e m f^{2}+24.49786 e m f-0.16463+T_{C J C}
\end{array}
$$


Bias errors associated with the temperature measurements at the inlet and outlet of the rock bed are listed in Table B.2:

Table B.2: Thermocouple bias error

\begin{tabular}{lcc}
\hline \hline Source of error & Spool TS & Spool B \\
\hline \hline Cold-junction temperature (calibration) & 0.25 & 0.25 \\
Thermistor location (experiment) & 0.2 & 0.2 \\
Cold-junction temperature (experiment) & 0.1 & 0.1 \\
Regression prediction error & 0.058 & 0.076 \\
Resistance temperature detector & 0.02 & 0.02 \\
Resistance read error (DMM) & 0.0397 & 0.0397 \\
Bath uniformity & 0.02 & 0.02 \\
Voltage read error (calibration) & 0.175 & 0.173 \\
Voltage read error (experiment) & 0.068 & 0.067 \\
\hline Total bias & 0.39 & 0.39 \\
\hline
\end{tabular}

\section{B.3 Air properties}

Equations used to define the air density and specific heat at the average temperature across the rock bed:

$$
\begin{aligned}
& \rho=1.12 \times 10^{-5}\left(\frac{T_{\text {pipe }}+T_{\text {charg }}}{2}\right)^{2}-0.010868\left(\frac{T_{\text {pipe }}+T_{\text {charg }}}{2}\right)+3.4298 \\
& c_{p}=5.8 \times 10^{-7}\left(\frac{T_{\text {pipe }}+T_{\text {charg }}}{2}\right)^{2}-0.000311\left(\frac{T_{\text {pipe }}+T_{\text {charg }}}{2}\right)+1.0468
\end{aligned}
$$


Total bias errors of the calculated values of the air density and specific heat for the temperature range of $5{ }^{\circ} \mathrm{C}-25^{\circ} \mathrm{C}$ are tabulated in Table B.3 and Table B.4.

Table B.3: Density bias error

\begin{tabular}{lc}
\hline \hline Source of error & $5-25{ }^{\circ} \mathrm{C}$ \\
\hline \hline$\theta_{T_{\text {pipe }}} B_{T_{\text {pipe }}}$ & 0.0008 \\
$\theta_{T_{\text {charg }}} B_{T_{\text {charg }}}$ & 0.0008 \\
Humidity & 0.0166 \\
Regression prediction & 0.001 \\
\hline Total & 0.017 \\
\hline
\end{tabular}

Table B.4: Specific heat bias error

\begin{tabular}{lc}
\hline \hline Source of error & $5-25^{\circ} \mathrm{C}$ \\
\hline \hline$\theta_{T_{\text {pipe }}} B_{T_{\text {pipe }}}$ & $4.3 \times 10^{-6}$ \\
$\theta_{T_{\text {charg }}} B_{T_{\text {charg }}}$ & $4.4 \times 10^{-6}$ \\
Humidity & 0.024 \\
Regression prediction & 0.002 \\
\hline Total & 0.024 \\
\hline
\end{tabular}

\section{B.4 Cross-sectional area}

The cross-sectional area of the outdoor duct is $0.610 \mathrm{~m} \times 0.2543 \mathrm{~m}$. Both height and width of the duct were measured by a measuring tape with a resolution of 
$1 \mathrm{~mm}$. This resolution introduces an insignificant error in calculating the area of $0.00033 \mathrm{~m}^{2}$.

\section{B.5 Uncertainty of $\dot{Q}_{a i r}$}

The absolute values of the independent variables of the derived quantity $\dot{Q}_{a i r}$, the associated sensitivity parameters, and overall bias error of $\dot{Q}_{a i r}$ are presented in Table B.5, Table B.6, and Table B.7, respectively.

Table B.5: Independent variables of the derived quantity $\dot{Q}_{a i r}$

\begin{tabular}{llc}
\hline \hline Independent variable & Value & Bias error \\
\hline \hline$V, \mathrm{~m} / \mathrm{s}$ & 3.5 & 0.605 \\
$A, \mathrm{~m}^{2}$ & 0.154838 & 0.00033 \\
$\rho, \mathrm{kg} / \mathrm{m}^{3}$ & 1.23 & 0.017 \\
$c_{p}, \mathrm{~kJ} /(\mathrm{kg} \mathrm{K})$ & 1.005 & 0.024 \\
$\Delta T, \mathrm{~K}$ & 10 & 0.556 \\
\hline
\end{tabular}


Table B.7: $\dot{Q}_{a i r}$ bias error

\begin{tabular}{lc}
\hline \hline Source of error & Value, $\mathrm{kW}$ \\
\hline \hline$\theta_{V} B_{V}$ & 1.16 \\
$\theta_{A} B_{A}$ & 0.01 \\
$\theta_{\rho} B_{\rho}$ & 0.09 \\
$\theta_{c_{p}} B_{c_{p}}$ & 0.16 \\
$\theta_{\Delta T} B_{\Delta T}$ & 0.37 \\
\hline Total & 1.23 \\
\hline
\end{tabular}

Table B.6: $\dot{Q}_{\text {air }}$ sensitivity parameters

\begin{tabular}{llll}
\hline \hline Parameter & Equation & Value & Units \\
\hline \hline$\theta_{V}=\frac{\partial \dot{Q}}{\partial V}$ & $\theta_{V}=\left.A\left(\rho c_{p}\right)\right|_{T_{a v g}} \Delta T$ & 1.92 & $\frac{\mathrm{kW}}{\mathrm{m} / \mathrm{s}}$ \\
$\theta_{A}=\frac{\partial \dot{Q}}{\partial A}$ & $\theta_{A}=\left.V\left(\rho c_{p}\right)\right|_{T_{\text {avg }}} \Delta T$ & 43.37 & $\frac{\mathrm{kW}}{\mathrm{m}^{2}}$ \\
$\theta_{\rho}=\frac{\partial \dot{Q}}{\partial \rho}$ & $\theta_{\rho}=\left.V A c_{p}\right|_{T_{\text {avg }}} \Delta T$ & 5.45 & $\frac{\mathrm{kW}}{\mathrm{kg} / \mathrm{m}^{3}}$ \\
$\theta_{c_{p}}=\frac{\partial \dot{Q}}{\partial c_{p}}$ & $\theta_{c_{p}}=\left.V A \rho\right|_{T_{\text {avg }}} \Delta T$ & 6.68 & $\frac{\mathrm{kW}}{\mathrm{kJ} /(\mathrm{kgK})}$ \\
$\theta_{\Delta T}=\frac{\partial \dot{Q}}{\partial \Delta T}$ & $\theta_{\Delta T}=\left.V A\left(\rho c_{p}\right)\right|_{T_{\text {avg }}}$ & 0.67 & $\frac{\mathrm{kW}}{{ }^{\circ} \mathrm{C}}$ \\
\hline
\end{tabular}




\section{Appendix C}

\section{Fan curve}

Figure C.1 represents the performance of the outdoor fan by relating the flow rate and static pressure.

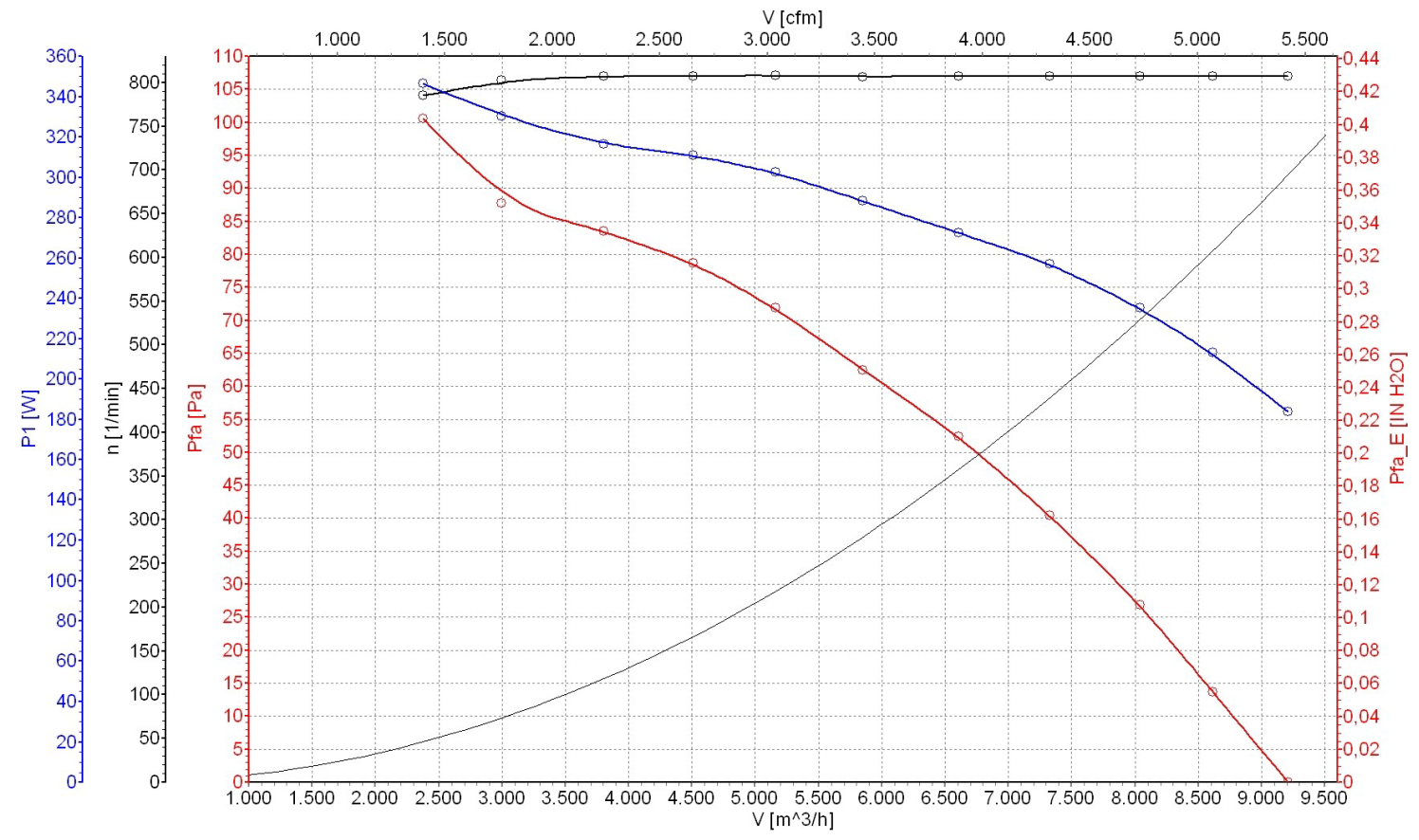

Figure C.1: Specification of the outdoor fan 